University of San Diego

Digital USD

Dissertations

Theses and Dissertations

2019-01-31

\title{
The Lived Experience of Spiritual Well-Being Amongst Informal Caregivers of Persons with Dementia on Palliative Care Living at Home
}

Michael Baumgardner

University of San Diego

Follow this and additional works at: https://digital.sandiego.edu/dissertations

Part of the Geriatric Nursing Commons, Other Nursing Commons, and the Public Health and Community Nursing Commons

\section{Digital USD Citation}

Baumgardner, Michael, "The Lived Experience of Spiritual Well-Being Amongst Informal Caregivers of Persons with Dementia on Palliative Care Living at Home" (2019). Dissertations. 125.

https://digital.sandiego.edu/dissertations/125

This Dissertation: Open Access is brought to you for free and open access by the Theses and Dissertations at Digital USD. It has been accepted for inclusion in Dissertations by an authorized administrator of Digital USD. For more information, please contact digital@sandiego.edu. 


\author{
UNIVERSITY OF SAN DIEGO \\ Hahn School of Nursing and Health Science \\ DOCTOR OF PHILOSOPHY IN NURSING
}

THE LIVED EXPERIENCE OF SPIRITUAL WELL-BEING AMONGST INFORMAL CAREGIVERS OF PERSONS WITH DEMENTIA ON PALLIATIVE CARE LIVING

AT HOME

by

Michael L. Baumgardner

A dissertation presented to the

FACULTY OF THE HAHN SCHOOL OF NURSING AND HEALTH SCIENCE

UNIVERSITY OF SAN DIEGO

In partial fulfillment of the

requirements for the degree

DOCTOR OF PHILOSOPHY IN NURSING

November 2018

Dissertation Committee

Ann Mayo, DNSc, RN, FAAN

Patricia Roth, EdD, RN

Jane Georges, PhD, RN 


\section{UNIVERSITY OF SAN DIEGO}

Hahn School of Nursing and Health Science

DOCTOR OF PHILOSOPHY IN NURSING

\section{CANDIDATE'S}

NAME: $\quad$ Michael L. Baumgardner

TITLE OF

DISSERTATION: The Lived Experience of Spiritual Well-Being Amongst Informal Caregivers of Persons with Dementia on Palliative Care Living

DISSERTATION

COMMITTEE:

Ann Mayo, DNSc, RN, FAAN, Chairperson

Patricia Roth, EdD, RN, Committee Member

Jane Georges, PhD, RN, Committee Member 


\begin{abstract}
Title. The Lived Experience of Spiritual Well-Being Amongst Informal Caregivers of Persons with Dementia on Palliative Care Living at Home.

Purpose. This study explored the lived experience of spiritual well-being amongst informal caregivers of a person with dementia who were living at home and enrolled in palliative care.
\end{abstract}

Background. Patients with dementia comprise the third leading diagnosis in palliative care patients and many receive informal care from family members. Palliative care improves quality of life in patients and their informal caregivers. However, little is known about spiritual well-being in the setting of caregiving of persons with dementia on palliative care. Thus, making the exploration of this phenomenon necessary.

Methods. This study, guided by van Manen's (1990) theory of interpretation, recruited 10 caregivers through a large healthcare organization in Southern California. The experience of each caregiver was collected through narrative interviews using openended questions. The transcribed texts were read and analyzed to interpret the meanings and arrive at a comprehensive understanding of spiritual well-being.

Findings. Analysis of the participant's experience revealed essential themes that included: Isolated from others; Hardships; Awareness; Being connected to the patient; Presence; Trust; Sacrifice; Belonging; Duty; Freedom; Strength; and Dedication. Upon deeper reflection on these themes a description of spiritual well-being in the context of the study's setting is presented.

Significance of Study. Findings from this study suggest that these informal caregivers rely on relationships with self, others, and the Sacred to remain hopeful. An 
understanding of spiritual well-being by palliative care professionals is important to provide appropriate spiritual guidance. Future research is warranted that examines spiritual well-being from the perspective of bereaved caregivers and the effects of alternative care modalities on caregiver overall health. 
(C) Copyright Michael Baumgardner All Rights Reserved 2018 


\section{DEDICATION}

To all who have taught me that it is possible to live until you die.

"You matter because you are you.

You matter to the last moment of your life,

and we will do all we can,

not only to help you die peacefully,

but to live until you die."

- Dame Cicely Saunders 


\section{PREFACE}

"There are no words to say, no words to convey, this feeling I have deep down inside for you." These words were found on an exterior wall to Il Ospedale di Bambino Gesu in Rome, Italy. While the author is unknown the sentiment adequately captures the experience of arriving at the completion of this dissertation. This finished work has been made possible by so many people who have had an influence in my life. In mentioning several of those persons here I know that I will undoubtedly forget a few very important individuals. So, in advance I ask your forgiveness and invite all of you to join in my celebration of your contribution to this moment in my journey.

This work would not have been possible without the guidance of three incredible nurse scientists - Drs. Ann Mayo, DNSc, RN, FAAN; Patricia Roth, EdD, RN; and Dean Jane Georges, $\mathrm{PhD}$, RN; my dissertation chair and committee members respectively. Your kindness, patience, and belief in the importance of this work has been invaluable to my commitment to see it to its fruition.

I am grateful to have made this journey with seventeen wonderful professional nurses. Our sharing Thursdays as a group became the glue to holding my vision of this project together. Each of us finished our individual studies at different times. But, it was the time shared on those Sacred Thursdays that nourished me intellectually and emotionally.

The connecting of spirituality and palliative care in this dissertation was possible because of two intersecting realities in my life. I am most appreciative of the support that I have received from the People of God in the Diocese of San Diego. Their witness to faith in moments of their spiritual journey has truly been inspirational. This appreciation 
is shared also with all who worked with me at San Diego Hospice and the Institute of Palliative Care. I had no idea of the blessing that I would receive from working with each of you during the most Sacred time in the lives of our patients and their families.

I have been extremely fortunate to have the support of both the University of California, San Diego Medical Center and Sharp Healthcare throughout this process. The names of each individual are too many to list here. However, your smiles, curiosity about the study, words of encouragement, and lending a gentle ear to listen to my frustrations and joy have all given me the energy to complete this work.

This research was made possible, in part, because of the financial generosity of others who believe deeply in the importance of developing new nurse scientists. I am grateful for the support of the Jonas Foundation, Elizabeth Mottet Endowment, and the USD Nursing Scholar PhD Award Scholarships. May this study be the beginning of my paying your kindness forward.

Finally, to my family. Dad, Mom, Raymond, Rob, Matthew, Candice Leigh, and Leo there truly are "no words to convey" what having you on my journey has meant. You have always inspired me to pursue a deeper understanding of my own lived experiences. I hope that I have done the same for you. 


\section{TABLE OF CONTENTS}

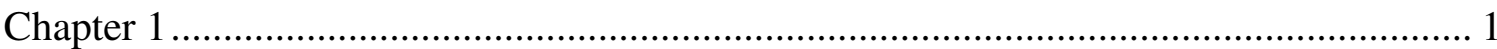

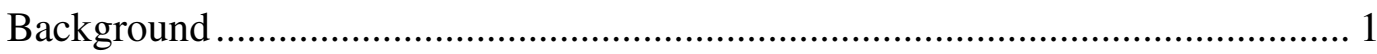

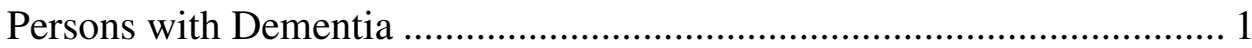

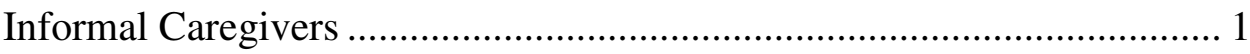

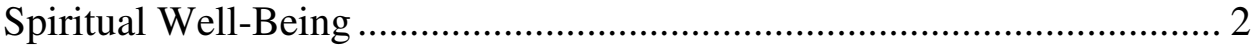

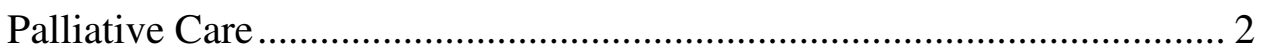

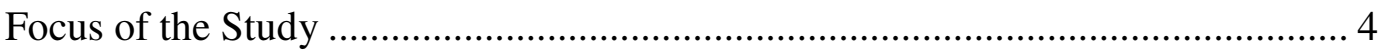

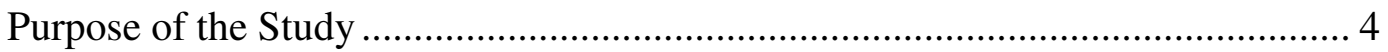

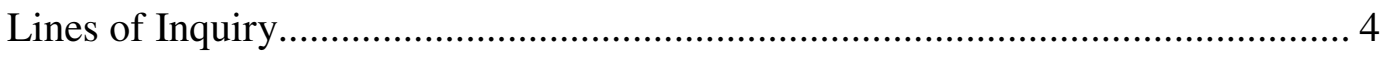

Study Philosophical Foundation ........................................................................ 5

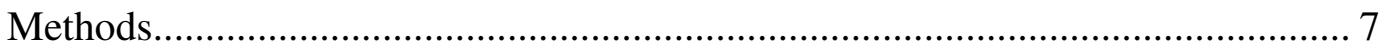

Bracketing of Previous Experiences ……………………........................... 7

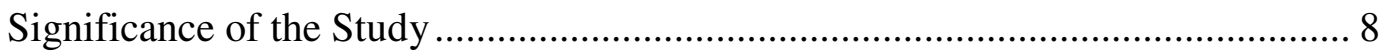

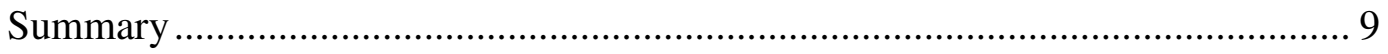

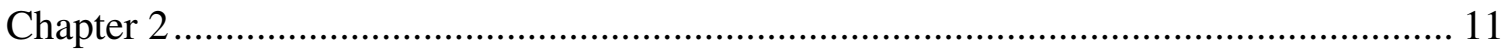

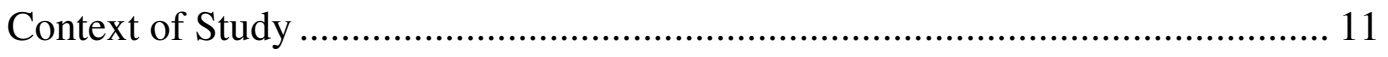

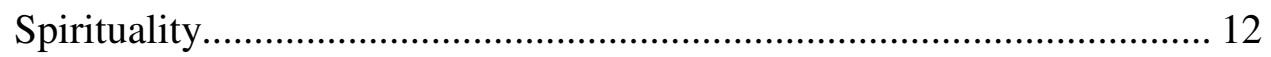

Conceptual Analysis of Spirituality ........................................................ 13

Paradigm for Exploring Spirituality..................................................... 15

Conceptual Framework of Spirituality...................................................... 16

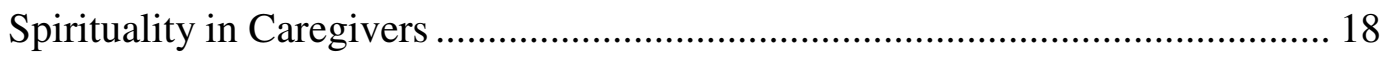

Caregiver Characteristics ........................................................................ 19 
Spiritual Perspectives and Spiritual Behaviors .......................................... 21

Spirituality Effect on Caregiver Burden .................................................. 23

Meaning of Spirituality in Caregiving ................................................... 25

Spiritual Needs of Persons with Cancer Diagnoses at End of Life............ 31

Lived Experience of Spirituality in Palliative Care ................................... 33

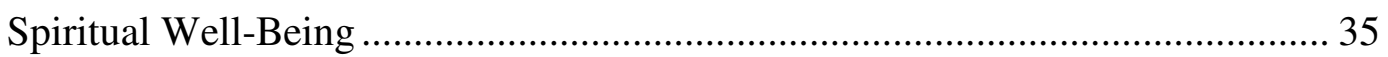

Dimensions of Spiritual Well-Being........................................................ 36

Spiritual well-being in survivors of cancer ...................................... 37

Spiritual well-being in palliative care patients................................ 41

Defining Attributes of Spiritual Well-Being............................................. 45

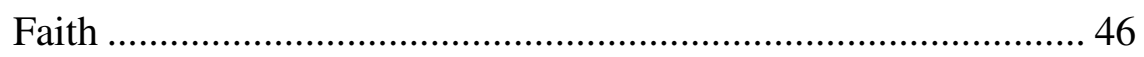

Spiritual Well-Being and Caregivers ........................................................ 46

Caregivers of Patients with Chronic Illness.............................................. 46

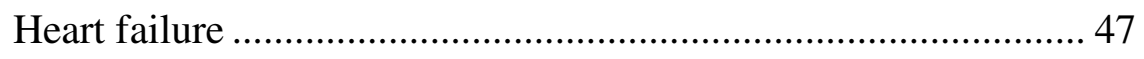

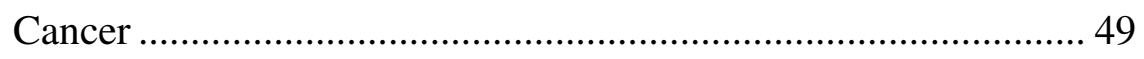

Chronic obstructive pulmonary disease ...................................... 52

Caregivers of Persons with Dementia........................................................ 56

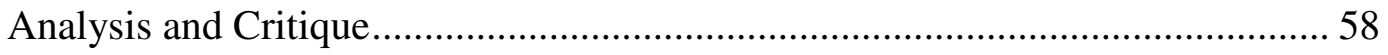

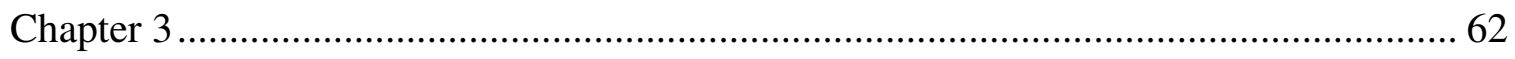

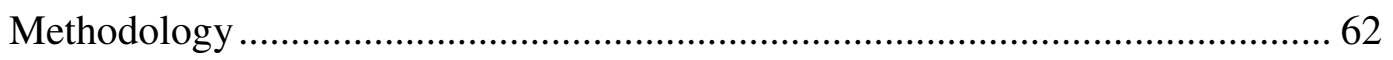

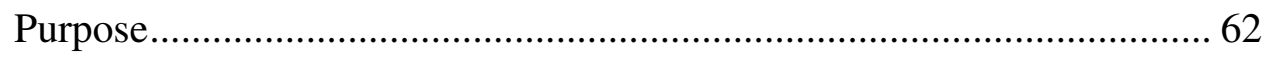

Methodological Approach of van Manen .................................................. 62

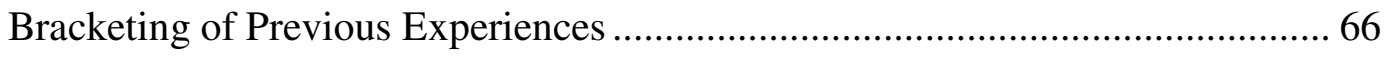




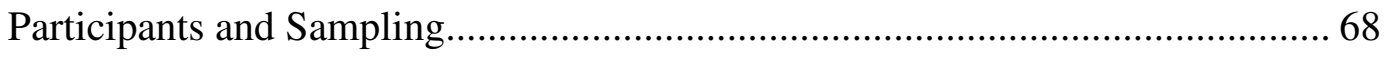

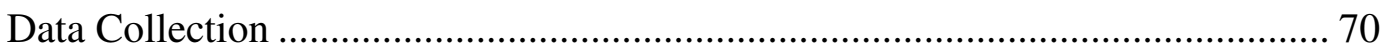

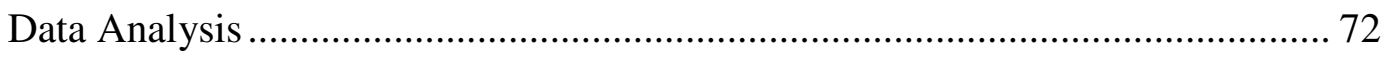

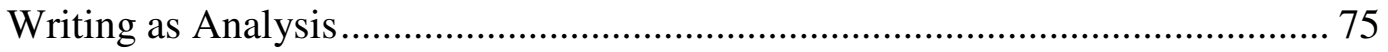

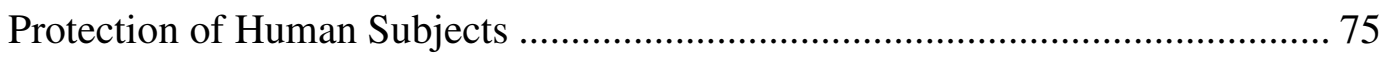

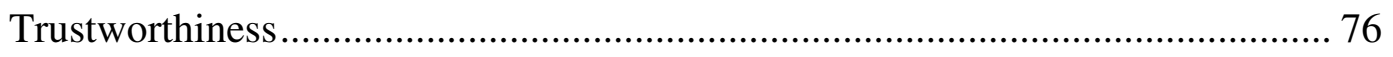

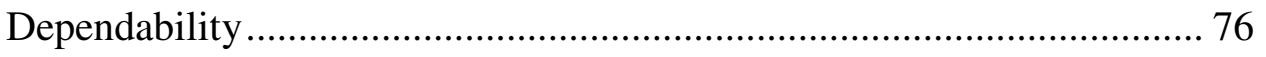

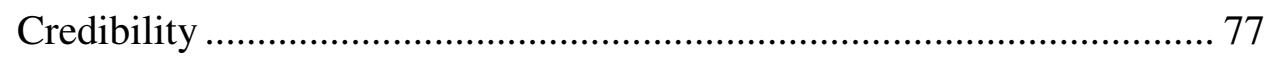

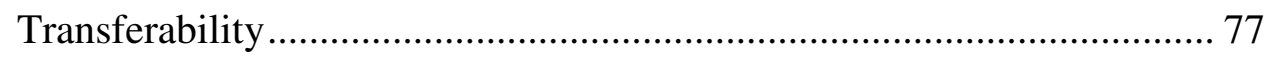

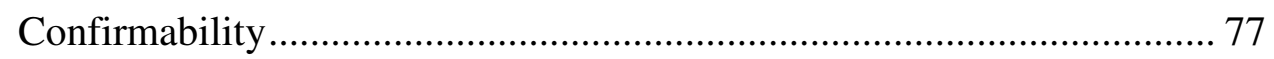

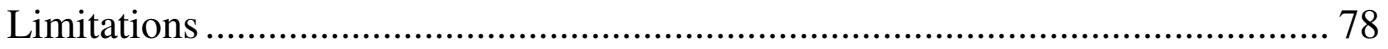

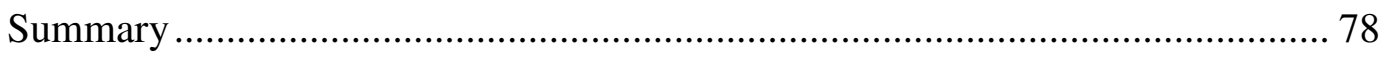

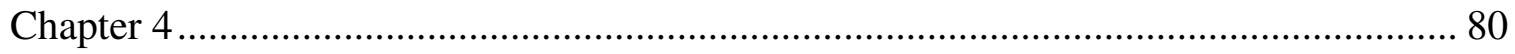

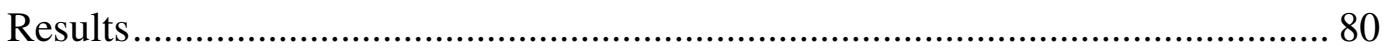

Purpose

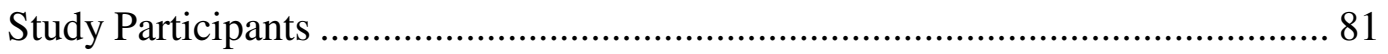

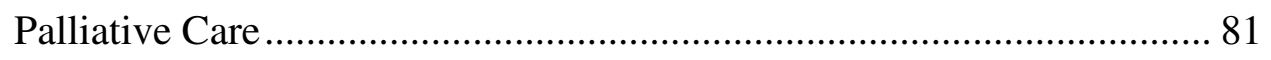

Caregiver Characteristics ..................................................................... 82

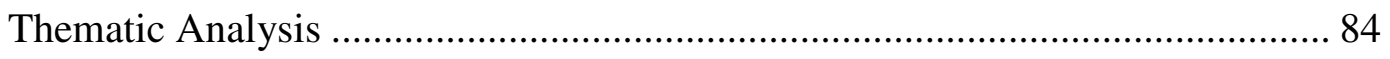

Line of Inquiry \# 1: Explore the lived experience of informal caregivers of a person with dementia enrolled in palliative care living at home. ........... 84 
Line of inquiry \# 2: Identify any spiritual feelings of these caregivers that may be present and explore the meaning of those feelings in the context of

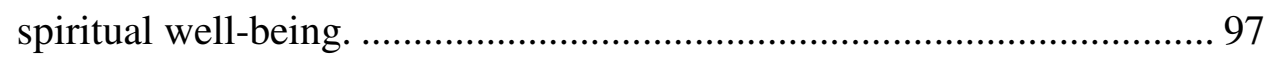
Line of inquiry \# 3: Explore, if present, the spiritual meaning of providing care in home to a person with dementia............................................ 105 Essence of the Lived Experience ...................................................... 116

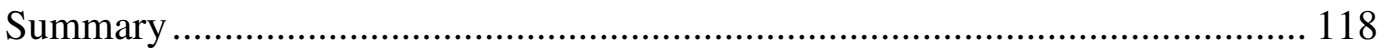

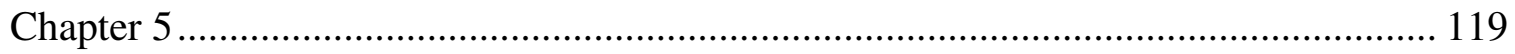

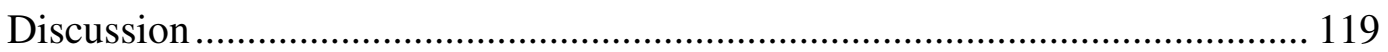

Summary of Findings.............................................................. 119

Reflection on Findings ......................................................... 121

Caregiver Characteristics ............................................................ 122

Caregivers' Lived Experience of Spiritual Well-Being ....................... 123

Limitations and Strengths of Study ........................................................ 128

Implications for Research ........................................................... 130

Nursing Research and Palliative Care.............................................. 131

Nursing Research and Spiritual Well-Being................................... 132

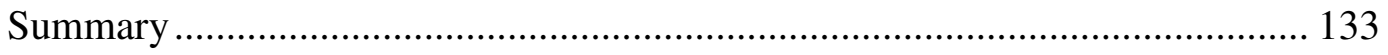

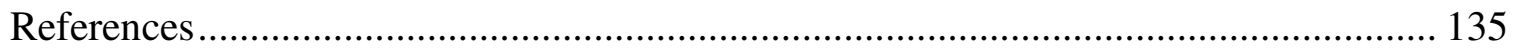




\section{LIST OF TABLES}

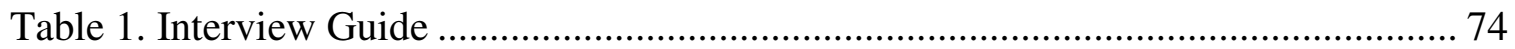

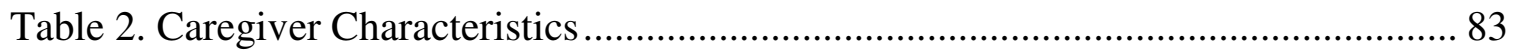

\section{LIST OF APPENDICES}

Appendix A University of San Diego Committee on Protection of Human Subjects .... 142

Appendix B Recruitment Flyer .................................................................. 145

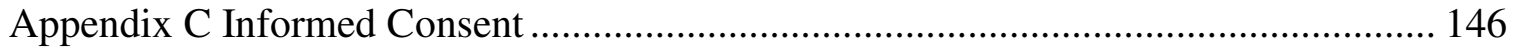

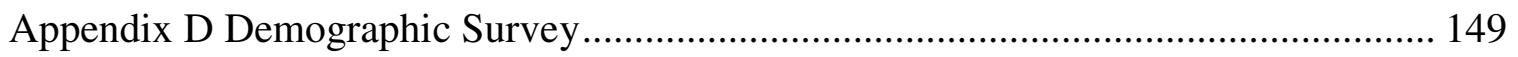




\section{Chapter 1}

This chapter will present an understanding of the need for research that explores the meaning of spiritual well-being amongst informal caregivers of a person with dementia on palliative care living at home. It will begin with an outline of the contextual setting of the phenomenon. The subsequent sections will review the focus of the study, purpose of the study, introduce the lines of inquiry, philosophical foundations, methods, bracketing of previous experiences, and the significance of the study.

\section{Background}

\section{Persons with Dementia}

Approximately 5.5 million Americans live with Alzheimer's disease and related dementias annually (Alzheimer's Association, 2018). Due to the difficulty in diagnosing Alzheimer's disease and related dementias until later stages in the disease process, this number is believed to be much higher. Alzheimer's disease is only one of the many subtypes of dementia but it accounts for approximately $60 \%$ of all cases. In the early stages of the disease, a person with dementia may simply have slower recall of persons, places, or words and have little problem being independent. However, as the disease progresses the individual may begin to struggle in providing appropriate self-care that ultimately results in the need for additional care (Harrison-Dening, 2013).

\section{Informal Caregivers}

It is estimated that more than 15 million Americans each year serve as a caregiver to a person with dementia (Caregiver Action Network, 2014). Many of these individuals spend on average $\$ 5,500$ annually of their own money in providing this care and often have little understanding of how to perform this role or what to anticipate as the disease 
progresses to eventual death (Alzheimer's Association, 2018). Research has shown that caregivers of a person with dementia suffer from increased burden, depression, and lower psychological well-being, all worsening without appropriate support as the disease progresses in their loved one. (del-Pino-Casado, Frias-Osuna, \& Palomino-Moral, 2011; Gallagher et al., 2011; Papastavrou, Kalokerinou, Papacostas, Tsangari, \& Sourtzi, 2007). Spiritual Well-Being

In many cases, informal caregivers of a person with dementia have nowhere to turn for assistance as they struggle to provide safe care for their loved one. As the demands from the type of care increases, the caregiver may even become isolated from family, friends, social, and spiritual support systems exacerbating the potential effects of stress on the caregiver (Gallart, Cruz, \& Zabalegui, 2013). Some evidence suggests that strong, spiritual well-being can protect against the effects of stress in family caregivers although this has not been studied among caregivers of persons with dementia (Salmoirago-Blotcher et al., 2012). The interest in the effect of spirituality on health and well-being is emphasized in holistic models of healthcare like hospice and palliative care.

\section{Palliative Care}

The National Hospice and Palliative Care Organization reported in 2017 that $15.2 \%$ of its palliative care services were provided to persons with dementia. Alzheimer's disease was the third leading diagnosis of all of its patients. Furthermore, between 2001 and 2007 the number of Medicare decedents who had an Alzheimer's Disease and Related Dementias diagnosis who received palliative care increased from 14.4\% to 33.6\% (National Hospice and Palliative Care Organization, 2017). These numbers would most probably be higher if health care providers made referrals earlier in 
the disease trajectory. However, because of the difficulty in diagnosing Alzheimer's Disease and Related Dementias, physicians may be reluctant to have their patients receive a palliative care consult (Afzal, Buhagiar, Flood, \& Cosgrave, 2010). As a result, many family members who take on the role of primary caregiver to a loved one diagnosed with Alzheimer's Disease and Related Dementias do so with limited support. Palliative care is one source of support for individuals with dementia and their family caregivers and is often used interchangeably with hospice care. While it is true that all hospice care includes palliative care, not all palliative care includes hospice care. The role of palliative care is to recognize the symptoms during the progression of these chronic illnesses and begin to address them prior to the need of hospice care (Ferrell, Coyle, \& Paice, 2015). If palliative care is offered early enough in the disease trajectory, both patient and caregiver may be able to address how they will approach the disease's effect on their relationship. Palliative care is most effective when it engages the patient, includes the family, promotes interdisciplinary approach, and displays therapeutic communication. When such support is offered, the patient, and family caregiver are more likely to experience increased coping and improved quality of life (Meghani, 2004).

Previously, the impact of spiritual well-being was not included in a quality of life assessment. However, there has been a growing interest in the effect of spiritual wellbeing on health outcomes. Much of the research on spiritual well-being has been from the perspective of the patient. Recently, this interest has been extended to caregivers of patients with a chronic illness (Burton et al., 2012). While there are instruments available to measure spiritual well-being there is a lack of understanding of the concept in the context of informal caregiving of a person with dementia living at home who are 
receiving palliative care. As such, there is a need to explore the meaning of this phenomenon within this setting.

\section{Focus of the Study}

Alzheimer's disease is a neurodegenerative disease that results in the individual being unable to care for himself or herself at some point in the disease's progression (Harrison-Dening, 2013). In many cases the care that becomes necessary for these individuals is provided by an informal caregiver in the community. The demands that this role places on the caregiver has been noted to increase burden, stress, anxiety, and poor health outcomes (Gallagher et al., 2011). Palliative care emphasizes the physical, emotional, and spiritual support of patient and caregiver as the patient progresses through the disease process. While Alzheimer's Disease and Related Dementias is the third leading diagnosis of patients enrolled in palliative care (Alzheimer's Association, 2018), there is little known about the caregiver's spiritual well-being within this context.

\section{Purpose of the Study}

The purpose of this study was to explore the lived experience of spiritual wellbeing amongst informal caregivers of a person with dementia enrolled in palliative care and living at home. The analysis of transcribed semi-structured interviews in conjunction with responses to a demographic survey and the field notes of this researcher, provided a

more robust understanding of spiritual well-being amongst informal caregivers of persons with dementia on palliative care living at home.

\section{Lines of Inquiry}

This phenomenological study had three lines of inquiry. The first was to explore the lived experience of informal caregivers of a person with dementia enrolled in 
palliative care and living at home. A second line of inquiry was to identify any spiritual feelings of these caregivers to a person with dementia that may be present and explore the meaning of those feelings in the context of spiritual well-being. The final line of inquiry was to explore, if present, the spiritual meaning of providing care in-home to a person with dementia.

\section{Study Philosophical Foundation}

Phenomenology is the philosophical pursuit of understanding the meaning of concepts, or phenomena, as they are experienced by the human person. It is both a philosophy and a qualitative research method (Tuohy, Cooney, Dowling, Murphy, \& Sixsmith, 2013). There were two main schools of thought during the development of phenomenology as a qualitative research method. The first school is known as descriptive phenomenology. This school emphasizes the philosophy of Husserl, who is widely accepted as the founder of phenomenology. The aim within this branch is to arrive at the true essence, or nature, of a phenomenon without reflecting on it by the individual. According to Husserl, this is accomplished by bracketing one's ideas of the phenomenon before undertaking the search to arrive at its purest sense. In this way, assumptions will not influence the interpretation of a phenomenon of interest described by the participant. This ultimately leads to a more precise understanding of the phenomenon (Dowling, 2007).

The second school is known as interpretive phenomenology also referred to as hermeneutics. This approach centers on the philosophical concept of "dasein" (being in the world) introduced by Heidegger. Interpretive phenomenology asserts that preunderstandings are part of who we are as human persons. Heidegger believed that these 
pre-understandings were a necessary component of probing into the lived experience of a phenomenon (Tuohy et al., 2013). This awareness of pre-understanding and open questioning of the lived experience, a process known as the hermeneutic circle, eventually leads to a shared understanding to the meaning of a phenomenon (Dowling, 2007).

These two schools of thought understand phenomenology as a philosophical science and not a research method. The philosophy of phenomenology is interested in arriving at meanings of abstract concepts like "meaning" or "being" (Dowling, 2007). The goal in Husserl's approach was to describe the characteristics of a phenomenon and not how a person experiences a phenomenon. However, for Heidegger the aim of phenomenology is to interpret an individual's lived experience of a phenomenon (Tuohy et al, 2013).

In the mid-twentieth century, the social and human sciences started to distance themselves from the natural sciences. As these sciences explored the meaning of lived experiences, the application of phenomenology to its research process became an appropriate decision. However, the critique at the time was that phenomenology was not a research method but a philosophy. The response within the social and human sciences was the development of methodological approaches that were informed by the philosophy of Husserl or Heidegger (Dowling, 2007).

The focus of hermeneutic phenomenological research is to pursue deeper meanings of the lived experiences of a phenomenon (Tuohy et al., 2013). Unlike other sciences that study the physical objects and things found in nature, the object of pursuit in hermeneutic phenomenological research are the emotions, feelings, and consciousness of 
persons who are experiencing a particular phenomenon (van Manen, 1990). The result of this search is to arrive at a more robust understanding of the meaning of a phenomenon.

\section{Methods}

There was no clear understanding of spiritual well-being in the context of a caregiver of a person with dementia enrolled in palliative care who is living at home. Therefore, a qualitative design based on the philosophy of interpretive phenomenology and analytic approach of van Manen (1990) was selected for this study. The caregiver interviews were audio-recorded and transcribed for analysis according to the steps outlined by van Manen (1990). The methodological approach that he suggests involves an iterative process of moving between six different activities. The initial activities are about becoming committed to the phenomenon so that the researcher remains invested in the quest to discover meaning. The middle activities involve exploring the lived experience of a phenomenon by individual human persons. The final activities are the fruit of phenomenology — the art of writing a representative description of the phenomenon. The success of this endeavor required that the researcher's interest in the phenomenon be acknowledged at the onset of the study to avoid unnecessary influence on the research process.

\section{Bracketing of Previous Experiences}

Munhall (1994) describes the importance of how the researcher's personal experience contributes to "the pursuit of understanding the meaning of being" in a phenomenological study. In doing this, the researcher acknowledges his or her previous experiences of the phenomenon of interest. This is an essential step for the phenomenological researcher for two reasons. First, it places these previous experiences 
in the fore-structure through self-revelation. Second, after recognizing the previous experiences, the researcher can place them to one side and be able to see the phenomenon truly as the participant describes.

This researcher's interest in conducting a phenomenological study on the lived experience of spiritual well-being of caregivers was influenced by both personal and professional experiences. Those experiences have shaped my understanding of the complexity of caregiving and the effects it has on those who are courageous, and able, to take on that role. There are moments of pain, frustration, guilt, and fear associated with this role. But there are also moments of joy, satisfaction, meaning, and fulfilled purposefulness when acting as an informal caregiver to a family member. The details of the researcher's own experiences of caregiving will be presented more fully in the study methodology in chapter 3.

This study explored the meaning of the lived experience of spiritual well-being amongst informal caregivers of a person with dementia enrolled in palliative care and living at home. This required me to put aside my previous experiences through regular review of them with my dissertation committee. In doing so, I was free to encounter this phenomenon within the situated context of the participant. This allowed for a truer representation of the meaning attributed by the caregivers to spiritual well-being.

\section{Significance of the Study}

The impact of caregiving on the health and well-being of a family caregiver of a person with dementia on palliative care living at home is far reaching. The rich descriptions collected from the participants of this study have contributed to an awareness of caregiving within this context. As a result of exploring this phenomenon from the 
perspective of the caregiver, valuable insight was obtained. While not generalizable, their experiences will enhance the healthcare professional's understanding of the importance of relationships to the spiritual well-being amongst family caregivers of a person with dementia.

The description of spiritual well-being that was derived from the lived experiences of these participants may help focus future research involving informal caregivers of a person with dementia. This research needs to begin with exploring how this description compares to other cultural groups and caregiving populations. This would further allow for specific spiritual interventions to be examined that may help increase the family caregiver's spiritual well-being and thereby promote enhanced health of the caregivers.

By improving the health of informal caregivers, patients with dementia may have increased likelihood of living longer in the community. This may bolster their own quality of life, strengthen the relationship bonds with the family caregiver, and provide a reduced cost to the healthcare system. All represent future research opportunities.

\section{Summary}

It is estimated that every 66 seconds another person in America will develop Alzheimer's Disease and Related Dementias (Alzheimer's Association, 2018). This exponential rise in persons living with Alzheimer's Disease and Related Dementias will thrust more family and friends into the position of becoming an informal caregiver. While today there are more than 16 million family members providing care to a loved one with Alzheimer's Disease and Related Dementias, this number will only continue to increase (Alzheimer's Association, 2018). Research involving informal caregivers of 
patients has shown that when left unsupported, the informal caregiver has poorer health outcomes (Gallagher et al., 2011).

The effect of spirituality and spiritual well-being on health outcomes has been studied in a variety of populations (Adams, Mosher, Cannady, Lucette, \& Kim, 2014; Bormann et al., 2009). Yet, much of the research has been done in caregiving populations other than Alzheimer's Disease and Related Dementias. Furthermore, little work has been done to describe the meaning of these concepts amongst caregivers. Thus, this qualitative research has expanded the science by contributing to a more robust description of spiritual well-being in the context of informal caregivers of persons with dementia. 


\section{Chapter 2}

\section{Context of Study}

There has been a slow, but gradual, increase in research with an interest in the effect of spirituality on health and well-being. Much of this research, though, has been approached from the perspective of the patient, particularly in patients with life-limiting illnesses (Canada et al., 2013). The advances in medical treatments and therapies have, in part, brought an increase in life expectancy to these patients. One result of living longer with a life-limiting illness is the concern of where, and from whom, these persons will receive care when they are no longer able to care for themselves.

In many cases a family member or close friend will become the primary caregiver. Research indicates family members who assume this new role as informal caregivers often poorly understand what will be required of them, which contributes to their less than optimal health outcomes. This reality has led researchers to begin to explore the effect of spirituality and spiritual well-being on health and well-being in some caregiving populations (Bormann et al., 2009; McClain, Rosenfeld, \& Breitbart, 2003; Spurlock, 2005). Despite this growth, though, there remains some confusion on what is meant by the concepts of spirituality and spiritual well-being in some caregiving populations.

This chapter will explore the meaning of spirituality and spiritual well-being within the context of the population of caregivers to persons with dementia. It will begin with a brief review of these concepts. The results of a comprehensive review of the literature will follow and explores these concepts within the context of caregivers of 
persons with dementia. The literature was searched through the databases of CINAHL, PsychINFO, ATLA, and PubMed. The strategy used for this search included the terms "Spirituality" OR "Spiritual well-being” AND "Older adult caregivers" OR "Caregiving” AND "Dementia” OR “Alzheimer". The inclusion criteria for the peer-reviewed journal articles were from studies published between January 1985 to December 2015 that examined spiritual well-being of caregivers of persons with dementia and were written in English.

\section{Spirituality}

The concept of spirituality and its use in nursing research is relatively recent. Reinert and Koenig (2013) noted that in a review of CINHAL and PubMed the number of published articles related to research on spirituality and nursing has increased dramatically in the last 25 years. Prior to 1990, there were fewer than 10 articles and none had a nurse as the first author. By 2007, there were more than 300 articles written in a four-year period, though only 19 have a nurse listed as the first author. This sudden shift is an indication of the renewed importance of nurses recognizing spirituality in patients' health and well-being. Interestingly, while there has been an increase of published articles on spirituality and nursing, there is no single agreed upon conceptual definition, paradigm, or conceptual framework. However, the current work in these areas is shared with the reader as background information. Lack of consensus reinforces the need for original explorations of personal meanings, not influenced by this work, as is being proposed in this study. 


\section{Conceptual Analysis of Spirituality}

The care of the whole human person—physical, emotional, social, and spiritual— has been a part of nursing for centuries. The effect of any of these on health and wellbeing requires a clear understanding of what is meant by the concept. Early attempts to define the meaning of spirituality did so by making a distinction between it and religion (Burkhardt, 1989). In her concept analysis, Burkhardt notes that spirituality is related, but not identical, to religion. Where the former is understood to be a process of searching for meaning, purpose, and relationship, the latter is a gathering of spiritual experiences into a belief system. In other words, spirituality is understood to be a more global concept that is an essential principle found in every individual, while religion is the specific expression of a collective group's spirituality through common ritual and practices.

Burkhardt identifies three main defining attributes to spirituality. First is the unfolding of the mystery of life's experiences. Here the individual confronts the challenges of life and through the process of searching, discovers a meaning and purpose in life. Second is the idea of harmonious interconnectedness. This refers to an individual's ability to be in relationship with self, others, and the Sacred that allows the person to arrive at a sense of peace. Finally, it includes an awareness of inner strength. This relates to the individual's recognition of the Sacred dwelling deep within that provides direction to an individual's life path. Burkhardt contends these attributes, in addition to the overlapping concepts of religion and spirituality, suggest the term "spiriting" more accurately captures the idea of "process" that is inherent to the concept 
of spirituality. The process of spirituality, then, allows the individual to experience, in part, meaning, purpose, and peace in life.

Tanyi (2002) acknowledges spirituality is an abstract concept that is subjective in nature. She recognizes that interest in the effect of spirituality on health and well-being has grown despite any consensus on its meaning. Her conceptual analysis seeks to enlighten the understanding of spirituality for use in nursing science. Like Burkhardt, Tanyi notes that spirituality and religion are often used interchangeably in literature. She draws a similar conclusion in that the former is an innate characteristic in an individual while the latter relates to a set of prescribed beliefs. The religious person will be guided in part by the shared spirituality of a faith group. In contrast, the nonreligious person will rely on the awareness of a vital principle within themselves to find direction. As such, all persons, both those who subscribe to a specific religion and those who do not, are affected by spirituality.

In her conceptual analysis of spirituality, Tanyi provides three defining attributes. First is the idea of belief or faith. This may initially appear to suggest that religion is necessary for spirituality to be present. However, while this may mean that a person adheres to a specific religion, it may also be a belief in a self-identified goal or value that motivates the individual with no personal religious significance. Second is having inner strength and peace. It is through a commitment to what a person believes to be true that sustains this internal characteristic. Finally, there must be a connectedness. This characteristic involves connection to the Sacred as well as a connection to others and nature. The former creates a vertical dimension, with the Sacred, while the latter comprises a horizontal dimension, with others, to the concept of spirituality. When both 
dimensions are examined together, spirituality is understood to be a process whereby an individual is searching for meaning, purpose, hope and transcendence in life.

These conceptual analyses demonstrate the challenges of providing a consistent definition. Burkhardt's presentation of spirituality captures the global dimension of this concept quite well. However, her attempt to introduce a new term-"spiriting"- may be confusing. It does illuminate the understanding that spirituality is a process, which was also emphasized by Tanyi. However, by using a new term, Burkardt has left the reader to wonder, what does "spirituality" mean? In seeking to bring clarity to this concept, Tanyi definition includes having a belief system. While she explains this belief can be rooted in a religious system or personal value, she does not make a clear separation between religion and spirituality. A strength of both conceptual analyses is the shared understanding that spirituality is recognized through a connectedness to self, others, and the Sacred. This linking of the vertical and horizontal dimensions emphasizes the pattern of development, or process, inherent to spirituality. While they both provide an understanding of spirituality, there remains a need for developing a way to examine this concept in nursing science.

\section{Paradigm for Exploring Spirituality}

Reed (1992) noted that the phenomenon of spirituality is pertinent to nursing science but in need of a paradigm to assist in bringing deeper understanding to the concept. Her paradigm attempts to reshape the understanding of the human person from a strictly empirical approach to one that is ontological. She argues there is a need to move away from the mechanistic model that emphasized changes in individuals were nothing more than a biological need to adapt to the stressors in life. This paradigm 
presents the physical and spiritual as two distinct components to the human person that function in a way that are unrelated. When viewed as such, the impact of spirituality on health and well-being is minimized. If the innate nature of spirituality is to be studied more fully a new model would be necessary.

In her paradigm, Reed suggests that the developmental-contextual model by Lerner provides such a context (Reed, 1992). It views change within the human person to be a natural process that results from the capacity of human persons to be transcendent. The challenges that an individual confronts, then, results not in a shift of equilibrium but a creation of energy that leads to the unfolding of the internal mystery of that person. As such, the individual in relationship to self, others, nature, and the Sacred discovers a sense of meaning and purpose in life. Thus, this paradigm recognizes that spirituality is always present, albeit with different levels of awareness, in the human person and is a vital part of the experience of life through intrapersonal, interpersonal, and transpersonal relationships. This understanding of spirituality presented by Reed is an important contribution to how spirituality is experienced in different populations and how it may affect overall well-being.

\section{Conceptual Framework of Spirituality}

The challenge to describe the meaning of spirituality is examined by Lepherd (2015). The very personal nature of spirituality has contributed to this struggle. Yet, if caring is approached from the lens of holistic health, emphasizing physical; psychological; social and spiritual dimensions, then a description of spirituality is necessary. Lepherd presents essential structures of spirituality and uses those components to develop a conceptual framework. The innate nature of spirituality, 
allowing the individual to transcend self to discover meaning and purpose, lays at the foundation of this framework.

There are five dimensions, or essential structures, to spirituality. First is an integrative energy. This force, or power, allows the individual to discover harmony in self while at the same time develop connections with others, nature, and a higher power. Second is the presence of a set of values and beliefs. These inherent elements of spirituality, like hope, trust, and love, all lead to an increase in how the individual discovers meaning in life. Third is the understanding that spirituality is a process and journey. It is something that develops over the span of a life time. How a person understands spirituality is a contributing factor to an individual's life journey. At the same time, how the person experiences life's journey will be important to the individual's understanding of spirituality. Fourth is the capacity for transcendence that results from connectedness. A person's spirituality is rooted in relatedness to self, others, a higher power, and nature, which all contribute to increased self-understanding and the ability to experience improved well-being. Finally, the fifth dimension is existentialism. This embodies the understanding of searching for meaning and purpose in life. Each of these dimensions impact how the individual lives his or her life.

Lepherd (2015) contends that an individual demonstrates spirituality both internally and externally. In other words, spirituality is both something that is personal and unknown but also public and observable. He suggests three areas for consideration. First, a person has the capacity to meditate. This can be done privately or through participation in a religious ritual. Second is putting specific values into practice. A person can show love, hope, trust, and forgiveness of others by approaching another 
person or holding that individual in their personal thoughts. Finally, there is the practice of communal rites found in a specific spirituality. There is significance to engaging in these by oneself and at other times in a group. Demonstrating behaviors associated with spirituality leads to specific outcomes.

Lepherd (2015) suggests that when an individual expresses spiritual behaviors he or she will experience an increase in peace of mind and self-fulfillment. This results from the harmonious connectedness that a person has with self, others, nature, and a higher power. It has the potential to alleviate suffering and facilitate well-being in an individual as he or she grows in knowledge of the mystery that is within. He notes that just as behaviors of spirituality are both internal and external, so too are outcomes. Thus, it will not always be easy to assess the impact that spirituality has on a person. Yet, it is the capacity for transcendence that makes spirituality unique. For it is through transcendence that the person is able reach the profound meaning of different life experiences.

\section{Spirituality in Caregivers}

The prolific writing on spirituality and nursing has focused in large part on understanding the effect of spirituality on the health and well-being of patients. When diagnosed with a life-limiting illness, a patient does not necessarily have an immediate decline. In many cases an individual will live several years with such an illness and eventually require assistance from a caregiver. Both the declining cognitive and physical function and related increased dependence of a person with dementia has been demonstrated as a predictor in caregiver burden (Gallagher et al., 2011; Papastavrou et al., 2007; Razani et al., 2014). In cultures where religion and spirituality play an 
important role these have been shown to provide some moderating effect on caregiver burden (Hodge \& Sun, 2012; Sun \& Hodge, 2014). The distinction between religion and spirituality is something, however, that needs further examination.

Research on the effects of spirituality on the health of the caregiver of a person with dementia is limited in part because the meaning of this concept within this population has not been fully explored. This section of the chapter, therefore, will review what is known about the spirituality of caregivers of a person with dementia. It will begin with a description of specific characteristics of a caregiver for a person with dementia. Then, studies that demonstrate the impact of spirituality on the health of caregivers will be examined. This will be followed by a review of research that has explored how caregivers of a person with dementia assign meaning to spirituality. Finally, based on the limited amount of evidence available, an understanding of spirituality of caregivers of person with dementia at the end of life will be presented.

\section{Caregiver Characteristics}

An informal caregiver is a person who provides unpaid assistance to a family member or friend living with an acute or chronic disease. This individual will assist with either an activity in daily living (ADL) or with instrumental activities of daily living (IADLs). An ADL is understood to include helping a care recipient with moving from a chair or bed, eating, bathing, or getting dressed; an IADL involves providing transportation, shopping, cooking, or paying bills for the care recipient. The Alzheimer's Association estimates that there are more than 16 million Americans providing this type of informal care to a person with dementia (Alzheimer's Association, 2018). 
It is important to know who is providing this care if its impact on the caregiver is to be understood. The 2018 Alzheimer's Disease Facts and Figures identify key demographics of this population. These caregivers tend to be women (66\%), married (66\%), white (66\%), over the age of 65 (34\%), living with the care recipient (66\%), and providing on average more than 21 hours of care each week with an approximate annual economic value of over $\$ 221$ billion (Alzheimer's Association, 2018). These demographics are similar to those found in most caregiving populations with a few key exceptions (Caregiver Action Network, 2014).

In general, informal caregivers of a person with dementia compared to informal caregivers of other older adults who provide care in the home for more than six years do so at approximately the same rate, $38.5 \%$. However, when the care recipient is in a residential care facility there is a marked difference in the length of time that informal care is being provided between these two groups. When the care recipient is in the residential care facility for six or more years, the rate of providing informal care for a person with dementia is $47.4 \%$ versus $29.4 \%$ for other older adults. As the duration of care lengthens, the physical and emotional demands on the informal caregiver worsen with caregivers of a person with dementia reporting twice as much physical, emotional, and financial burden compared to caregivers of other older adults. When asked to rate their emotional stress, 59\% of informal caregivers of a person with dementia indicated this to be either high or very high and $40 \%$ reported suffering from depression (Alzheimer's Association, 2018). Because of the effect of this role on caregivers' health, additional research is needed to explore the meaning of physical, emotional, social, and spiritual aspects of caregiving. 


\section{Spiritual Perspectives and Spiritual Behaviors}

The spiritual perspective of 17 spousal caregivers of a person with dementia were compared to those of 23 non-caregiver spouses of healthy patients in a descriptive correlational study (Kaye \& Robinson, 1994). This study elaborates on the understanding of spiritual perspective that suggested this to be an internal dimension that conveys an individual's connection to the Sacred through transcendence (Reed, 1992). The embodiment of a spiritual perspective may assist the informal caregiver of a family member with dementia reframe the sense of loss they commonly experience into a positive experience. The study tested the hypotheses that in spousal caregivers of a person with dementia, increased spiritual perspective would be related to increased social support, decreased depression, and a stronger relationship in those variables when compared to non-caregiving spouses.

The convenience sample of all Caucasian women was described as similar in terms of age and education level. Participants self-identified as either Protestant or Catholic. The primary variables used in this study included spiritual perspective, depression, and social support (Kaye \& Robinson, 1994).

Multiple instruments were used in this study. The Spiritual Perspective Scale was used to measure spiritual perspectives and spiritual behaviors. This 10-item instrument examines both the spiritual views believed by a person and related spiritual practices. It has been used in both healthy and ill populations with a Cronbach's alpha consistently above 0.90. The Center for Epidemiological Studies Depression Scale (CES-D) was used to measure depression. Participants rate the number of times they feel depressed in the previous week from 0 (rarely) to 3 (all of the time). Total scores range from 0 to 60 with 
higher scores indicating greater levels of depression. It has a strong Cronbach's alpha above 0.90 . Finally, three instruments were used to measure different aspects of social support: The Global Satisfaction Scale (GSS), Expressed Support (EXS) and Social Network List (SNL). The GSS, a 9-item instrument, examines the participants' satisfaction with the support received from others on a 7-point scale that ranges from "very dissatisfied" to "very satisfied." The EXS, an 8-item instrument, measures supportive characteristics that participants perceive as available in their relationships on a 4-point scale that ranges from "strongly agree" to "strongly disagree." The SNL reports on the frequency and quality of contact between the participants and individuals who are important to them. Each of these instruments was reported as having been used with caregivers of persons with dementia. However, the only reliability statistic provided was that for the EXS with a Cronbach's alpha of 0.87 .

In caregivers of persons with dementia there was a statistically significant inverse relationship between depression and perceived social support $(r=-0.56, p<0.05)$. The non-caregivers also had a statistically significant inverse relationship; however, it was between depression and expressed support $(r=-0.46, p<0.05)$, not perceived support. This suggests that depression in both groups is affected by social support. In caregivers, the relationship is noted in the perception of satisfaction with the support received from others. In non-caregivers, this relationship is observed in the availability of support in their relationships.

In care caregivers of persons with dementia, there was also statistically significant correlation between contact with others and use of social support $(r=0.54, p<0.05)$ and contact with others and available social support $(r=0.55, p<0.05)$. This suggests that 
when caregivers perceived others as available they were more likely to reach out to them for support. There was only a weak relationship $(r=0.02, p<0.05)$ between contact with others and available for support in non-caregivers.

There was no statistically significant difference between the two groups on spiritual perspective and satisfaction with available support. In caregivers, the relationship was positive $(r=0.39)$ but not significant. In non-caregivers, there was also no significant relationship; however, the relationship was negative $(r=-0.30)$. These findings do support the hypothesis that caregivers would have higher spiritual perspective compared to the non-caregivers but only in the study sample. These findings are not generalizable due to the lack of significance.

The findings of this published study support the assertion that the association between spiritual perspective, depression, and satisfaction with social support would be stronger in caregivers of persons with dementia than non-caregivers. The impact of spiritual perspective and behaviors on satisfaction with social support and depression amongst caregivers of persons with dementia observed in this study would suggest this population may rely on members of their faith community for support. Additional research is needed to explore these and other positive outcomes that result from reframing the caregiving experience through transcendence. This study was also limited by its small and homogenous sample. Further research is warranted that would expand the findings of this study into other ethnic and religious groups.

\section{Spirituality Effect on Caregiver Burden}

Shah, Snow, and Kunik (2002) examined the relationship between spiritual and religious coping styles to caregiver burden and depression in a population of caregivers 
of persons with dementia. This study used a cross sectional cohort design of 48 caregivers who attended an Alzheimer's Association support group in the southern United States.

The participant characteristics in this study were comparable to demographics from other studies of caregivers of persons with dementia. The majority were female (74\%), married (91.7\%), mean age of 64 years, predominant ethnicity was Caucasian (93.8\%), and about half (52.1\%) provided care to a person with dementia in their home.

The Zarit Burden Interview, Geriatric Depression Scale, Duke University Religion Index, and the Religious Coping Activities Scale were the selected instruments and reported to be widely used in caregiving populations. The Duke University Religion Index measured religiousness along three specific dimensions: organizational, nonorganizational, and intrinsic. The Religious Coping Activities Scale examined how often a person relies on religion to respond to stressors in life.

Most caregivers identified themselves as either spiritual or religious (96\%), with a specific religious affiliation (92\%) where Christianity $(81 \%)$ was the predominant faith. While there was no significant correlation between the subscales of the Duke University Religion Index to either depression or burden, the intrinsic subscale had the strongest correlation with depression and burden ( $r=0.149$ and 0.100 respectively). A negative but insignificant association ( $r=-0.170)$ was found between spiritually based coping and depression as a result of caregiving. However, the most significant positive association was between discontent (the measurement of anger toward God or religion due to the stressors involved in caregiving), and both depression and burden ( $r=0.520$ and 0.509, $p<0.001$ respectively). Hierarchical regression models revealed that caregiving at home 
versus the patient living in a facility accounted for $13 \%$ of variance in depression $(F=6.93, p<0.01)$ and $18 \%$ of variance in burden $(F=9.85, p<0.005)$. Religious discontent, the only variable that demonstrated significance, explained $24 \%$ of variance of depression $(F=13.09, p<0.001)$ and $22 \%$ of variance in burden $(F=14.82, p<0.001)$.

There was a brief mention of qualitative data at the very end of the study. It was reported that caregivers commented that it was faith in God and prayer that gave them hope. Because of this hopefulness, the caregivers believed it was possible to find an "inner peace" with their role. These are important pieces of qualitative data that were not probed further. Future research should examine meanings that caregivers attribute to spirituality. The demographic survey only asked if the caregivers were spiritual or religious. While these are two distinct but overlapping concepts, it would have strengthened the study method to distinguish one from the other for the participant. A question could have been posed, "Do you consider yourself spiritual?" and "Do you consider yourself religious?" This is especially important given the strong relationship shown between anger with God/religion and caregiver depression and burden. Additional research is needed to explore the distinction between the concepts of spirituality and religion in caregivers.

\section{Meaning of Spirituality in Caregiving}

The meaning of caregiving for a person with dementia was explored in a qualitative study (Smith \& Harkness, 2002). The purpose of the study was initially to gain a better understanding of caregiver "needs" in the context of being a caregiver for a person with dementia. The authors note that caregiver "needs" can range from physical pain, psychological struggles, social isolation, and altered spiritual awareness. The focus 
of the interview process was to elicit, in general, the meaning of caregiving. However, participant responses consistently addressed the impact of spirituality on their role as caregivers to a person with dementia.

This study enrolled 45 participants who were either actively caring for a person with dementia or had cared for a person with dementia who had recently passed away. Again, this study collected similar demographics to other studies on caregivers of a person with dementia. Most were female over the age of 65 (87\%), caregivers tended to be spouses (51\%), living with the care recipient (49\%), providing more than 16 hours of caregiving daily (33\%), and held employment in addition to their caregiving role (40\%). The caregivers were asked to rate where they believed the person with dementia was at in his/her disease progression: 10 responded that the care recipient was in early stages, 21 mid stage, 11 late stage, and three care recipients had died at the time of the study.

The researchers followed a semi-structured process that included intensive interviewing to gather descriptive stories from the participants to understand their experience of being a caregiver of a person with dementia. The interview questions were amended after the first interview to include a question related to meaning-making. This additional question allowed for caregivers to recount how their experience of caregiving had been influenced by various sources such as the disease itself, family, friends, and their spiritual connections. The caregivers were interviewed in their homes. Transcriptions of all digital recordings of the interviews were then analyzed and themes generated. These were then further analyzed and categorized into two domains. The first domain included caregiver needs, concerns, and satisfaction. The second domain was meaning-making. 
In comparing the qualitative data, the study found the themes that emerged from what caregivers repeated most often as it related to their faith communities was either "supportive" or "generally unsupportive." The majority of caregivers (80\%) were able to describe a significant event related to their caregiving role that had been impacted by their spirituality or religion. More than half of the caregivers (53\%) provided descriptions of their religious affiliation in a positive tone like "friendly." A smaller segment (13\%) referred to their faith communities as "phony" and generally unavailable. However, when they responded to how spirituality impacted their role as a caregiver they spoke about their individual relationship with God and the care recipient. They commented that it was "God who I leaned on," "God was teaching me," and "Mom lived a full life." Several of the caregivers shared in-depth accounts of how their faith influenced their experience as a caregiver. One stated, "My faith is what gets me through ... it is the only thing I can depend on." A few, though, noted their caregiving role was influenced through something spiritual but not religious. For example, a caregiver mentioned that she had been angry initially but over time became more caring, "I have changed and have a new purpose in life."

The findings of this study suggest that the concepts of religion and spirituality, while distinct, both have a powerful influence on the caregiving experience. The caregiver may have a religious affiliation that incorporates specific beliefs. The daily living of these beliefs involves a relationship with the members of a church and with God. In contrast, a caregiver who has a secular spirituality embodies a perspective of life purpose and meaning that is unique to the individual. It may be expressed through relationships with self, others, nature, and the Divine. The statements made by the 
caregivers in this study demonstrate that spirituality and religion should be understood as different but with equal ability to allow for the caregiver to make meaning out of the experience.

While this study unexpectedly discovered that caregivers of persons with dementia are affected by religion and spirituality, it was not an a priori study aim to explore the meaning of spirituality in the context of caregiving for a person with dementia. Interestingly, the authors do not report spiritual or religious affiliations, background, or practices of the caregivers. If this had been included, a more robust representation of spirituality in the context of caregiving may have resulted. Therefore, further investigation that examines spirituality in this population is warranted.

The progressively debilitating nature of dementia can place tremendous demands on a caregiver. A result of the mounting responsibilities due to a care recipient's decline has been an increase in caregiver burden (Perren, Schmid, \& Wettstein, 2006). The gradual loss of physical and cognitive abilities in the person with dementia suggests caregiver's stress will only increase. As such, an understanding of how to assist the caregiver in recognizing meaning and purpose in their role was needed. The understanding of how spirituality develops within the context of caring for a person with dementia was the focus of one such qualitative study that utilized a descriptive, naturalistic field study design to investigate the meaning of spirituality in caregivers of persons with dementia (Acton \& Miller, 2003).

This study had a total of 9 participants recruited from an Alzheimer's Association caregiver support group and from a subsequent snowballing technique. The participants were on average 59 years old, all were Caucasian, 7 of the caregivers were daughters, 
$33 \%$ worked in addition to the caregiving role, and only $22 \%$ provided direct care to the person with dementia in their home. Participants in this study all self-identified from a Judeo-Christian faith; there was no description of which faith groups nor the specific religious practices that were a part of their routine.

The focus of the qualitative interview was to have participants respond to a general question, "How do you understand the word spirit or spirituality?" Additionally, the researchers would use probing questions, "Has there been a change in your spirituality?" The 1-2 hour interviews were transcribed and reviewed by the researchers to identify statements related to spiritual meaning. These were subsequently coded to assist with the goal of presenting main concepts and themes attributed to the meaning of spirituality for these caregivers.

The participants identified four essential elements to spirituality. The first was the understanding of connectedness. It was their relationship with God, others, and self that provided strength in their role as a caregiver. The second was the idea that spirituality is a life-long commitment. The participants noted that spirituality was a process "slowly evolved" that required daily attention. The third was the importance of communication. This involved spending "real time" in dialogue with God and others. The fourth was discovering that the perspective of others was vital. As the caregiving role progressed, the participants realized that they were not engaged in it alone but with God and others. One of the participants best captured these essential elements into her description of spirituality as, "Faith in God, faith in others, and faith in self."

In reviewing these essential elements of spirituality during further data analysis, the researchers found by chance that the caregivers noted specific outcomes of 
spirituality. These outcomes were sustained by both internal resources-a relationship with God and belief in self-worth, and external resources—-belonging to a group that is supportive. These serendipitous findings revealed four outcomes of spirituality. The first was comfort. The caregivers believed the comfort that came from spirituality helped reduce their sadness. The second was peace. The presence of worry in caregivers was ameliorated by the sense of peace that resulted in having an awareness of their spirituality. The third was acceptance. The understanding of having a relationship with God and others helped the caregivers accept the importance of their role. The fourth was finding purpose in life. Several of the caregivers noted that they had discovered a unique and special purpose in life being a caregiver. These outcomes were made possible through both a strong internal connection with God and an external connection with others, particularly in the setting of church affiliation.

The findings of this study are consistent with other attempts to describe meaning to the concept of spirituality. The participants described spirituality as an interconnectedness with God, others, and self. There was, however, no presentation of the caregiver's personal faith and religious practices compared to those of the person with dementia. If these were included, the findings may have produced a richer description of both spirituality and its development. Additionally, the opportunity for caregivers in this study to engage in spiritual support activities may have been increased because in most instances the care recipients were not living with them. In future research, a comparison of how spirituality is described between caregivers who provide care in the home versus those who do not would be a significant contribution to the understanding of spirituality 
in the context of this population. This study would also have been strengthened by including caregivers from across the trajectory of dementia decline.

\section{Spiritual Needs of Persons with Cancer Diagnoses at End of Life}

In a study by Taylor (2003), an exploration of specific spiritual needs of the patient and the caregiver was conducted. Taylor acknowledges that previous studies have demonstrated how patients with terminal diagnoses will often turn to their spirituality to address the distress brought on by their illnesses. However, she notes there had been no attempt to identify specific spiritual needs of the patient or caregiver at the end of life.

This was a descriptive, cross-sectional, qualitative study. The semi-structured interview process asked 21 patients with cancer diagnoses and 7 caregivers, "can you tell me about any spiritual needs that you may have had since your cancer diagnosis (or since your loved one received a cancer diagnosis)?" When additional understanding was necessary, the researcher used a probing question like, "Can you tell me more about that?" The interviews were approximately 1-2 hours in length, audio-recorded, and transcribed for analysis.

The researcher used a content analysis approach to reduce the data into a list of spiritual needs. After interviewing 23 respondents, similar needs began to emerge and were then verified by questioning another 5 participants. In most cases, the researcher had to introduce the participants to examples of spiritual needs before they would begin to comment specifically about their own spiritual needs. Additionally, it was noted that while some respondents quickly concluded that they had more spiritual needs after receiving the diagnosis, there were others who said they either had about the same or no new spiritual needs. 
The analysis of the interview data revealed seven categories that contained the needs identified by the participants. These categories were summarized as needs with relating to the transcendent; needs for expressing thanks and hope; needs to share and feel love from others; needs to examine a particular belief system; needs of having meaning and purpose in life; needs for expressing specific religious interventions; and needs for making one ready for death. Taylor found these categories were similar when compared between the patient and caregiver. This may be explained by the fact that patients will often look to the caregiver to help address spiritual needs at end of life. For example, in order to avoid missing caregiver-specific distress, it is important to be aware of their spiritual needs during the caring process. Taylor also noted that the concept of spiritual need may connote to some that there is something deficient in their spirituality, thereby making participants less willing to respond to questions. She recommends that approaching the concept by inquiring about "spiritual interests" or "matters of the heart," the participant may be more likely to engage in questions and answers.

Because a person's spirituality is very intimate, it should not be surprising that some were reticent to discuss specific spiritual needs. In many cases, it was only after establishing a trusting relationship between the researcher, patient, and caregiver that dialogue ensued. While Taylor's study presents an extensive list of categories of spiritual needs for patients with cancer diagnoses and their caregivers, it did have gaps in knowledge that require further study. First, by Taylor's own admission, the language used to ask questions about spiritual needs may have been too theoretical. This disconnect may have limited the type of spiritual needs identified. Second, the sample size was particularly small with only one third being reported as caregivers. The 
conclusion that the spiritual needs identified are similar between patients and their caregivers, then, needs to be explored further before it can be transferable.

\section{Lived Experience of Spirituality in Palliative Care}

The lack of understanding of spirituality in the context of caregiving at the end of life was explored in a phenomenological study (Penman, Oliver, \& Harrington, 2009). This study had two main purposes. The first was to elaborate on the meaning of spirituality within the context of palliative care. The second was to understand how a person engages in spiritual matters at the end of life. These goals were most likely to be successful through examining the lived experiences of those going through the process of palliative care.

The participants included four care recipients and 10 caregivers. The majority of the caregivers were female $(80 \%)$ who were over the age of $50(70 \%)$. The participants all identified themselves from a Judeo-Christian faith being either Catholic (64\%) or Protestant (36\%). The research interview questions focused on soliciting responses to the question, "Tell me about your experience of spirituality."

The interviews lasted approximately 1.5 hours and took place in the homes of the participants. Each of the interviews was digitally recorded and transcribed to be included in data analysis following the method of van Manen (1990). In analyzing the transcribed data, two approaches were used: Holistic, gleaning the meaning from reading the text as a whole, and selective, a repetitive reading of the text to isolate phrases that revealed meaning to the phenomenon. The result of the study analysis revealed seven main themes under the headings of either spirituality or spiritual engagement. 
The participants' understanding of spirituality was focused on the moment in which they were living. This was evident in the four themes that were attributed to the meaning of spirituality. The first was that spirituality was something that referred to God. In particular, participants mentioned that spirituality was a "belief in a living God" who is invested in their happiness at each stage of life. The second theme described spirituality as coping. The participants believed that spirituality was especially important in moments of crisis, such as a life-limiting illness. They stated that spirituality "helped take the pressure off" and "not feel[ing] so sad and abandoned." A third theme of spirituality was that it embodied religion. It was important to participants to belong to a faith community that gave them a sense of "pride and joy." The fourth theme was that spirituality was associated with relationships. The participants believed that having interpersonal relationships and giving service to others was a part of their spirituality and a "great motivator" in taking on the caregiving role.

The participants articulated that it was their spirituality that motivated them to be engaged in the activity of caregiving. This became clear as three themes related to spiritual engagement emerged. The first was describing spiritual engagement as "maintaining relationships." The participants appreciated the depth of support received and intimacy displayed during the time of providing care. A second theme was captured in the word "love." It was important to caregivers to understand their role as selfless and dedicated to feeling for others. The final theme of spiritual engagement was the ability to participate in rituals that were specific to the faith of the participants. Prayer was the most common ritual referred to by the participants who described this as "powerful," "uplifting," and "helpful" in their role. 
In this study, seven principal themes under the headings of spirituality and spiritual engagement emerged. The participants were from countries where religion was an important part in the culture. This may be one explanation for their descriptions of spirituality being filled with references to God and their participation in religion. Many participants had emigrated from countries that also had a rich history of a person's daily life being connected to the activities of their religion. This may explain why they described spiritual engagement with references to the importance of being present to another person.

This study demonstrated the importance the phenomenon of spirituality had in the experience of palliative care recipients and their informal caregivers. However, it appears from the identified themes to represent more the importance of religion than it does spirituality. The focus question asked the participants about spirituality and the responses were more about religion. To strengthen the methodology, a probing question may have identified any nuance between these concepts and strengthened the study. The absence of other expressions of faith, as well as persons who identify as non-religious but spiritual, limit the findings of this study.

\section{Spiritual Well-Being}

There continues to be growing interest in the concept of spiritual well-being and its effect on the health and well-being of the individual. In a similar way to the concepts of spirituality and religion, spiritual well-being can be confused with religious wellbeing. The multidimensional nature of this concept has made its conceptualization challenging (Peterman, Fitchett, Brady, Hernandez, \& Cella, 2002). The only known conceptual analysis on spiritual well-being that has been published was in Chinese. 
Therefore, there remains a gap needing attention to bring clarity to the meaning of spiritual well-being.

This section of the chapter will explore the meaning of spiritual well-being as articulated in previous research. First, the known specific dimensions of spiritual wellbeing will be reviewed. Second, the known defining attributes of spiritual well-being will be discussed. Finally, the effect of spiritual well-being on caregivers of individuals with chronic illnesses will be explored.

\section{Dimensions of Spiritual Well-Being}

The multidimensional nature of this concept is apparent from a review of literature. Spiritual well-being may be the result of different relationships that develop over time. One of these relationships is one that an individual has with self, others, and nature. These relationships are understood as making the horizontal component to spiritual well-being. This dimension is generally referred to in the literature as Existential Well-Being. Another relationship is the one the person has with the Sacred. These relationships are understood as comprising a vertical component to spiritual wellbeing. This dimension is often referred to as Religious Well-Being in the literature (Peterman et al., 2014).

The review of spiritual well-being that follows is an examination of how these dimensions are described within The Functional Assessment of Chronic Illness Therapy Spiritual Well-Being. This is a commonly used instrument that measures spiritual wellbeing in populations of individuals who are chronically ill. Both studies examine spiritual well-being in patients with cancer. However, the first study examines this 
concept in long term survivors of cancer, while the second study investigates the effect of palliative care on the spiritual well-being of cancer patients.

Spiritual well-being in survivors of cancer. In a study by Edmondson, Park, Blank, Fenster, and Mills (2008), the relationship between religious and existential wellbeing to health-related quality of life (HRQOL) was explored amongst long-term survivors of a cancer diagnosis. Religion and spirituality, as variables that may predict the HRQOL, have been explored in a growing number of studies. However, there remains a debate over what aspects of these concepts may promote higher HRQOL. Further complicating this discussion is the belief that spiritual well-being is an individual state that lies on a continuum comprising religious and existential well-being. This approach will always result in a higher composite score for individuals who have strong religious beliefs compared to those who do not ascribe to a faith practice. The authors contend that any attempt to link the composite score of spiritual well-being to improved HRQOL may be misleading due to the lack of distinction between the dimensions of spiritual well-being.

Edmondson et al. (2008) proposed that by looking at religious well-being and existential well-being separately it can be determined which concept has the most significant effect on HRQOL. Religious well-being measures the level of comfort derived from being in a relationship with the Sacred or higher power in one's life. Existential well-being measures the extent to which an individual has meaning or purpose in life. The participants of this study were from northeastern United States, mostly female $(68 \%)$, under the age of $55(M=45.3, S D=6.5)$, White $(89 \%)$, married $(70 \%)$, college educated (66\%), and with the breast as the primary cancer diagnosis site $(46 \%)$. 
The Functional Assessment of Chronic Illness Therapy-Spiritual Well-Being was the instrument selected to measure the components of spiritual well-being in the participants of this study. The two subscales examined a person's understanding of meaning and peace in life and the level of comfort that is derived from an individual's belief. The first subscale is a measurement of existential well-being, while the second measures religious well-being. Each of the 12 items measures how a participant experienced spiritual well-being during the previous week on a scale of 0 (not at all) to 4 (very much). Both have strong Cronbach's alpha that were greater than 0.87 in the study.

The Medical Outcome Survey Short Form-12 was the instrument used to measure HRQOL. This instrument measures how a person's physical and mental health affects the ability to perform daily activities. Despite known psychometrics of this instrument, there was no presentation by the authors of the instrument's reliability or if the instrument produces valid data.

The Interpersonal Support Evaluation List has multiple subscales. For this study, social support was measured using the appraisal, belonging, and tangible support subscales of this instrument. The items of each subscale represent a participant's perception to accessibility of social support rated from 1 (probably false) to 4 (definitely true). The study authors stated the instrument had been used in a variety of populations with high intercorrelations and a high Cronbach's alpha (0.87).

The Life Orientation Test-Revised is a 10-item scale that measures optimism and pessimism. A participant rates the degree of agreement to each item from 1 (strongly disagree) to 5 (strongly agree). This instrument has been used in other studies with 
similar constructs and study authors reported it had a moderate to high Cronbach's alpha $(0.84)$.

Finally, the Brief Multidimensional Measure of Religion/Spirituality was used to measure an individual's religious beliefs and practices. It has two subscales. The first measures a person's private religious practice (prayer or meditation). The frequency of these practices is ranked from 1 (never) to 7 (many times a day). The second measures organized religious commitment (attendance at church or religious community activities). The frequency of attendance is indicated from 1 (never) to 5 (more than once a week). Study authors report this instrument has been used in the general population and subscales have a moderate Cronbach's alpha (0.74 and 0.72, respectively).

The first aim of the study was to explore the relationship of religious beliefs and practices with spiritual well-being. There was a stronger relationship of these variables with religious well-being compared to a much weaker relationship with existential wellbeing. The relationship between religious well-being and organized religious community activities was moderate $(r=0.56, p<0.01)$, and slightly stronger with private religious practices $(r=0.61, p<0.01)$. The relationship of existential well-being with these variables was considerably weaker $(r=0.15, p<0.05 ; r=0.19, p<0.01$ respectively). This is not surprising given the focus of the instruments' questions being primarily on religion.

The second aim of the study was to test the hypothesis that existential well-being mediates the effect that religious well-being has on HRQOL. The lack of a significant relationship between religious well-being and HRQOL subscale physical health prevented it from mediation testing. Religious well-being did have a significant but weak relationship with the HRQOL subscale mental health $(r=0.17, p<0.01)$. Existential well- 
being had a significant moderate relationship with both the physical and mental health subscales $(r=0.26, p<0.01 ; r=0.59, p<0.01$, respectively). A hierarchical linear regression model demonstrated that the small effect of religious well-being on mental health (beta $=0.19, \mathrm{p}<0.01)$ was reversed $($ beta $=-0.14, p<0.05)$ when existential well-being was held constant (beta $=0.67, p<0.001)$. In this analysis, existential well-being was able to mediate the effect that religious well-being had on the mental health subscale.

The final aim of the study was to test the hypothesis that existential well-being would explain the variance in physical and mental HRQOL. A hierarchical regression model with the physical component subscale and a second with the mental health subscale as criterion variables was run to analyze the effects of demographics, psychsocial, religious well-being, and existential well-being variables. When the criterion variable was the physical component, the model was significant $(F=9.47, p<0.001)$ and existential well-being explained the most variance with an adjusted $R^{2}$ of $0.03(p<0.01)$. When the criterion variable was the mental health component, the model was again significant $(F=12.18, \mathrm{p}<0.001)$ and existential well-being explained the most variance with an adjusted $R^{2}$ of $0.09(p<0.001)$.

This study made important contributions to the understanding of the two components of spiritual well-being. As demonstrated, there was a significant difference between the effect that religious well-being and existential well-being had on HRQOL. However, these findings should be understood cautiously. This study had a very limited population variance explained from the regression model was quite small and could be interpreted to be clinically or practically insignificant. Furthermore, while the authors discuss that religious well-being and existential well-being are two distinct components, 
they also mention in their discussion that "religion is only one means for establishing existential well-being." This assertion, at the very least, contradicts their conclusion that spiritual well-being has two distinct components: religious well-being and existential well-being. The debate over the meaning of spiritual well-being will continue to benefit from qualitative studies that probe the depth of its meaning in a variety of populations.

Spiritual well-being in palliative care patients. In a study of patients with a diagnosis of lung cancer and their family caregivers, Sun et al. (2016) explored the effect of palliative care on spiritual well-being. The investigators acknowledged that spiritual well-being is the least understood and most understudied of the quality of life domains. In part this is due to inadequate definitions of the concept. Yet, patients with advanced cancer continue to raise questions on spiritual needs and desire assistance in seeking meaning and purpose in their life journey. Because the palliative care model recognizes the importance of including a spiritual assessment and because there is also a lack of research on spiritual well-being in patients with lung cancer, these investigators sought to examine the association between the two. The study aims were to analyze spiritual wellbeing of patients with a lung cancer diagnosis and their caregiver, are the spiritual wellbeing outcomes different based on religious affiliation, and were there differences in spiritual well-being in usual care versus intervention?

This was a prospective, sequential, quasi-experimental study of 475 patient participants and 354 family caregiver participants that used tandem enrollment. This design reduced the risk of contamination of usual care versus intervention. Inclusion criteria were that patients were diagnosed with stage 1-4 non-small cell lung cancer receiving treatment, and the family caregiver was identified by the patient as the primary 
caregiver. All participants first enrolled in the care as usual study phase and then enrolled in an intervention group.

There were three processes to the intervention protocol. The first was a full quality of life assessment. This assessment was used to develop an individualized palliative care plan. The second process was regular review at interdisciplinary meetings. This review resulted in recommendations of spiritual support services for both patient and caregiver. The third process was an educational series led by advance practice nurses that focused on spiritual well-being. The patients and caregivers were separated into like groups for the approximately 30-minute session. Both groups selected the topics of most interest. The patients wanted to hear information on hope, inner strength, and uncertainty. The caregivers identified the topics of most interest to be purpose and meaning in life, hope, and redefining self and priorities.

The spiritual well-being of patients was measured using the FACIT-Sp. This instrument has 8 items that measure meaning/peace and 4 items that measure faith. The total score has a range of 0 to 48 , with higher scores indicating stronger spiritual wellbeing. It has been utilized in studies enrolling participants with cancer diagnoses. Psychometric testing has resulted in high reliability, alpha coefficients $>0.81$.

The spiritual well-being of family caregivers was assessed using the City of Hope Family Caregiver Quality of Life instrument. There is a subscale within this instrument that measures spiritual well-being through 7 items that focuses in part on spiritual activities, religious functions, and life's mission or purpose. Each item has a range of 1 to 10 , with higher scores indicating worse quality of life. Test-retest reliability with this instrument is high $(r=0.89)$. 
The demographic characteristics of the caregivers in this study were consistent with research of other caregiving populations. The majority $(>60 \%)$ of the participants were married, college educated, and non-Hispanic White females. Participants were mostly either Protestant ( $>40 \%$ ) or Catholic (>20\%), with a small representation of other faith denominations.

There was little change in spiritual well-being total and subscale scores for patients and family caregivers when comparing baseline to 12 -week post-intervention. However, there were interesting differences when the scoring for each item was reviewed. In the patient group, low scoring items (less than 3) included, "I feel peaceful" ( $M=2.79, S D=1.14$ at baseline, $M=2.93, S D=1.11$ at 12-weeks) and "I feel comfort in my faith or spiritual beliefs" ( $M=2.79, S D=1.47$ at baseline, $M=1.47$ at 12-weeks). Amongst the caregivers, the low scoring items (less than 5) included feeling uncertain about the future ( $M=3.80, S D=3.08$ at baseline, $M=4.02, S D=2.85$ at 12-weeks) and patient's illness affected life positively ( $M=4.49, S D=3.36$ at baseline, $M=4.85, S D=3.21$ at 12 weeks). The low scores of each supports the conceptualization of spiritual well-being as a multidimensional phenomenon.

A second aim of the study was to compare spiritual well-being subscales between patients and caregivers who reported a religious affiliation to those who had no affiliation. While the researchers indicated in the methods section that they would run a multivariate analysis, they only report descriptive statistics. There was no statistically significant difference found in the meaning/peace outcome between these groups of patients. However, there was a statistically significant difference in the faith outcome between the patients with a religious affiliation compared to those without a religious 
affiliation $(M=12.12, S D=4.55$ and $M=6.93, S D=5.30$, respectively) $p=0.010$. In family caregivers, there was no statistically significant difference in any of the spiritual wellbeing outcomes based on religious affiliation or no religious affiliation. The finding for patients who belonged to a religion having a higher faith subscale is not surprising. The absence of any significance, though, amongst caregivers is acknowledged by the authors to suggest that another scale with higher sensitivity may have been more appropriate.

The final aim explored potential differences between care as usual and the intervention groups. Patients in the intervention group compared to the care as usual group had a statistically significant improvement in the meaning/peace subscale $(M=24.75, S D=6.04$ versus $M=27.28, S D=5.42$, respectively) $p<0.001$. There was no similar finding in the faith subscale for the patients. The family caregivers who received usual care had an overall spiritual well-being that was statistically significant compared to those who received the intervention $(M=6.53, S D 1.80$ versus $M=6.32, S D=1.59$, respectively) $p=0.049$. The topics included in the intervention all relate to the meaning/peace subscale and thus support the improvement observed.

The focus of this study was to examine the effect of palliative care on spiritual well-being outcomes. The subscales of a spiritual well-being instrument and individual items were used to measure meaning, peace, and faith in patients and family caregivers. This was a strength of this study compared to that of Edmondson et al. (2008) who based their conclusion on total subscale scores and not on the individual items as well. The study's design of comparing a group of patients with a religious affiliation versus a group with no affiliation validated findings from Edmondson et al. (2008) that found religion is not necessary for spiritual benefit. In addition, the importance of a palliative intervention 
is noted by the findings in comparing usual care to intervention. The outcomes with a statistically significant difference found between the groups were in each of the areas that were included in the topics of instruction selected by the participants. This suggests that including topics from the faith subscale in future intervention studies is warranted. This study further elaborates on the depth of the multidimensionality of spiritual well-being and need for ongoing research in additional patient populations.

\section{Defining Attributes of Spiritual Well-Being}

The concept of spiritual well-being is generally understood as comprising two intersecting dimensions: religious well-being and existential well-being (Edmondson et al., 2008). Yet, these are merely components to the measurement of spiritual well-being. Walker and Avant (2011) encouraged researchers to clearly identify what attributes are necessary for a concept to be present. In this review of literature, there are three themes that, when present at the same time, represent spiritual well-being.

Meaning or purpose. According to Edmondson, et al. (2008), this attribute best represents a person's existential well-being. A meaningful life is one that is understood, by the individual, as productive. When life has meaning, or purpose, an individual is believed to have an understanding that his/her life has a value. As such, one's journey in life can remain focused.

Peace. In contrast to meaning/purpose that explored a person's existential wellbeing and life-satisfaction, this attribute assesses life-fulfilment. It is not concerned with the understanding of life having reason but rather, focuses on how the path that an individual is on creates harmony in oneself. The presence of peace is an awareness, then, 
that a person can reach within oneself to find comfort (Bai, Lazenby, Sangchoon, Dixon, \& McCorkle, 2015).

Faith. This attribute represents the connectedness that one has with a higher power or the Sacred, what Edmondson et al. (2008) referred to as religious well-being. By probing this attribute, though, through religious neutral terms that do not address a specific deity, the presence of faith regardless of tradition can be identified (Peterman et al., 2002). It does acknowledge the influence that a belief system may have on a person. This influence can be either positive or negative depending on a doctrinal teaching of a religious group. What this attribute examines is the comfort and strength that an individual acquires from a specific faith tradition that is important to him/her.

\section{Spiritual Well-Being and Caregivers}

The focus of measuring spiritual well-being has largely been from the perspective of the patient. When a patient has a prolonged period of illness, a family member may be needed to assist with care. The review of literature that follows examines how spiritual well-being has affected caregivers of patients who have been diagnosed with chronic illnesses that typically span several years.

\section{Caregivers of Patients with Chronic Illness}

Patients with chronic illnesses may have a slow deterioration in their health. Initially after receiving the diagnosis, these individuals can provide their own care. Yet, they are often living with a person who may eventually have to assist in their care. These informal caregivers experience the effects this role has on their physical, emotional, and spiritual well-being. The diagnosis of heart failure, cancer, and chronic obstructive pulmonary disease are examples of chronic illnesses that are characterized by a slow 
decline (Wilkinson \& Lynn, 2005). This section will look at studies of informal caregivers of patients with these diagnoses and the effect that the role of caregiving has on their spiritual well-being.

Heart failure. The gradual progression of this chronic disease demands that caregivers be available more often to assist with a person's activities of daily living. These physical requirements, combined with the uncertainty of when the next moment of decline will occur, place emotional burden on the caregiver (Yeh \& Bull, 2009). The purpose of this study was to describe the meaning of spiritual well-being for caregivers of persons with heart failure and to explore the relationship between coping, spiritual wellbeing, and mental health of caregivers of persons with heart failure.

This was a descriptive correlational design set in the Midwestern United States. The 50 caregivers who participated in the study had similar demographics from other studies involving caregivers. The majority (70\%) were women, married (74\%), and providing care for at least a year $(68 \%)$. Their family members were recently hospitalized in one of two hospitals in the acute care setting. The smaller of the two hospitals had a religious affiliation.

A number of instruments were utilized in this study. The JAREL spiritual wellbeing scale was used to measure participants' faith, life responsibility, and life satisfaction. The total score of spiritual well-being with this instrument had a range of 21-126, with higher scores indicating higher spiritual well-being. The instrument has a strong internal consistency (Cronbach's alpha $=0.90$ ). The caregiver's coping was measured with the Carers' Assessments of Managing Index. Total scores ranged from 38-152, the higher scores indicating more effective coping. Reliability for this instrument 
was reported as strong with a Cronbach's alpha of 0.86. The Symptom Questionnaire was used to measure the caregiver's mental health. The range for this instrument was 092, with higher scores indicating more negative symptoms and poorer mental health. It was reported to have a strong Cronbach's alpha of 0.96 .

The caregivers reported high levels of spiritual well-being $(M=105.7 ; S D=14.1)$. This was supported by their strong agreement to several items in the instrument including: "prayer is an important part of my life" $(M=5.42 ; S D=1.18)$ and "I find meaning and purpose in my life" $(M=5.28 ; S D=1.14)$. The caregivers also reported high levels of coping $(M=112.4, S D=12.3)$. The caregivers were moderately anxious $(M=8.5$, $S D=6$ ), with scores below 7 indicating normal anxious characteristics. The scores for depression, somatic, and hostility subscales were all normal.

In a bivariate analysis, spiritual well-being was demonstrated to have a significant inverse relationship with negative mental health $(r=-0.55, p=0.000)$. The researchers identified that it was primarily the subscales of faith and life satisfaction that produced this relationship. The item addressing life responsibility was not significantly related to negative mental health $(r=-0.28, p=0.051)$. They contended that additional qualitative work on items within the subscale of life responsibility was needed before more definitive conclusions could be made about its contribution to the caregiving experience. There was also a significant inverse relationship between coping strategies and negative mental health symptoms $(r=-0.44, p=0.001)$. The subscales problem solving and coping, and dealing with stress symptoms were the most significant contributors to this correlation. 
The use of the FACIT-Sp, rather than the JAREL spiritual well-being scale may have been a better instrument to use in this study. The FACIT-Sp measures three generally accepted subsets of spiritual well-being: meaning, purpose, and faith. As a reminder, these subsets encompass the understanding that spiritual well-being can be viewed through two dimensions. One is the vertical dimension that explores relationship with a higher power (also commonly referred to as Religious Well-Being). Another is the horizontal dimension that examines the relationship with self, others, and nature (also known as Existential Well-Being). It is a more concise instrument that has been developed for assessment of spiritual well-being in the setting of chronic illnesses so it may prevent respondent fatigue. Additional research is warranted to understand how spiritual well-being is experienced by caregivers of a family member with a chronic illness.

Cancer. The sudden diagnosis with a life-threatening illness can be a stressful event that may impact quality of life. When an individual is able to emotionally process such an event, the person is able to reframe its meaning and thereby experience improvements in the quality of life (Lee, 2008). This common construct in meaningmaking theories was used to inform the purpose of this study that explored the relationship between specific caregiving experiences and spiritual well-being in caregivers of patients in the initial phase following a diagnosis of cancer (Adams et al., 2014).

This current study analyzed caregiving experiences (family support, self-esteem, impact on finances, and impact on schedule of personal activities) and each of the subscales of spiritual well-being (meaning, peace, and faith) shortly after the caregiver 
became aware the patient was diagnosed with cancer. It is during this initial period that questions around meaning and purpose in life are particularly relevant (Winterling, Wasteson, Glimelius, Sjoden, \& Nordin, 2004). Data at the 4-month interval was then analyzed for comparison. This interval was chosen as it was the time when the patient and caregiver were most often discharged from the cancer facility back home. The researchers hypothesized that higher self-esteem would result in improved spiritual wellbeing while lower family support, higher concern of personal finances, and schedules related to personal activities would decrease spiritual well-being in caregivers.

There were 106 family caregivers of a patient recently diagnosed with cancer originally consented for this study. However, 36 were lost to attrition. The final sample size of 70 caregivers had a mean age of 59 years, mostly women (74\%), almost entirely Caucasian (96\%), slightly more than half unemployed (51.9\%), and equally distributed on education levels. The caregiver resided with the patient during the initial 4 months after the patient was diagnosed with cancer at a cancer center in the northwestern United States.

The Caregiver Reaction Scale measured the perception of the caregiving experience. This is a 20 -item instrument with four subscales that measure family support, self-esteem, finances, and schedules. Each item is scored from 1 (strongly disagree) to 5 (strongly agree). Higher scores indicated greater lack of family support, higher self-esteem, greater impact of the caregiving experience on finances and personal schedule. It has been used widely with caregivers in this population for research and has a reported Cronbach's alpha of 0.88 . 
The Functional Assessment of Chronic Illness Therapy-Spiritual Well-Being Scale was used to measure meaning, peace, and faith in the caregivers. Each of the 12items of this scale is rated from 0 (not at all) to 4 (very much). Higher scores indicated greater total spiritual well-being in each of the subscales. This scale has been used extensively in multiple populations and has a strong reliability as indicted by its Cronbach's alpha of 0.88 .

The caregiver experiences (lack of family support, self-esteem, impact on finances, and schedule of personal activities) were all significantly correlated to each other at baseline. Each dimension of spiritual well-being (meaning, peace, and faith) was positively correlated to each other at baseline and at the 4-month interval. However, the only caregiver experience that had a significant relationship with all the components of spiritual well-being at the 4-month follow-up was lack of family support. It was negatively correlated to meaning $(r=-0.66, p<0.01)$, peace $(r=-0.54, p<0.01)$, and faith $(r=-0.31, p<0.01)$. Higher levels of self-esteem were correlated with peace $(r=0.25$, $p<0.01$ ), but not meaning or faith. Greater impact of caregiving on finances was negatively correlated with meaning $(r=-0.25, p<0.05)$, but not peace or faith. Greater impact of caregiving on the schedule of personal activities was negatively correlated with meaning $(r=-0.35, p<0.01)$ and peace $(r=-0.40, p<0.01)$, but not faith.

A hierarchical general linear model predicted domains of spiritual well-being at 4 months. When controlling for age, gender, and education only, lack of family support was significantly related to lower levels of both meaning $(t=-4.49, p<0.001)$ and peace $(t=-2.12, p=0.04)$, but not faith $(t=-0.20, p=0.85)$. Overall, the caregiving experienceslack of family support, self-esteem from caregiving, impact on schedule, and impact on 
finances_-accounted for $18 \%$ variance in meaning, $5 \%$ variance in peace, and $0.001 \%$ variance in faith.

The findings of this study underscore the importance of family support in predicting components of spiritual well-being. The measurement of caregiving experiences was in the initial period after learning that a family member had been diagnosed with cancer. Both the patient and the family caregiver were residing in a cancer facility during this period. This placement may have led to fewer opportunities for the caregiver to process the experience with others of importance in their lives. This was a potential limitation of the study. The caregiving experience in the home during this initial period should be considered in future research to compare to the results of this study. Another weakness of this study was its lack of a more a diverse participant population. Until there is research that includes participants from other socio-economic and faith backgrounds, the conclusions of this study are not generalizable.

Chronic obstructive pulmonary disease. In patients diagnosed with a lifelimiting disease, there can be a prolonged period of deterioration that ultimately requires caregiving assistance from a family member (Wilkinson \& Lynn, 2005). These informal caregivers over time are at risk for poor health outcomes as a result of the demands that are a part of this responsibility (Rabow, Hauser, \& Adams, 2004). In a cross-sectional study by Burton et al. (2012) three caregiving populations_caring for patients with cancer, congestive heart failure $(\mathrm{CHF})$, and chronic obstructive pulmonary disease (COPD) - were examined for predictors of burden and psychosocial-spiritual outcomes: for example coping style, family support, social network, and impact on health. The focus of this study was first, to determine if burden and well-being differed based on diagnosis 
and second, to determine whether patient factors or caregiver characteristics have a larger effect on burden and well-being.

The completed study collected specific measures on the patients and caregivers independently. The patients were measured for functional impairment and disease severity. The former was a self-report measure of the extent to which patients required assistance in either basic or advanced self-care tasks. The later was a combination of subjective responses from patients regarding their perception of the level of health and objective self-report of how many days the patient spends either in bed or chair. This measurement allowed researchers to determine progression of disease in patients.

Caregiver data include general demographics, socioeconomic, and social resources. The coping style of caregivers was measured with the Mini-Mental Adjustment to Coping scale. This instrument measures 5 specific coping styles with higher scores indicating more frequent use of that coping style. The subscales have a low to moderate Cronbach's alpha (>0.48).

Caregiver social resources were measured through a 1-item instrument. It asked the caregiver to respond to his or her desire for help from others in performing caregiving duties. It has five possible responses ranging from "strongly agree" to "strongly disagree." The researcher reports that it has been validated in previous studies, but no psychometric test result is provided.

The Caregiver Reaction Assessment was used to measure caregiver burden. This 24-item instrument includes subscales that measure caregiver esteem, lack of family support, impact on finances, impact on schedule, and impact on health. Higher scores of 
the subscales indicate strong agreement that the particular dimension contributes to caregiver burden. The Cronbach's alpha for each subscale was moderate ( $>0.67)$.

The Center for Epidemiological Studies Depression Scale was used to measure depression in caregivers (Cronbach's alpha $=0.83$ ), the Profile of Mood States anxiety subscale was used to determine presence of anxiety in caregivers (Cronbach's alpha $=$ 0.88), and the Functional Assessment of Chronic Illness Therapy-Spirituality subscale was used to indicate level of spiritual well-being in caregivers (Cronbach's alpha $=0.83$ ). After reverse coding the FACIT-Sp, higher scores for each of these instruments indicated poorer well-being.

There were 139 patient/caregiver dyads involved in the study that were equally distributed amongst the three disease processes. While patients were in advanced stages of their respective diseases—stage IV cancer, New York Heart Association Class III or IV CHF, and COPD presenting with hypercapnia—they were reported as relatively healthy and having low caregiving needs. However, there was a difference in functional level noted based on diagnosis: cancer (11.76\%), CHF (34.78\%), and COPD (23.81\%). In addition, there was a difference observed in disease severity based on diagnosis: cancer (43.14\%), CHF (17.39\%), and COPD (28.57\%).

Caregiver demographics were consistent with other studies: female (81.3\%), married (70.5\%), Caucasian (70\%), working at least part-time (50\%), and with a median age of 57 years. The caregivers did report having a large social support network $(M=13$, $S D=6.89)$ from whom they could seek help. There was a notable difference in employed caregivers based on patient diagnosis of cancer (37.25\%), CHF (47.83\%), and COPD (71.43\%). A corresponding difference was observed in caregivers' inability to pay bills 
based on patient diagnosis of cancer (80.39\%), CHF (67.39\%), and COPD (26.19\%).

There was no significant difference, though, based on diagnosis for either caregiver burden or psychosocial/spiritual well-being. The patient/caregiver dyads were part of a longitudinal study; however, the data presented are a cross sectional analysis of baseline assessments.

The odds of having high versus low caregiver burden were examined for possible predictors. Caregivers who indicated that the caregiving role impacted their health were 1.58 times more likely to experience burden $(99 \% \mathrm{CI}=1.00,2.49 ; p<0.01)$. Additionally, caregivers who reported a lack of family support in their caregiving duties were 1.95 times more likely to experience burden ( $99 \% \mathrm{CI}=1.95,3.19 ; p<0.001)$. The strongest indicator of poor caregiver well-being was an anxious preoccupation coping style. Caregivers who reported this coping style were 1.26 times more likely to be depressed (99\% $\mathrm{CI}=1.06,1.51 ; p<0.001), 1.38$ times more like to be anxious $(99 \% \mathrm{CI}=1.14,1.68$; $p<0.001$ ), and 1.28 times more likely to have low spiritual well-being (99\% CI=1.05, $1.55 ; p<0.01)$.

These findings suggest that less emotional support and poor coping styles are significant contributors to increased burden and low spiritual well-being in caregivers. There was no evidence to infer that disease severity or a specific disease was a significant contributor to caregiver burden or spiritual well-being. The caregiver characteristics, and not patient factors, were shown to predict the likelihood of increased burden and poorer spiritual well-being. The number of family/friends present $(M=13, S D=6.29)$, combined with the expressed desire for more help $(M=2, S D=1.19)$, suggested that caregivers may be in need of a higher quality, or depth, of assistance from their family/friends. 
Additionally, the significant link between the anxious preoccupation coping style and lower spiritual well-being supports the need for early identification in caregivers who display this coping style. In doing so they could be supported through the trajectory of the disease with positive coping strategies that may lead to decreased burden and improved spiritual well-being.

It is important to note, however, that the findings of this study are from baseline data of patient/caregiver dyads who self-report as being relatively healthy for their specific diagnoses. The assessment of the effect of the prolonged nature of caregiving is lacking, then, as a result of the design of this study. Further research that explores how burden and spiritual well-being changes throughout the trajectory of providing care to a loved one with a chronic illness is needed.

\section{Caregivers of Persons with Dementia}

The caregiver of a person with dementia may experience a gradual increase in stress and burden during their family member's decline (Gallagher et al., 2011). As noted in studies reviewed in this section, spiritual well-being has been shown to have an effect on quality of life outcomes in other populations. The relationship between spiritual well-being and caregiver burden, therefore, was examined in a population of caregivers of persons with dementia (Spurlock, 2005). The study's hypothesis was that there would be an inverse relationship between spiritual well-being and caregiver burden.

A cross-sectional correlational research design was used in the study with a convenience sample of 150 participants recruited through a variety of settings that provide care to persons with dementia. The participants were mostly married (72.8\%), Protestant (57.1\%), women (84.0\%), with approximately equal number of African 
Americans and Caucasians, and a mean age of 58.9 years $(S D=13.73)$. The age of the caregivers was significantly different for caregivers who were Caucasian compared to African American $(t=3.695, p<0.001)$. The majority of participants identified daily prayer $(73.1 \%)$ as a regular spiritual practice and more than half stated they attended weekly religious services as part of their routine.

The Spiritual Well-Being Scale measured caregivers' perceptions of spiritual well-being. It consists of religious well-being and existential well-being subscales. This 20-item Likert scale scored 1 (strongly agree) to 6 (strongly disagree). Each of the subscales has strong reliability, all greater than 0.86. The Burden Interview Scale measured caregiver stress and burden. This scale has been used widely in the population of caregivers of a person with dementia. Participants can select from a range of responses from never to nearly always. The total score for this scale has a range of 0 to 88. It has a strong Cronbach's alpha of 0.91 and a test-retest has resulted in a reliability of 0.71 .

The African American caregivers reported a higher level of spiritual well-being $(M=104.45, S D-15.48)$ compared to Caucasian caregivers $(M=96.69, S D=12.43)$. The caregiver burden levels were lower for African Americans $(M=29.46, S D=14.40)$ compared to Caucasian caregivers $(M=37.99, S D, 13.87)$. For the entire sample, spiritual well-being was demonstrated to have a significant inverse relationship $(r=-0.493$, $p<0.01)$ with caregiver burden. This suggests that spirituality may be one way to improve coping through stressful periods of caregiving.

The findings of this study do support the presented hypothesis that there would be an inverse relationship between spiritual well-being and caregiver burden in caregivers of 
a person with dementia. However, the study focused these findings primarily on distinctions of race. This was not clearly discussed in the methods section and may have been an incidental finding on the part of the researcher. Nonetheless, what may have been the study's objective is confusing to the reader. The study presents the findings of how the whole sample practices spirituality. But, if the purpose was to demonstrate the difference in the relationship between spiritual well-being and caregiver burden based on race, then the study could have been strengthened by presenting the spiritual practices of each race. While this is an obvious weakness of the study, the researcher does establish a foundation for future research to be conducted within this population.

\section{Analysis and Critique}

This review describes how the subjective nature of spirituality can make its meaning allusive. Spirituality is a concept that has often been used interchangeably with religion in the literature. While it is true that all religions have a shared spiritual component, not all spiritual persons are connected to a religious institution. As outlined in this chapter, spirituality is understood as an innate characteristic in a person that aides in a person's search for meaning and purpose in life. The individual arrives at this meaning and purpose through a process, or pattern of development, that is inherent to spirituality. A key attribute of spirituality, noted in literature, is the connectedness that exists in an individual with self, others, and the Sacred. This is made possible by the capacity for a person to be transcendent. In moving beyond the boundaries of self, then, the individual strengthens the intrapersonal, interpersonal, and transpersonal relationships in life. 
There is a clear lack of agreement on the meaning of spirituality in the context of caregiving that requires ongoing investigation. The concept use in literature continues to recognize the similarity between spirituality to religion. Yet, there are growing attempts to tease out the difference in their meanings. The findings that increased social support is negatively associated with depression suggests that connections with others is an important attribute of spirituality. In a similar way, the increased levels of discontent associated with increased caregiver burden may indicate that perceptions of God made by religions have a lasting effect on the caregiver. The descriptions that caregivers provide indicate that spirituality is an awareness of connectedness to self, others, nature, and the Sacred. This is a process of shared dialogue with these connections that lead to comfort, peace, acceptance, and purpose in life.

The challenge of understanding the meaning of spirituality is further complicated by attempts to measure it as a quality of life indicator. Spiritual well-being is a multidimensional concept that is generally understood to have two intersecting dimensions. The first is a vertical dimension that measures a person's connectedness with the Sacred. This dimension is commonly referred to as religious well-being. The second is a horizontal dimension that measures a person's connectedness to others. This dimension is known as existential well-being. An instrument that is commonly used in research involving chronic illness to measure spiritual well-being is the Functional Assessment of Chronic Illness Therapy-Spiritual Well-Being. The extensive use of this instrument in various populations has improved the use of its subscales and their contribution to the meaning of spiritual well-being. As noted in this chapter, this concept has three defining attributes. These are understood to be meaning (purposefulness in 
life), peace (harmony in life), and faith (connectedness in life). Therefore, these three components together are what contribute to the concept of spiritual well-being.

In studies of caregivers for persons with a chronic illness, it is clear that spiritual well-being plays an important role in the caregiving experience. Caregivers with higher levels of spiritual well-being had lower negative mental health and burden. Additionally, the opportunity to engage others in dialogue about their experience of taking care of a loved one was important to their spiritual well-being. This suggests that caregivers need to have supportive structures in place that promote their relationship with the Sacred and with others. When these mechanisms for creating positive meaning to their experience are available then spiritual well-being is more likely to have a mediating effect on the burden related to caregiving.

The interest in spiritual well-being on health outcomes started largely in patient populations with life-limiting illnesses. The association found between spiritual wellbeing and improved health-related quality of life amongst patients has led to research questions that have explored similar associations in caregivers. However, much of this research has been targeted to caregivers of patients who are diagnosed with cancer, heart failure, or chronic obstructive pulmonary disease. The unique characteristic of gradual cognitive decline of persons with dementia, though, presents challenges for their caregivers not necessarily seen in other populations. This distinction makes understanding the concept of spiritual well-being amongst caregivers of persons with dementia essential. In arriving at a clearly developed meaning of spiritual well-being, its effect on health outcomes in caregivers of persons with dementia can then be explored. There has been no attempt identified in this review of literature that provides such an 
understanding. Therefore, the purpose of this study is to explore this gap in knowledge and describe the meaning of spiritual well-being amongst informal caregivers of persons with dementia on palliative care living at home. 


\section{Chapter 3}

\section{Methodology}

This chapter provides a detailed outline to the design of this study. It will begin with a discussion on the phenomenological approach according to van Manen (1990). In addition, the process for participant recruitment, semi-structured interview guide, data collection, and data analysis are presented.

\section{Purpose}

This study had three principal lines of inquiry. The first was to explore the lived experience of informal caregivers of a person with dementia enrolled in palliative care. A second line of inquiry was to identify any spiritual feelings of these caregivers to a person with dementia that were present and explore the meaning of those feelings in the context of spiritual well-being. The final line of inquiry was to explore, if present, the spiritual meaning of providing care in home to a person with dementia.

\section{Methodological Approach of van Manen}

The focus of hermeneutic phenomenological research is to pursue deeper meanings of the lived experiences of a particular phenomenon. Unlike other sciences that study the physical objects and things found in nature, the objects of pursuit in hermeneutic phenomenological research are the emotions, feelings, and consciousness of persons who are experiencing a particular phenomenon. Because this approach seeks to discover meaning, the approach adopted must avoid the temptation to enter a study with a fixed methodology. However, the work of other hermeneutic phenomenological researchers does help provide a foundation, or map, that may help guide the researcher to 
a place of reflection. The work of van Manen (1990) has been increasingly used as such a guide for human science researchers. According to van Manen (1990), this involves an iterative process of moving between six different activities, described below, that provide a methodological structure for interpreting lived experiences.

The first activity is deciding on the phenomenon that the investigator wishes to explore. The work of the hermeneutic phenomenological study is to bring a deeper meaning to a phenomenon of interest through exploring the lived experience of others. In studying the lived experience of a phenomenon, the investigator needs to remain invested in the question of "what is this experience like?" This question, and the answers that are discovered, are what should always animate the being of the investigator. As a result, the reflective writing that flows from the responses to this question will enhance the description of the experience.

The second activity requires the investigator explore the phenomenon as it is lived by both the investigator and the participants. At the core of a hermeneutic phenomenological study is the goal of arriving at a shared meaning of the phenomenon of interest. This involves a process of gathering examples of lived experiences of the phenomenon that will become the material to be examined. The collection of these experiences may be done through a variety of methods. Regardless of the approach selected, it is essential the investigator remain focused on the central phenomenon to make the connection between the meaning of the phenomenon for one individual and how that meaning may be shared in the human experience of others.

The third activity involves the investigator becoming engaged through profound reflection in order to grasp what makes the phenomenon of interest have a unique 
significance. This is a process that involves appropriating, clarifying and defining the meaning units of a particular lived experience. In the search for a more robust description of the phenomenon, meaning units provide a structure to the experience. In this activity, the investigator seeks to isolate these meaning units from particular lived experiences that have been collected through the study's methods. This can be done by reading the text as a whole to discover a phrase that best captures the meaning; by engaging in selective reading of the text to identify particular statements that unearth the meaning of the text; or by reading each sentence to find a description of the experience. As these meaning units become identified, the investigator can ask more clarifying questions of the participants to search for a deeper meaning of a phenomenon.

The lived experience and its accompanying structural meaning units compose the larger human life world of phenomenological research. While there are many different life worlds, the basic level found in each is the understanding of human existence. At this most general level, life world can be understood to have four foundational domainslived space, lived body, lived time, and lived human relation - that prove instrumental in phenomenological research. Each person may experience larger life worlds differently, but all will experience them through these existential realities. In light of this, phenomenological investigators use these domains throughout the process of questioning, reflecting, and writing.

The fourth activity is the process of describing the meaning of a phenomenon that has been spoken by the participants. The investigator can only put into words the descriptions of lived experiences provided by a participant if the investigator has been listening attentively to the participant. The two engage in a dialogue that ultimately leads 
to the mutually desired goal of a richer meaning of a lived experience. The investigator embraces the elucidations of the participant's experience of a phenomenon while at the same time welcoming the silences that weave their way into those conversations. Both allow the description of the lived experience to be written in a way that draws the reader into an awareness of their own personal experience of the phenomenon.

The research activity of the investigator is a putting into words the description of the phenomenon that is derived from that dialogue. In writing, the investigator takes a reflective stance, looking back at the content of the dialogue in a way that, when written, makes the phenomenon of interest intelligible to the reader. This is very much an iterative process that requires the investigator to write and then step back and evaluate if what has been written accurately describes what has been collected. Thus, the intelligible description can never be accomplished through one attempt, rather, this is best accomplished through writing, rewriting, and writing again.

The fifth activity speaks to the necessity of remaining focused on the pursuit of discovering the meaning of a phenomenon of interest. This demands the investigator present texts that are oriented towards the phenomenon; strong in its interpretations to exclude other competing interests; rich in the descriptions of lived experience; and finally, filled with a depth that reveals the fuller meaning of the phenomenon that joins prior experiences with the present one to understand the phenomenon as it is intended to be. In meeting these requirements, the resulting text has the power and validity to stand in the field of human science.

The sixth activity asks the investigator to see both the significance of each part that contributes to the meaning of the whole and recognize that it is the pursuit of rich 
descriptions of the whole that is the focus. This requires the investigator remain open from the onset of the study to see where the material gathered leads, which at times may demand a new approach that will guide the investigator to a deeper understanding of the phenomenon. While a new approach may become necessary, it is essential to remain focused on the specific research question while gathering material to avoid missing the significance of the lived experience.

In order to appreciate the importance of the individual meaning units of a phenomenon to the ultimate description of the whole phenomenon, there must be an iterative component to the research process. The investigator will need to decide how to organize the meaning units to be analyzed. This may be accomplished by looking for emerging meaning units; reconstructing the gathered material into one coherent story; present one structure of a phenomenon and then develop other related examples; approach an understanding of a phenomenon through a hypothetical dialogue with another known author; or finally, generate a description using the life world existentials of time, space, body, and relation. Regardless of the approach adopted, the investigator must remember that all hermeneutic phenomenological studies evolve through the writing process. We write, rewrite, and write again to interpret the gathered material from dialogues with participants to arrive at a text that presents the most robust description of the phenomenon as they have lived it.

\section{Bracketing of Previous Experiences}

As mentioned in chapter one, this researcher's interest in conducting a phenomenological study on the lived experience of spiritual well-being of caregivers was 
influenced by both personal and professional experiences. Some of these experiences are discussed here briefly to illustrate the importance of caregiving to the researcher.

At an early age, I witnessed how family members were often thrust into the role of caring for a loved one with chronic illnesses. This was the case for both my maternal grandmother and my mother. I watched my grandmother struggle with the commitment to keep my grandfather at home through his long decline after having a stroke. Her caregiving role occurred long before I was of an age to inquire what that role meant. However, in reflecting on that experience, it appeared to be what she considered as a natural obligation of being married at that time. I also saw firsthand my mother take on the role of caregiver to her aunt during her aunt's decline from Alzheimer's disease. It was obvious that she had to balance the numerous hours of informal caregiving with the equally numerous hours of raising a family. Again, this took place before I could investigate the meaning for her of that experience. Much later in life she would share with me the frustration she felt in having to take on that role with little support from others in the family. Yet, the caregiving role was one that she felt an obligation to fulfill.

As a Catholic priest, I was deeply moved by the witness that others provided in caring for a member in their nuclear family. There was one that powerfully influenced my understanding of being a caregiver. While introducing myself to an older couple in church before Mass, I asked the gentleman who he was with and he told me, "Oh, she just sits with me." The woman rolled her eyes as if to dismiss the comment. After Mass as I was greeting people, she embraced me and whispered into my ear, "I'm sorry about earlier Father, Matt has dementia." It became clear to me over time that Laura faithfully 
brought Matt to church because it is what gave her strength to endure the challenges of being a caregiver.

As a Registered Nurse, I saw how devoted individuals to a loved one afflicted with a chronic illness would struggle at different points along the road of caregiving. There was one patient/caregiver relationship that has stuck with me for some time. Margaret had been bed bound after suffering a stroke in addition to having dementia requiring care from Stacey her daughter. Stacey was overcome with guilt when her mother was hospitalized with an infection. The guilt turned into anger at anyone who would try to help care for her mother. Over time I was able to help her open up by asking her to teach me how she would help make her mother comfortable at home. She gradually trusted me enough to step away from the bedside and get the rest she needed so that she could continue her role as caregiver.

These examples illustrate the complexity of caregiving. There are moments of pain, frustration, and guilt associated with this role, but there are so many more moments of joy, satisfaction, and meaning that come from being an informal caregiver. In exploring the meaning of spiritual well-being from the context of a caregiver, I needed to put aside my previous experiences. In doing so, I was free to encounter this phenomenon within the situated context of the participant.

\section{Participants and Sampling}

The setting of this study was in the homes of primary informal caregivers of persons with dementia in Southern California. The principle line of inquiry of this study was to explore the lived experience of informal caregiving within this context and subsequently to identify the meaning of spirituality in the participants who were 
immersed in the role of providing care to a person with dementia. As such, the research design called for a purposive sampling approach to obtain participants who were open to sharing how they have experienced this phenomenon.

The research line of inquiry being addressed required that the sample be of informal caregivers of persons with dementia. The inclusion criteria for participating in the study included being the primary informal caregiver, providing care to a person with dementia who lives in the community, able to read and write in English or Spanish, be over the age of 18 , and able to provide informed consent. If the person with dementia resided in a care facility, the caregiver was excluded from the study.

The participants were invited to participate through collaboration with hospices and a large healthcare organization in Southern California. The process of inviting informal caregivers to participate began after permission to enter those sites was obtained through the Institutional Review Board. The posting of informational flyers, direct invitation, and referrals were the strategies used to include family caregivers into the study.

The nature of a phenomenological research design suggests that sample size be determined by the analysis of the emerging phenomenon. It is recommended to continue to gather data until there is a saturation of content and no new meaning units surface during interviews. This process was assessed by constant review of data and in consultation with dissertation team. According to Dukes (1984), the purpose of a phenomenological study is to determine essential elements of a phenomenon. While this can be accomplished in an individual case, she recommends that the sample size be no 
fewer than three and no more than 10. This will prevent the researcher from avoiding the temptation to see specific elements that he or she may desire.

\section{Data Collection}

The consenting participants were given a brief survey to collect individual demographic data. The information (gender, age, ethnicity, relationship to the person with dementia, number of years knowing the person with dementia, number of years caregiving for the person with dementia, spiritual/religious affiliation, type of spiritual/religious practices, and frequency of spiritual/religious practices) obtained from the survey contributed to the richness of the study allowing the investigator to generally describe the participants with this aggregated data.

After completing the survey, the participants' understanding of the central phenomenon — spiritual well-being — was explored through the use of a semi-structured interview. This format allowed for the participants to speak openly about the lived experience of the central phenomenon and allowed for the researcher to collect specific data related to spiritual well-being within the context of informal caregiving.

The investigator of this study was the sole interviewer of the participants. However, the investigator engaged in continual evaluation of the interviews with his dissertation team to assess if questions were gathering sufficient information. The study participant interviews all took place in the home of the informal caregiver to respect their confidentiality. While it was anticipated that the participant may have direct care of the person with dementia and be unable to leave their loved one unattended this was not found to be the case. 
The interviews focused on exploring the lived experience of informal caregivers of persons with dementia. The responses to the questions were digitally recorded with the consent of participants. This allowed the interviewer to be fully present with the participant and able to take short field notes. The following open-ended questions were used during the course of the 45 to 60 -minute interview:

Question 1 What does being a caregiver to your loved one mean to you?

Probe: While being a caregiver to "name" what has your sense of purpose in life been like?

Probe: Do you feel that being "name's" caregiver has affected your inner peace?

Probe: Where have you experienced support in being a caregiver?

Question 2 What does spirituality/spiritual well-being mean to you?

Probe: Has your role as "name's" caregiver changed how you feel spiritually?

Probe: Have you discovered new ways to express your spirituality while being a caregiver?

Probe: Has being a caregiver to "name" made you aware of any spiritual needs?

Question 3 Would you like to share anything else about your experience as a caregiver?

In the event the researcher assessed the need for a follow-up question that would lead to richer data, he asked one of the following:

Can you tell me more about that? 
How did that make you feel?

After the interview had concluded the researcher downloaded the digital audio file of the interview to the investigator's password-protected computer that had a privacy lock to ensure security of content. This digital recording was sent via e-mail to a professional transcription service through a secure/encrypted source.

\section{Data Analysis}

Phenomenological research is a process of reflection that ultimately leads to a deeper understanding of the essential structures of a phenomenon. These structures, or meaning units, are discovered through textual analysis of semi-structured interviews with participants who describe their experience of the phenomenon. The identification of these meaning units will individually point towards an aspect of the phenomenon but not the whole phenomenon. They are best understood, then, as fasteners that will eventually hold together the description.

These meaning units can be identified through thematic analysis of a transcribed interview. According to van Manen (1990), there are three main approaches to such an analysis. The first is to examine the text as a whole. After reading the text we attempt to capture the meaning of it through a phrase. The second approach involves reading the text multiple times. We reflect back on that reading and attempt to identify the phrase that was most revealing of the phenomenon. We return to the text to read it again but this time to highlight areas where those phrases are present. The final approach would be to read the text line by line. At the end of each sentence we would ask of it what it is telling us about the phenomenon. For the purposes of this study, the highlighting approach was the mode of analysis for discovering the particular meaning units of the phenomenon. 
The way that humans experience the world varies based on the context of their experience. However, there are four qualities that are understood within phenomenological research to be present in all human experiences and collectively comprise what is referred to as the lifeworld. These qualities, known as "existentials," are important ways to engage in the reflective practice of analysis. The first, lived space, helps answer questions about how we live our lives on a daily basis. The second, lived body, refers to how we experience ourselves, and others, in the world. The third, lived time, speaks less to time of day and more to how we experience time, for example, moving too slow or fast. The final quality, lived other, addresses how we relate to and maintain a relationship with others. The ability to differentiate these was important to the textual analysis that eventually arrived at deeper meaning of the phenomenon.

Table 1 illustrates how semi-structured interviews were analyzed in terms of each study aim. The digital audio recordings of these interviews were transcribed to assist in analysis. Each lifeworld existential outlined above was reflected on individually before reading the transcribed interview texts. As noted earlier, the texts were read using the highlighting approach to become aware of any meaning units that were identified by participants. The investigator reviewed with the dissertation committee throughout textual analysis phase to validate these meaning units and how the understanding of the particular lifeworld existential helped surface the identified meaning unit. When reflecting on the lived experience through these steps was completed the process of phenomenological writing took place. 
Table 1.

Interview Guide

\begin{tabular}{lll}
\hline Lines of Inquiry & Interview Guide & Lifeworld Existentials
\end{tabular}

Line of Inquiry \# 1

Explore the lived experience of informal caregivers of patients with dementia enrolled in palliative care

- Describe the account of caregiver's sense of meaning/purpose through the process of caregiving

- Describe the account of caregiver's sense of peace through the process of caregiving

Describe the account of caregiver's sense of connectedness through the process of caregiving

Line of Inquiry \# 2

Identify spiritual feelings of caregivers and explore meaning of those feelings to the experience of SWB as an informal caregiver to a patient with dementia

Line of Inquiry \# 3

Explore spiritual meaning of providing care in home
- A.) What does being a caregiver to your loved one mean to you?

- B.) While being a caregiver to "name" what has your sense of purpose in life been like?

- Do you feel that being "name's" caregiver has affected your inner peace?

- Where have you experienced support in being a caregiver?

- How would you describe yourself spiritually before becoming "name's" caregiver?

- Now that you have taken on this caregiving role, how would you describe yourself spiritually?

- Can you tell me about the decision to care for "name" in your home?

- What do you feel the experience has brought to you and to your relationship with "name"? 


\section{Writing as Analysis}

Phenomenological writing is best accomplished by remaining in conversation with the transcript from the semi-structured interviews through the rich practice of reading and writing. Such a practice demanded that this investigator be attentive not only to the spoken words but also to the story that can be told by the silence that lays around each word as well. The same process of reading and writing related to the elaborate field notes that were collected during the data collection period was necessary. The process of analysis, then, was reading, listening, writing, reflecting, and rewriting. As a result of this phenomenological writing process, the investigator was able to present a robust description of the phenomenon.

\section{Protection of Human Subjects}

The Institutional Review Board of the University of San Diego provided study oversight. Participants signed an informed consent that reviewed the purpose of study and potential risks and benefits before being enrolled in the study.

The digital recordings of interviews will be stored for 5 years on an encrypted flash drive for purposes of responding to any queries related to resulting publications. Digital recordings, verbatim transcriptions of interviews, and de-identified demographic data will be kept in a locked cabinet at researcher's home. After 5 years, all data will be destroyed.

A potential risk of this study was the possibility of anxiety or stress from discussing care of a loved one. This was mediated by ensuring the participant could stop the interview at any time and if they chose, they could elect to be removed from the study. A potential benefit of this study was a renewed understanding of the relationship 
that the participant shared with their loved one. This could have potentially resulted in further discussions between them that enhanced the quality of life. Additionally, there was the possibility that the interview process would enhance the participant's understanding of spirituality and develop a stronger commitment in their relationship with the Sacred.

\section{Trustworthiness}

The criteria used to assess the quality of a qualitative research are different from those used in quantitative research. The qualitative researcher interprets the data as it is collected so that probing questions can be asked of participants to obtain a clearer understanding of the lived experience. This researcher, though, was consistent in following a semi-structured interview format to demonstrate the validity of the research. The criteria commonly used in qualitative research to assess its quality is the concept trustworthiness. A study is said to be trustworthy when it is thorough (Holloway \& Wheeler, 2010). This researcher achieved this through meeting four criteria: dependability, credibility, transferability, and confirmability.

\section{Dependability}

In qualitative research the main instrument is the researcher himself. Thus, for a qualitative research study to be understood as dependable, its methodological approach must be consistent and its process for analysis must be clear (Holloway \& Wheeler, 2010). This proposed research met the criteria of dependability through both an audit trail that linked the collected data to the final conclusions and the use of thick descriptions that captured the intended meaning of the participant's lived experience and the researcher's personal understanding of the phenomenon. 


\section{Credibility}

The analysis of the participants' responses in qualitative research is meant to yield a rich description of the phenomenon under study. When this description resembles the meaning the participants attribute to the phenomenon in their responses, the findings are credible (Holloway \& Wheeler, 2010). In this study, both the constant review of the data with dissertation committee members and reflexivity by the researcher facilitated meeting the criteria of credibility.

\section{Transferability}

The focus of qualitative research is on a specific phenomenon in a particular setting. The findings, though, may have significance to other similar groups. When the information from one study is applicable in a subsequent study, it is understood as transferable (Holloway \& Wheeler, 2010). The final description of the phenomenon based on interviews of participants in this study was reviewed with the researcher's dissertation committee to ensure the criteria of transferability applied to the findings.

\section{Confirmability}

The qualitative researcher must be open about preconceived understandings and assumptions about the phenomenon to be studied. The disclosure of these and selfreflection on them by the researcher will ensure confirmability. This will demonstrate links between data and conclusions (Holloway \& Wheeler, 2010). To meet the criteria of confirmability for this proposed research, an audit trail and review by dissertation committee members supported the findings and reduced bias. 


\section{Limitations}

The study findings are reflections of the participants alone. However, the documented experiences of being a caregiver to a person with dementia contained in the interviews may be reconfirming to some caregivers and may be helpful in expanding the view of how some healthcare professionals view caregivers.

An additional limitation of this study was gender. It is well documented that most informal caregivers are women (Alzheimer's Association, 2018; Family Caregiver Alliance, 2018). While this study was able to recruit and analyze the lived experience of two men, the addition of more men may have enriched the findings.

Nationally, recipients of palliative are overwhelmingly Caucasian (National Hospice and Palliative Care Organization, 2017). The focus of this study was on caregivers of persons with Alzheimer's Dementia enrolled in palliative care in Southern California. This region of the United States is heavily populated with persons of Hispanic heritage. While this study was able to recruit two caregivers who are immigrants from Mexico, the small number of participants limited the study's ability to make specific conclusions on the perspective of caregiving as it is experienced in the Latin culture.

\section{Summary}

The understanding of spiritual well-being amongst informal caregivers of persons with dementia on palliative care living at home is very limited. This gap in knowledge made the selection of a qualitative study most appropriate. The hermeneutic phenomenological approach using van Manen's (1990) process of analysis was determined to be best suited for the study's lines of inquiry of exploring the meaning of 
this phenomenon. An interview guide was designed to assist the researcher in the pursuit of a deeper understanding of the caregivers' experiences of spiritual well-being. The interview guide, in combination with the transcription of digital audio recordings and extensive field notes, were used in the analysis process of the collected data. The following chapter will present the findings of this analysis. 


\section{Chapter 4}

\section{Results}

This chapter presents the findings from this study. It begins with a description of the study's participants obtained through the set of survey questions answered at the beginning of each interview. The remainder of the chapter presents the themes identified in the responses to the questions contained in the interview guide and are presented as they relate to each of the study's lines of inquiry. (See Table 1). It is the work of phenomenological writing in this study that ultimately allowed for a deeper reflection and analysis of the participants' experiences, eventually revealing a few key themes as substantially contributing to an essence of spiritual well-being in the context of informal caregiving to persons with dementia on palliative care living at home. When referring to participants and specific individuals they mention in their responses, either a number for the participants (e.g. Participant 1) or a pseudo name for individuals mentioned in the responses is used to maintain the anonymity of these persons.

\section{Purpose}

This study examined the experience of spiritual well-being amongst family caregivers of persons with dementia on palliative care living at home. The primary line of this study's inquiry was to explore the lived experience of the family caregivers through focused questions on meaning, purpose, inner peace, and support. A second line of inquiry was to identify any spiritual feelings that may be present in these caregivers and explore the meaning of those feelings in the context of spiritual well-being. This was accomplished through focused questions on the caregiver's experience of spirituality 
before and after becoming the primary caregiver for the person with dementia. The final line of inquiry was to explore, when present, the spiritual meaning of providing care in the home by using focused questions on the decision-making process to care for the patient at home and the impact on their relationship. When appropriate, probing questions were used to obtain even more robust descriptions.

\section{Study Participants}

\section{Palliative Care}

There were 10 caregiver participants who were interviewed in their homes between October 2017 and August 2018. All but one of these individuals was recruited from a large healthcare organization in Southern California. The one exception was from a community-based organization. In each case, the caregivers indicated that they had been originally referred to palliative care services by their family member's primary care physician. On review of their responses during the interview, the caregivers used the term "hospice care" exclusively. It is not known if they were aware of the distinction between receiving palliative care versus hospice care. The caregivers were all aware of the medical, psychological, and spiritual services offered by these two organizations. Only four caregivers denied spiritual services because they did not feel the family member was actively dying. Several of the caregivers commented that their "hospice care" team provided invaluable assistance. This included educating them on how to assist with different activity of daily living tasks for their loved one and offering them brief periods of respite to care for themselves. All of the caregivers indicated how important each of the services were to their ability to continue to care for their loved one at home. 


\section{Caregiver Characteristics}

A representation of the characteristics for each caregiver who participated in this study is in Table 2. The study included 8 females and 2 males whose ages ranged from 45 to 84 years. The participants identified their ethnicity as either White $(n=5)$, Hispanic $(n=4)$, or White/Latino $(n=1)$.

Each participant's relationship to the patient, their caregiving experience, and employment status are summarized in Table 2. The caregivers identified their relationship to the patient as a child $(n=6)$, spouse $(n=3)$, or "other" $(n=1)$. Of those who identified themselves as a spouse, 2 were females and 1 was male. The employment status of the participants included 6 retired persons, 3 full-time inside the home and 1full-time outside the home. Of those who reported working full-time inside the home, 2 shared that the caregiving role was their full-time job. The amount of time the participants have been caregivers for the person with dementia ranged from 3 months to 10 years.

The participants were asked to respond to questions regarding how they identify themselves spiritually, to note any specific spiritual practices that they rely upon, and the frequency they engage in those practices. Those responses are also summarized in Table

2. The participants indicated that they were either spiritual $(n=6)$, not spiritual $(n=3)$ and 1 who did not respond but stated in the interview that she was Catholic. The affiliations were Protestant $(n=3)$, Catholic $(n=2)$, evangelical non-domination $(n=1)$, other $(n=1)$, and "none" $(n=3)$. The most frequently used rituals by the participants were prayer $(n=4)$, "strong beliefs" $(n=1)$ and church attendance $(n=2)$. The use of these rituals was reported to be daily $(n=4)$, weekly $(n=1)$, or constantly $(n=1)$. 
Table 2.

Caregiver Characteristics

\begin{tabular}{|c|c|c|c|c|c|c|c|c|c|c|}
\hline ID\# & Age & Gender & Ethnicity & $\begin{array}{l}\text { Work } \\
\text { Status }\end{array}$ & Relationship & $\begin{array}{c}\text { Time as } \\
\text { Caregiver }\end{array}$ & $\begin{array}{c}\text { Time on } \\
\text { Palliative } \\
\text { Care }\end{array}$ & $\begin{array}{l}\text { Spiritual } \\
\text { Tradition }\end{array}$ & $\begin{array}{l}\text { Types of } \\
\text { Practices }\end{array}$ & Frequency \\
\hline 1 & 54 & F & $\begin{array}{l}\text { White/ } \\
\text { Latino }\end{array}$ & $\begin{array}{l}\text { FT Inside } \\
\text { Home }\end{array}$ & Daughter & 10 years & 6 months & Spiritual & Prayer & Constant \\
\hline 2 & 45 & M & $\begin{array}{l}\text { Hispanic/ } \\
\text { Latino }\end{array}$ & $\begin{array}{l}\text { FT Inside } \\
\text { Home }\end{array}$ & Son & 10 years & 10 years & NA & No & No \\
\hline 3 & 79 & F & White & Retired & Spouse & 7 years & 2 years & NA & - & - \\
\hline 4 & 57 & $\mathrm{~F}$ & $\begin{array}{l}\text { Hispanic/ } \\
\text { Latino }\end{array}$ & $\begin{array}{l}\text { FT Inside } \\
\text { Home }\end{array}$ & Daughter & 2 years & 6 months & NA & None & None \\
\hline 5 & 84 & M & White & Retired & Spouse & 2 years & 6 months & Presbyterian & $\begin{array}{l}\text { Church } \\
\text { Attendee } \\
\text { and Prayer }\end{array}$ & Daily \\
\hline 6 & 75 & F & $\begin{array}{l}\text { Hispanic/ } \\
\text { Latino }\end{array}$ & Retired & Spouse & 2 years & 1 year & Catholic & $\begin{array}{l}\text { Rosary and } \\
\text { Prayer }\end{array}$ & Daily \\
\hline 7 & 61 & $\mathrm{~F}$ & White & $\begin{array}{l}\text { FT } \\
\text { Outside } \\
\text { Home }\end{array}$ & Daughter & 3 months & 4 months & Methodist & Prayer & Daily \\
\hline 8 & 73 & F & White & Retired & Daughter & 3 years & 1 year & Lutheran & $\begin{array}{l}\text { Strong } \\
\text { Beliefs }\end{array}$ & Daily \\
\hline 9 & 76 & $\mathrm{~F}$ & White & Retired & Girlfriend & 4 years & 11 months & Evangelical & $\begin{array}{l}\text { Church } \\
\text { Attendance }\end{array}$ & Weekly \\
\hline 10 & 67 & F & White & Retired & Daughter & 5 years & 2-3 months & $\begin{array}{l}\text { Christian/ } \\
\text { Catholic }\end{array}$ & NA & NA \\
\hline
\end{tabular}




\section{Thematic Analysis}

There was a total of 10 interviews conducted in this study that ranged in time from 38 minutes to 77 minutes. The digital audio recordings were professionally transcribed. Each transcript was reviewed by the researcher to ensure accuracy of content and de-identify all references to particular individuals and places. In the discussion that follows, the direct quotes from interviews reflect the names substituted through the process of de-identification. The analytic approach of Van Manen (1990) was selected for use in this study. This approach, described in Chapter 3, allowed the researcher to reflect carefully on the content of each interview as it related to the four different life worlds central to the meaning of the phenomenon of interest—spiritual well-being in the context of caregiving for a person with dementia enrolled in palliative care and living at home. The interviews followed the study interview guide to explore the experience of each caregiver as it related to the lines of inquiry of this study. (See Table 1.) Those three lines of inquiry and the respective themes are described in the presentation that follows.

\section{Line of Inquiry \# 1: Explore the lived experience of informal caregivers of a person with dementia enrolled in palliative care living at home.}

The caregivers in this study provided rich descriptions of their experience. While not overtly asking about spiritual well-being in this initial line of inquiry, the questions did probe the caregivers' understanding of meaning, purpose, inner peace, and support related to caregiving. The detailed accounts in their responses helped identify four predominant themes related to this line of inquiry. The first was "Isolation from others," which was described as limiting the caregiver's ability to interact with people outside of 
the home. Second was "Hardships." Here, the daily demands of caregiving were described as taking a toll on the caregivers. The third theme was "Awareness," indicating the opportunity to self-reflect on the relationship with their loved ones heightened the caregiver's attention to the meaning of their role. The final theme was "Being connected to the patient." In contrast to the first theme, here, the caregivers conveyed a profound importance of being near their loved ones. These themes are examined below in more detail.

Isolation from others. The caregiving role clearly limited the abilities of the participants to interact with others outside of the home. This was both a physical and psychological experience of isolation. In some cases, it was the overwhelming demand to be with the person with dementia that led to the caregiver feeling isolated from others. In other cases, it was a self-imposed isolation from others. The caregiver's description of the experience as, "I also felt trapped," "confinement now that she is not able to get up and go out," "I am going to be locked here all weekend," "They were avoiding us," and “where do I set boundaries?" supported this theme.

Participant 9 described the caregiving experience in terms of being trapped. She longs for the opportunity to engage in many of the social activities that she and the person with dementia once did together as a couple. This caregiver experiences living in the home with her boyfriend as being all alone even when they are in the same room. This is frustrating and increases her perception of being isolated from others.

"I can't leave John and that's a big difference and, ah, since he, ah, of course, doesn't drive anymore and he, that was one of the first things that happened to John is that they took his license. So, he felt trapped, ah, but I also felt trapped. Well, now more so because I can't leave him. At first, I could leave him, you know, and that he was okay with that if I ran to the store, you know, but now I 
can't even run to the store. If he's taking a nap, I can't leave." (page 7, lines 1217)

Participant 10 described her experience as being left all alone to care for her mother. She feels poorly prepared for this role and frightened by how it will progress.

With few friends and family to offer support, she has welcomed the brief respite she receives when her mother goes to daycare during the week. However, she is left to worry that when the weekend arrives, she will once again be isolated indoors alone with her mother.

"And I was kind of like thinking that Friday was coming. Oh, now I have the whole weekend. I'm going to be locked here all weekend and, um, the repetitious of when she gets agitated" (page 9, lines 10-11)

Participant 8 moved into her parents' home to help her father with caring for her mother who has dementia. She reflected on how the three of them were very active early on in the caregiving experience. They visited parks to swing on the playground equipment or walked laps in the shallow end of the neighborhood pool. The progression of her mother's dementia and the death of her father has changed this active lifestyle. She acknowledges the physical condition of her mother who is now bed-bound contributes to her experiencing caregiving as a confinement to home and isolation from others.

"Um, you know it's [caregiving] brought me a lot closer to my mother. Um, it's been rewarding and still is. Um, it (PAUSES) requires, um, a lot of time. I do have help in the morning. Ah, from 9 to 1 , I have some, someone comes to help and then I'm here in the afternoon and evenings with my mom and so, um, it's limiting on that end of it because of the confinement that she's not able to get up now and go out. Um, so, um, two years ago, we were out and about. Ah, she was able to be in a wheelchair and we would go, we have a lovely park near here and every afternoon, we would go out to the dog park over there and, um, it was wonderful." (page 1, lines 13-19) 
In the case of participant 6 , this isolation was experienced when her family found it to have become increasingly difficult to be around her husband (their father and grandfather) who had dementia. Her husband had always held an important place in their daughters' and grandchildren's lives. They respected him and relied on his advice when they needed to make important decisions, such as a granddaughter's choice of college to the grandson's decision to enter the military. When the family stopped coming to the home after her husband's diagnosis of dementia, participant 6 experienced a painful isolation from these people, whom she loved.

"They were not ready for that, for grandpa funeral, talking about a funeral. In the beginning, it was he and I alone. Just he and I and the nurses. Well before hospice, Dr. Connor, but it was he and I because the children didn't want to know any and I mean they love him and they love me, but they didn't want to, they, they were avoiding us. They were not coming. They left us alone for several months." (page 7, lines 22-26)

Both parents of participant 1 have required her assistance as a caregiver. Their dependence on her in relation to health care needs has created a division between herself and her siblings. She has gradually felt isolated from them because they had not shared in the caregiving experiences. This has forced her to establish boundaries to respect herself and limit her interactions with others.

"Where do I set boundaries, where do I come in. It [caregiving] is a great opportunity to learn to set boundaries. Healthy, and it's also a really great opportunity to see where in your own life you're not having healthy boundaries." (page 1, lines 23, 24, 26 and 27)

"[healthy boundaries are] where am I not honoring myself, my core values . . . is saying no to my brother or sister being disloyal to me." (page 2, lines 24 and 26)

It has been important for participant 3 to be the primary caregiver for her husband. She recognized the challenges of this role and has not wanted to put others 
through the demands of caregiving. She has accomplished this by keeping others,

particularly her daughter, at a distance from the experience.

". . . it also means for me to be his caregiver that I am sparing my daughter. She already is still raising her small, her youngest, ah, child. I'm sparing her the, um, the problem that would, she's a working woman you know. Ah, she could not do it like I can do it, um, because I have the time." (page 5, lines 40-43)

Several participants had a hopeful anticipation of no longer being isolated from

life outside of caregiving at some point in the future. Their description of that next stage

was a stark contrast to the isolation that being a caregiver had required of them.

"I just want, I just want to breathe, I think, and I think, oh my God, I'm 67 and I'm finally going to get to breathe maybe one day when my mom passes. So, I'm kind of looking forward to her passing in some ways for my selfish ways."

Participant 10 (page 5, lines 30-32)

“. . . not to appear cold or calculating or, um, (PAUSES), ah, I don't know how to put it, but I'll just be blunt. I am looking forward to the day when it's over. Yes, it's been a long haul. Um, (PAUSES) so then I will possibly have, um, a few years to reconnect with the me that has gotten lost in the caregiving. The, um, connecting with friends again. Meeting up with some of my groups that I belong to that I have not been able to, ah, attend their meetings for a couple of years now and they email me you know how are you doing, Judy, and so forth and, um, so it's wonderful to know they're just waiting for the day when I can come and join them again in, ah. So, that's what I'm looking forward to." Participant 3 (page 7, lines 23-30)

"I try to enjoy life you know out there and, ah, you know it's hard because I have to stop and, um, you know take care of my mom and, ah, it's very hard, but I know at, at the end you know I'm going to be blessed and, ah, and then life goes on.” Participant 2 (page 2, lines 31-34)

"I'm just going to continue doing what I can for her but then I don't want to stay home anymore after that. I want to be out.” Participant 4 (page 9, lines 26-27)

Hardship. There are numerous burdens associated with the responsibilities and demands that caregivers experience in their role. Many of the participants spoke of how these burdens had become a hardship for them to endure. Despite the challenges 
presented by these hardships, the participants described a value of being connected through the caregiving role to their loved one. Their descriptions of the experience as, "It changed my life and you know everything is pretty much on hold," "our life is kind of at a standstill," "caregiving really takes a toll on a person," "wow, I really took on a big role," "being the sole person is just unbearable," and "We learn it [dementia progression] on raw meat," helped identify this theme.

Participant 2 has had to make many changes in his life to provide care for his mother in their home. He has gone from "living life to its fullest" to focusing exclusively on his mother. This "having to put life on hold" is something he shares in common with the experience of participant 9. Yet both of these participants discovered that the caregiving role connected them to their loved.

“And it's [caregiving] hard. You know I have a girlfriend, so it's really hard, but my main focus, you know, on is taking care of my mom to try to balance everything out. So, it really has changed my life and, you know everything is pretty much on hold." Participant 2 (page 2, lines 38-41)

“I can't just leave my mom like that and take off. So, it really changed a lot, and I see what people talk about on caregiving and taking care of a person. You know it really takes a toll on a person." Participant 2 (page 3, line 39 to page 4 line 6)

"Well, I care deeply for him. I love him, and we've had a good time. His wife died right around the same time my husband did, and we met through his daughter, who I worked with and we kind of hit it off and he I have traveled in the motor home and we've done a lot of things together, and now it's just, you know our life is kind of at a standstill." Participant 9 (page 2, lines 22-27)

"It is very challenging day in and day out and especially when he gets up sometimes in the middle of the night and wants to take a shower at midnight because somebody's picking him up the next morning. Well, what does that do to me? I don't get to sleep. I've never been one to sleep a lot anyway, but I do need three or four hours (LAUGHING). So, it's just the whole circumstance is very difficult." Participant 9 (page 9, lines 20-28) 
Participant 1 had been the caregiver to both her father, who died previously, and now her mother. This decision required that she remove herself from other worries in life and become singularly focused on the caregiving role. She acknowledges that having to care for one parent so soon after losing another has made it difficult to articulate the meaning and purpose to caregiving. In addition, she has found that in taking on the caregiving role with little support from her family has been an overwhelming hardship.

"It was a conscious choice to put my life on pause and dedicate it to them. Losing my dad, I thought I was going to have a little bit of time to breathe. And kind of get my bearings again and I didn't and I feel like it was very drastic because my brother who was like my rock became the boss and took the reins, and he's very business, he manages thousands and thousands of people in a factory, and so he's like give me numbers and do this and so it's like I was just, wait a minute. I don't know what I'm doing." (page 8, lines 11-13, 15-19)

Participant 6 noted that the dementia diagnosis is something that caught her by surprise. Her husband was very "sharp mentally" and devoted to details. The emotional pain of a dementia diagnosis with no warning has been tremendous. She has had to experience the hardship of watching her beloved husband gradually decline. While supported by her hospice team, she has felt poorly prepared for what that diagnosis meant and the hardship that she would have to endure.

“...why Dr. Connor didn't put things together and analyze the situation and warn me, tell me. Why he didn't tell me? I would think that he would suspect something. Somebody had told me I know there is nothing we can do, but at least I would have been ready." (page 2, lines 15-18)

"When we first started on hospice, I didn't know what hospice was. Didn't, absolutely nothing about hospice. Of course, my ignorance it has to do with that it has never been in my family ... Now the children know what to look for, but we learn it on raw meat. We learn it with our tears. And the pain is still here. It's very deep and big pain. Very, very deep." (page 3, lines 1-15)

Participant 10 acknowledges that taking on the caregiving role for her mother has been extremely difficult. It has been complicated by the strained relationship that they 
have shared over the years. Now that she has had to take on this role, she is

overwhelmed by what is required of being a caregiver. She experiences the connection to her mother through the caregiving role to be quite challenging.

“...the resentment comes up because she was never there for me, but I'm here for her and I'm the only one here" (page 5, lines 7-8)

"Because I see people that have families and spouses and brothers and sisters, and they take part of the burden off, but being the sole person, I just, it's unbearable. That's the hardest part." (page 6, lines 8-10)

The hardship that comes with the demands of the caregiving role can also leave the caregiver in awe on what they have undertaken. Both participants 2 and 3

commented on wondering how they came to be, and remain, caregivers to this day. The caregiving role, while challenging, has allowed them to remain connected in a significant way to their loved one.

“...you know you sit there and think about everything and it makes me feel good inside that I'm taking care of my mom, but you know sometimes, I was like, wow, I really took on a big role and you know what did I get myself into?" Participant 2 (page 7, lines 1-3)

“...we had a situation where Matthew fell and cut the back of his head and I took him to urgent care for staples and so forth and so I said to Stacey [the hospice nurse], it's times like this when I question my resolve to care for Matthew at home." Participant 3 (page 2, lines 37-39)

Awareness. The caregivers described the importance of awareness to the overall experience. This was, in some cases, an attention to past events they had shared with their loved one. However, in most instances it was an awareness of being present to their loved one in the moment. This awareness had a powerful contribution to their understanding of the meaning of caregiving. The caregivers' own words, "it makes me feel happy and aware of myself," "looked back on my life and realized the hardships of 
my childhood," "it makes me sad to see this brilliant man wasting," and "I realized the depth of my feelings," support this theme.

Participant 4 shared how she had been separated from her mother for many years. She has rediscovered meaning in their relationship during this period of caring for her mother. By being aware of her internal reactions to her mother's emotions, she has been able to remain focused on caregiving.

"She responds to it [my presence]. I mean I could be there and not feel it [her response], but I could be with her and make her feel good and I can feel it and she can have that emotion and reflect back on me and it makes me change. It makes me feel happy and aware with myself and to carry on throughout the day or whatever I need to go on and still with the same level of the energy and the emotion that she gets me, because that's what makes me go." (page 11, lines 4044)

Participant 6 described her husband who has dementia as someone who was devoted to her and her children. His dedication to them has encouraged her to be a fierce advocate for his best interests at the end of life. She had never known a person with dementia before her husband was diagnosed. This has required her to learn each day how to be a caregiver. During this time, she has become acutely aware of both the wide spectrum of emotions that go with caregiving and the impact those emotions have on her approach to caregiving.

"It's a mix of emotions. It is despair, sadness, ah, (PAUSES), Why my husband? Why? And, ah, mostly sadness to see my companion, my loved one wasting. I'll give you an example. Um, a couple days ago was our wedding anniversary and I was shaving him in the bathroom and when we do that, I talk to him. I try to talk to him a lot and I told him, honey, today is our wedding anniversary and he just look at me. Nothing register in his face and I repeat it. I say, honey, we got married 46 years ago today and nothing. He didn't say nothing and it makes me very sad because everything is gone. He doesn't remember. He used to take me out for dinner. He used to bring me flowers. He used to get me the most beautiful cards, telling me how much he loved me, and when I told him, nothing registered in his face. So that make me very sad. Not about the anniversary. It makes me sad to see this brilliant man (PAUSES) wasting. Ah, despair because this is a horrible 
disease that robs the human being of everything. They lose their memory. He doesn't know the children, the grandchildren. He knows me most of the time. Sometimes he doesn't remember his name. So, it robs the memory and it takes away your dignity (PAUSES) completely." (page 1, lines 14-30)

"It [the times when he remembers me] makes me so happy. It is, it's one of the brightest moments of my whole day. Nobody knows how sad it is to see your loved one going. It's very, very sad and I have my faith in God that sustains me. I don't know how other people can go through. It's devastating." (page 4, lines 2629)

Participant 3 described the caregiving role as something that could only be possible for those who have a strong commitment to their loved one. She has been married to her husband for over 60 years. While they have a daughter, she lives out of town. The caregiver, her mother, is trying to protect her from the challenges associated with this role. This caregiver's awareness of the difficulties she has experienced in life has given her the fortitude to persevere in the caregiving role.

"I certainly can look back at my life and realize that the hardships of my childhood and, certainly the difficult periods of my married life developed within me a core of strength that allowed me to see the end of the journey or the culmination of that caring so that, in fact, there will be an end to it." (page 1, lines 39-46)

Participant 5 considered the time as his wife's caregiver to have been a blessing.

Their 58 years of marriage have been filled with many happy memories. He is aware now how important it is to reflect back on the time they have shared together and recognize how those memories sustain him in the caregiving role.

"I guess I've grown, realized the depth of my feelings for my wife that I had sort of assumed during our long marriage and you don't think about them and then this has caused me to reflect back on, on all the good times and the positive things that have happened." (page 1, lines 29-31) 
Participant 10 has not experienced the caregiver role as being pleasant. She has become aware of how the challenges of caring for her mother is stealing many of the good memories that they have shared together.

"Yes, and I don't want these bad memories and I'm developing them and they're staying in my head now and the further it goes, I keep these sad memories better than the, the past memories that I would wish that I could keep." (page 2, lines 24)

Being Connected. The importance of being connected to their loved one was a point consistently mentioned throughout the interviews. The caregivers described how that nearness to their loved one had created a connection between them. It was this enhanced understanding of being connected to their loved one that contributed to the caregiver's hopefulness in their sense of purpose and meaning in life. The in vivo quotes such as, "taking care of her and what her needs are. Inside it is really a bless you know," "telling her how much I love her and she'll say you do and then say I love you too," "This is my chance to be with her, to care for her and for me to know her" and "the Lord is letting me care for him," all support this theme.

Participant 8 commented on how the experience of being her mother's caregiver has been rewarding. She described her relationship with her mother during her life as extremely close. Now, as her mother's caregiver, she has had several opportunities to discover meaning in the role that maintains a powerful connection with her mother.

“...well physically holding her hand, talking to her, often in the afternoon I'll sit down and read I don't know how much of it she's listening, but just having me here. Yes. You know telling her how much I love her, and she'll say, 'you do?' and then she'll say, 'I love you too'." (page 3, lines 25-26, 34-35)

Participant 4 had left her childhood home at a very early age. Those lost years have always left her with an emptiness. She understands the caregiving role has provided 
a sense of purpose to both recover those lost years and connect once again with her

mother.

"I spent a lot of years away from her. I left the home when I was very young and I missed the years that I wasn't there and somehow I want to recover those years I spent out of the home not knowing her. I left at an age very young, 16, 17, and I think at that age, you're still learning a lot about you. It's a different stage in life and not being there with her, I missed those years and I want them back and I want them now. This is my chance to be with her, to care for her, and for me to know her and also for her to know me as a married person with a husband and a family." (page 6, lines 1-7)

Both participants 3 and 6 understand their purpose in life is now to be present to

their loved one with dementia. The caregiving role has allowed them to deepen the connection they have with their family member.

"I've got, every day I wake up, I know that this is another day that I have an opportunity to take care of Matthew. So, that's my purpose. That's what's right in front of me right now." Participant 3 (page 7, lines 31-33)

"He gives us all his love and the Lord is being so good to me giving me the opportunity to take care of him and in a little way kind of not repay, kind of do something for my husband because he was so good for me with us. So that's the way I look at it. The Lord is giving me the opportunity to take care of him." Participant 6 (page 3, lines 24-27)

The experience of caregiving for participants 2 and 5 has allowed them to reflect back on their loved ones fondly. This process of reflecting in their caregiving role has brought a sense of meaning to see a deep blessing in their shared life together.

"Well, you know it's just the way I feel inside is, you wake up in the morning and you see my mom there and when I do take care of her you know it makes me happy. You know it makes me happy inside that I'm partaking in and taking care of her and her needs. Inside it's really a bless inside." Participant 2 (page 1, lines 22-25)

“...we've been married, 58 years and, I'm blessed with I think to have had a good solid marriage. I think, if anything, it's [the caregiving role] made me appreciate my marriage to her and appreciate the good times that we had." Participant 5 (page 1, lines 15-18) 
In summary, the experience of caregiving for these participants has had a strong impact on them and their relationship with the person with dementia. The caregivers were engaged in the interviews through questions on their experience of meaning, purpose, inner peace, and support. These experiences are not known to have been included previously in research of caregivers of persons with dementia on palliative care living at home. In this group of caregivers, there was a general feeling that they were unprepared for this role. They experienced the mounting challenges and physical demands to be overwhelming at times. Yet, by creating a space of nearness between themselves and the person with dementia, they discovered an inner peace that supported them in this role.

The experiences shared by the participants provided rich data to analyze that ultimately supported the following themes: Isolation from others, Hardships, Awareness, and Being connected to the person with dementia. Upon deeper reflection and analysis over time with all of these themes, the specific themes of "hardships" and "being connected" were most salient and relevant to understanding an essence of the phenomenon of spiritual well-being amongst family caregivers of persons with dementia on palliative care living at home. The participants acknowledged that "hardships" in the caregiving role were full of challenges, yet it was the caregiving role that allowed them to have an important connection to their loved one. The theme "being connected" expressed the caregiver's feeling their role filled them with a meaning and purpose in life that created a sense of hopefulness. 


\section{Line of inquiry \# 2: Identify any spiritual feelings of these caregivers that may be present and explore the meaning of those feelings in the context of spiritual well- being.}

The caregivers were more hesitant to opening up to a discussion on spirituality. The dialogue that did eventually develop, though, had several meaningful descriptions of their experience of spirituality. The caregivers were invited to respond to questions on their perception of spirituality in general and then in their personal journey. In the case of the latter, caregivers were asked to describe the meaning of spirituality both before being a caregiver and subsequently in that role.

There were four themes related to this second line of inquiry identified through textual analysis. The first was "Presence," an experience of sacredness, or the Divine. This was made possible for many caregivers by simply being with their loved one. A second theme was "Trust." It was important for these caregivers to have a belief in something, or someone, greater than themselves to persevere in the caregiving journey. The third theme was "Sacrifice," meaning the role of caregiver required they give up something of themselves to continue the daily care of their loved one. The final theme was "Belonging." This was the experience of being a part of a group, spiritual or secular, and its importance to these caregivers despite their inability to be physically present at those gatherings. In this section, each of these themes is explored in depth.

Presence. In several of the interviews it was evident that experiencing a closeness with others was important. There were two participants who spoke of their understanding that God is always present in our lives. Several other caregivers noted what made spirituality present was the ability to touch physically or just be near others. 
In recognizing this presence, the caregivers discovered a sense of hopefulness that God/spirituality is listening to them, protecting them, and sharing in their experiences. The theme "presence" was supported through the participants own words, "I cannot see the Lord, but I know he's there," "I will find it [spirituality] in just being with her," "it [spirituality/God] is always there," and "really touch each other fills my heart."

The many different painful experiences in the life of participant 6 have helped confirm her faith that God is always present. She acknowledges this conviction has been true even when she may not have been receptive to Him. This understanding of God's enduring presence gives her the spiritual strength of hopefulness to face new challenges.

"Probably it's all my faith in God and I think to me, I have the support of friends and family and the nurses, the hospice and the support group, people like you, but I think my faith in God is what is helping me go through. If you can call that because this is spirituality to me. I cannot see the Lord, but I know he's here and he's listened to my prayers." (page 14, lines 9-14)

Participant 5 shared that his upbringing formed his belief in God. As he has grown, so too has his faith in God's presence all around us. While identifying himself as a person of faith, he has always remained hopeful to the idea that God is not someone that can be found only in a church but is readily available to listen to our needs.

"I think it's [spirituality/God] always there and you, it's not something that you have to go to church to get. It's something that you can [find] through your own prayers and your own makeup, it's available to you." (page 5, lines 42-45)

The profound relationship that participant 7 has shared with both her mother and father is where she has experienced the presence of God. The physical closeness they experienced now reassures her that God's presence will always be a part of the experience of her journey.

“..you know lovers, they entwine their fingers, and my mom and I we would entwine our fingers together and just you know squeeze and just really, really 
touch each other and oh my gosh, I can't tell you how full my heart." (page 8, lines 16-19)

In a similar way, Participant 4 has identified that closeness to another person is what makes spirituality present or known. This presence has had a more profound significance for her compared to the practice of a religion. Because of this experience, she remains hopeful that her caregiving role has meaning.

"I'll find it [spirituality] in just being with her. Just doing, caring for her in a way makes me feel happy. To me [that] is spiritual because it makes me feel good about it. I don't know if you're looking for something that's religion or religious, but I think it's spiritual to me, it's just seeing her happy, content up to a point that it makes me feel that I'm doing something good and that makes me feel happy, and I can carry on with my day just being happy in thinking about it." (page 11, lines 23-28)

Trust. Many of the participants noted the caregiving role was, in large part, made possible through trusting in the assistance of others. This outreach was experienced either through their lived spirituality or lived relationships. For some caregivers, there was a trust in what they perceived to be the promises of their faith in God that helped them in this role. In other caregivers, it was the ability to trust in themselves that guided them through the caregiving journey. The theme "trust" was identified through the comments of the participants, "I have my faith in God that sustains me," "God is in your soul, it is a belief and we've never really seen Him," "there is someone out there to take care of me," and "I didn't have a care in the world."

The act of having faith in God is something that has sustained participant 6 in the caregiving role. The pain associated with watching her husband deteriorate has been too overwhelming to continue without trusting that God has been with her on this journey. She acknowledges that she had not always been committed to that belief but has found that in times of need we "can turn to Him" and He will help. 
"It was devastating for me and for the children because I saw the children suffering, the grandchildren. Ah, then I look, started looking, started talking to God again and I say, dear Lord, please forgive me. Please. I was busy having a good time and I've been talking with the Lord since then and the Lord was merciful.” (page 16, lines 26-29)

The spiritual journey of participant 7 has taken her through a variety of spiritual expressions. However, she admits that in the end, any spirituality is predominately about trusting in something that cannot be seen physically but is present in each individual.

"I think that you know God is in your soul, right? It's a belief and we've never really seen him. So, it's a faith, a base of faith inside of you." (page 17, lines 3435)

The spirituality of participant 5 has helped him move through this caregiving journey. It has taught him to trust that he is not alone as he strengthens his commitment daily to care for his wife at home.

"I think it's [spirituality/God] probably strengthened my belief and know that there's someone out there that will take care of me when I really need it." (page 6, lines 3-4)

There were some participants, however, that acknowledged as not having a need to trust in God or spirituality. Neither was there a desire to consider what this would mean or contribute to their journey. Rather, they discovered the absence of an experience of spirituality to free them to find an inner peace within themselves.

"I will always remember my father-in-law, um, saying that he believed that he was a non-believer himself and he said I, I'm like a tomato plant. I grow, I bear fruit and then I wither and die and go back to the soil. So, well of course I thought he was, as a Witness, a poor, ignorant man, but now I too believe I'm a tomato plant. I grow, I bore fruit, I now wither and die and go to the ground. It's very freeing and, ah, (PAUSES) freeing is the best word I can say. Yeah, I have no concerns." Participant 3 (page 15, lines 31-36)

"I didn't have a care in the world of taking care of somebody you know. Just we went out there and I went out there and didn't have to worry about anything. Um, that was I mean I don't know how else to describe it. Just didn't even think about this kind of stuff [spirituality]." Participant 2 (page 7, lines 39-42) 
Sacrifice. In many cases the caregiving role required the participants to give up something of themselves to focus on the care of their loved one. The act of making the sacrifice was not always done easily by the participants. Some caregivers experienced this as a positive attribute, while others felt the sacrifice brought extraordinary changes to their lives. As a result of their responses, " $[I$ am $]$ a giving person," "a strong spirituality is a kind and good and giving person," "your whole life changes ... you have to care now," "I am sacrificing everything for her," and "we are at a standstill," the theme "sacrifice" was identified.

When her father needed assistance in caring for her mother, participant 8 moved back home from out of state. She commented that it had been both her professional experience and spiritual identity that allowed her to make this sacrifice.

"Um, well being a nurse, you know, ah, [I am $]$ a giving person." (page 5, line 33)

The spiritual journey of participant 7 has been extremely influential at different key moments in her life. She recognized that sacrificing self-serving attitudes and instead looking for the good in others has enabled her to become a better person.

"I think a spiritual person is a good person. Someone who's kind and generous and thoughtful. I just don't judge nonbelievers and believers and so to me a strong spirituality is a kind and good and giving person and it's that simple." (page 18, lines 19-22)

Prior to becoming a caregiver, participant 2 was able to go about doing things in life that he wanted to do. Caregiving has changed his approach to life. Now he has had to sacrifice doing those things that brought him enjoyment and instead focus on his mother. 
"But now that you know you take care of a person your whole life changes because you really can't, like how do I say, like you really can't, ah (PAUSES), you have to care, you know. You have to care now." (page 8, lines 23-25)

There were two caregivers that had to sacrifice many things in their lives to attend to the needs of their loved one. Both participants 9 and 10 shared how they have had to make sudden changes in their lives when they became caregivers. They have discovered that putting their lives on a pause has resulted in profound loses in their lives.

"[O]ur life is kind of at a standstill. Um, well, we're not socializing. We used to get together with friends and play games on the weekends. He's not able to do that anymore and since he can't carry on a conversation, I've noticed that people aren't coming over and we're not getting invitations." Participant 9 (page 2, lines 26, 31-33)

"Oh yeah. I'm sacrificing everything in my life for her. I've given up a lot and I'm sacrificing, and I know so many people that they [tell] stories of putting their parents in a home and they don't have that burden. They go, oh yeah I know what it's like and, but they just go on visits. They don't know what it's like being a 24/7 [caregiver] and the only person and, yeah. I just, my life's on hold." Participant 10 (page 12, lines 40-46 to page 13, lines 1-2)

Belonging. The significance that comes from being a member of a group was mentioned in many of the interviews. In some cases, these groups referred to a spiritual community. However, in other cases, participants found that it was a connection to a secular group that brought them increased meaning. The demands of caregiving, however, did not always allow the participants to remain active in those groups. The theme "belonging" was identified through their responses, "having a belief in a higher being," "it is good to go [to church] and socialize," "there is another place we go afterwards," and "being a non-believer is not a bad thing."

In being a caregiver for her friend, participant 9 noted the importance of belonging to a church community in her journey. The connection with others that such a membership brought her was significant and now, it is sorely missed. 
“...it's [church] been important to me and, sometimes I feel a need [to go]. I always look forward to the Wednesday night because here we go to church, we sing a few songs and then we have a little bible study in the sanctuary, and it just helped break up the week and although, you know I pray on my own every day, but it's good just to go and socialize." (page 14, lines 17-22)

It was also important for participant 9 to express her spirituality in some manner while remaining a caregiver to her friend. She was rarely able to attend important prayer gatherings because she was unable to leave her friend alone. With the help of others, she found a strength in the private expression of her faith that sustained her connection to her church community.

“I don't know the bible as well I'd like to, but I have a friend who's urged me just to wake up in the morning and read on my own and so I have been doing that for about a month or so and it does kind of give you a peace for the day." (page 15, lines 6-9)

The caregiving role for participant 8 has been exhausting, both physically and emotionally. She has found having support from different individuals and groups has made this journey much easier to endure.

"We have a wonderful [hospice] nurse, Ruth, and the chaplain comes and the doctor. You know I think once a month she comes. I couldn't do it if I were here all day without a break. It would be very difficult." (page 4, lines 25-27)

"Well, um, to me because I am a, you know a religious person it's [spirituality], it's a belief in a higher being." (page 5, lines 23-24)

Participant 10 identified herself as being from the Catholic tradition. She has grown away, however, from the ritual practice of that faith, although she has a deep longing to belong to what God represents and offers.

"God and there's another place we go afterwards and, um, learning to accept death and I guess I'm looking that direction because that's what's happening now and (PAUSES), right now I'm just like, my chest is like breathing real hard right now. It's just hard to answer. Just thinking that spirituality. I want to be more spiritual, I guess, but I'm kind of lost because of all these things that have been going on." (Page 10, lines 34-36, 40-41) 
"I was spiritual and believed in Christianity, but my beliefs were that you didn't have to go to church all the time to be a good person. I mean that is more than anything, being nice to everyone. Being caring. Being loving. Just compassionate in life didn't have to mean going to church." (page 11, lines 16-19)

Of the three participants who identified themselves as not being spiritual, only participant 3 explained in detail how she came to become comfortable as a non-believer. Her family had made several changes in the expression of their faith over the years. Yet, her questioning attitude is what ultimately led her to this peaceful place of being a member of the community of non-believers.

"I'm escaping towards the, um, realization that being a nonbeliever is not a bad thing. It just happens, as I've said to my daughter, um, (PAUSES) you know not to burden her with the thought that, oh my God, mom won't go to heaven, you know. (PAUSES) I would say to her if there is a God in heaven and he is a God of love, he'll look at me and say, Judy, you silly thing, come on up here and I'm going to have a, you know give you a hug. I'm going to be accepted by God if, as I said, if all those things are true because I haven't taken a, um, how should we put it, an angry or, um, I'm trying to think of the words. (PAUSES) I have come to my nonbelief through a sincere journey of investigation and for me the answers that I needed were in the realization that for me belief was not essential for me." (page 18, lines 11-20)

In summary, the participants of this study were initially reserved in their comments on spiritual feelings. However, when approached first from a general understanding of spirituality they were more open to discuss their personal feelings on spirituality. The experiences shared by the caregivers suggested that spirituality was both important and distinct from religion. The majority of caregivers in this study conveyed a sense that God/spirituality dwelt within the individual. This understanding of God/spirituality created a feeling of hopefulness for the caregivers that they too would experience being cared for in their journey. 
The textual analysis of the participants' responses identified four themes of the experience of spirituality in the context of the study's setting: Presence, Trust, Sacrifice, and Belonging. Of note, an extended reflection and analysis of each of these themes identified "presence" to contribute to a deeper significance of the study phenomenon. This was because the participants described "presence" as enhancing their sense of hopefulness in their caregiving role. They expressed that the feeling of hopefulness was strengthened in their belief in God/spirituality listening to them, protecting them, and sharing in their experience of caregiving.

\section{Line of inquiry \# 3: Explore, if present, the spiritual meaning of providing care in home to a person with dementia.}

The caregivers highlighted the importance of the relationship they share with their loved one during this time of caring for them in the home. Many of the caregivers indicated that the responsibility to care for their family member brought value to their own purpose in life. The caregivers recognized this time as an opportunity to further enhance the meaning of their relationship both with their loved one and with God.

The textual analysis identified four themes related to this third line of inquiry. "Duty" was the first theme to emerge. This was the idea that the caregiver's relationship with their loved one, and in some cases with God, had created a sense of duty to care for

this family member until the end. The second theme was "Freedom." Also relationshipbased, this meant the relationship between the caregiver and loved one was able to flourish without limitations as a result of providing care in the home. The third theme was "Strength," meaning the caregivers persevered in their role because of a determination that they were aware of in themselves or that others pointed out to them. 
Finally, there was the theme "Dedication," indicating the daily challenges of caring for their loved one did not diminish, but rather, emboldened the caregiver's resolve to provide loving care in the home through the dying process. These themes are discussed in the section below.

Duty. The caregiver's relationship with their loved one, and in a few cases their relationship with God, was important to their experience. Those relationships nurtured a feeling of duty within the caregivers to provide care in the home versus placing their family member in a skilled facility. This was also referenced as a moral obligation for a few of the caregivers. In some cases, there was advanced discussion about their loved one's wishes that made this decision easier. There were other examples, though, where the caregiver acted out of a sense of duty to care for their loved one in the home even when they would have chosen otherwise. In most descriptions, the caregivers expressed a feeling that the duty to care was one that allowed them to remain connected to their loved one in a meaningful way. The responses of the participants, "I always felt like it's my duty because I did get more," "I just can't see putting my wife in a situation like that," "never put me away," "we are honoring their request," and "I want to say maybe loyalty to not just shove him out," have contributed to the identification of "Duty" as a theme.

While growing up, participant 1 felt her experience was vastly different from her siblings. In part because of this difference, she felt an indebtedness to her parents to be there for them as they go through the end of life experience.

"I guess in a sense, it's kind of like a moral obligation because she did it for me. And just, it just feels like a moral commitment, a moral obligation as a daughter." (page 1, lines 11, 13) 
"But I always felt like it's, it's been my, my duty because I did get more. To you know, to kind of pay it back in a sense." (page 7, lines 22, 24)

The parents of participant 7 shared with her their wishes for end of life care

before they became ill. Because of this, she recognized that it was her duty to honor that request for both her father, who died previously, and currently, her mother, providing them with the love they desired at the end of life. The connection she experiences with her mother reassures her that she will be in a secure place of love.

"Yes, it was both of my parents' request not to be put in a home. They didn't want to be abused. They didn't want to be a, you know, crazy person sitting in a wheelchair with no love. They wanted their loved ones around them. That's what they wanted. So, we honored that request by having my dad live with me the last eight years of his life and we're honoring that request now by having my mom stay at home with caregivers and my brothers and I are there a lot." (page 22, lines $7,11,15-18)$

The husband of participant 6 had a strong fear of being lost in a nursing home.

While she could never determine what caused that fear or what he meant by being lost, she feels obligated to keep her promise to care for him at home. This participant expressed an understanding that caring for her loved one in the home allowed her to remain connected to him in a meaningful way. She also acknowledged a feeling of honoring God's allowing her to care for her husband at home.

"I see that (PAUSES) the Lord's giving me, is allowing me to take care of him and I'm happy that I can take care of him. I am happy that I can do it and make him feel secure. I tell [him] I will take care of you always and because I think he knew or he suspected he asked me not only one time, he asked me oh I will say half a dozen times never to put him in a nursing place. Never put me away please and I promise him that I will never put him in one of those places." (page 17, lines $37-44)$

The importance of family has had a strong influence on participant 2. He believes the relationship between family members includes a duty to take care of a loved one in the home until death. In doing so, he feels the caregiving experience allows him to 
remain connected to his mother in a way that he would not experience if she had been in a nursing home. This is what has motivated him to serve as his mother's caregiver.

"No, there was, you know, nobody going to take care of my mom. So that's when I stepped up to the plate and I did it. You know I didn't understand anything of it. I don't know I just did it. You know and I can't see my mom being thrown to a convalescent home and then nobody cares and you know my mom had kids and you would expect them to take care of their own mom, you know, but, I just took on the role and I just pushed everybody out of the way and then I took on the role." (page 9, lines 23-25, 29-33)

In being long time live-in friends, participant 9 has encountered some unique challenges. The biological children of her friend have been reluctant to be involved in his care and consider him to be in a safe environment at her house. Despite her frustration and concerns about her own health, she recognizes a sense of obligation to her friend and a feeling of remaining connected to him, which has helped her continue to care for him in the home.

"I want to maybe say loyalty to not just shove him out. I mean we're not married but we act as man and wife and so I keep thinking, well, if we were married, I would be caring for a husband, you know, but on the other hand, my son is worried about my physical health and I worry about that too, the stress." (page 15, lines 28-31)

The experience of seeing others in a nursing home has had a powerful impact on participant 5. Reflecting back on those encounters and the meaning of his relationship with his wife has led this caregiver to conclude his wife deserved better than that level of care. He made a commitment, and one he is determined to keep, to care for his wife at home. This duty to care for her at home has allowed him to feel that he is providing a secure place of love until the end.

"Well, I guess I experienced two or three people that have been in nursing homes and visited with them and observed the level of care that they get and I mean they're fed and kept warm and bathed but other than that they're just sitting in a 
wheel chair looking at a television set with no love or brain, mental stimulation at all and I just made a decision I was not going to put my wife through a facility that they're going to be sitting in a room with 10 or 15 other people and without really no one really caring about them other than taking care of their physical needs. And I visited several people that I've known had strokes or had to go to a facility like that and physically they're taken good care of, but they get no, very little real stimulation. No one really talks to them and no one plays cards with them. No one discusses with them. No one asks them questions. They're just sort of there and I just can't see putting my wife in a situation like that." (page 7, lines 23-29, 33-37)

The professional experience of participant 8 as a nurse is something that has formed her opinion of nursing homes and the type of care a person receives in those facilities. This assessment has prevented her from being able to place her mother in a nursing facility.

"I would never have her go to an assisted living. She would not be alive now if she had. Sadly, assisted livings is, well, as a nurse you know, there's just never enough hands and, ah, yeah. No." (page 6, lines 25-27)

While many of the caregivers understood that providing care in the home was a duty or obligation, this was not the case for participant 10 . The decision to care for her mother at home was not her first choice. She has pleaded with hospice staff to help her find a more appropriate place for her mother.

"Financially, I can't afford it [placing in a nursing home] and she doesn't quite qualify for the hospice home care. So, Medi-Cal, there's a two-year waiting period. So that's out of the question. So, there is isn't a choice. That's why I begged them. I go I'm here alone. I'm not with any family. Can't you do something more for me to get her into some place?" (page 14, lines 2-4, 9-10)

Freedom. There was a clear indication the participants in this study did not want to have their relationships with their loved one restricted in any fashion. They also expressed a desire to nurture and heal, where necessary, the relationship they have shared with their loved one. Most caregivers believed this would be best accomplished through caring for their loved one in the home. The theme "Freedom" emerged through the 
participants' responses, "It makes me feel more comfortable. I can go anytime to see her," "I am better right here with him right now," "family members were not allowed to stay at night," "I would have no communication with him at all," and "you learn to just let it [the resentments in life] go."

There were several participants who expressed a strong desire to maintain a connectedness with their loved one. They wanted the ability to interact with them at any time of the day or night. This was something they feared would be taken away if their loved one was placed in a nursing facility. The caregivers did not want to have any limitations placed around their ability to interact with loved one.

"I think for me is that I want to be able to be with her as much as I can and knowing that I do have the possibility of doing that at home. It makes me feel more comfortable. I can go anytime see her. It's just in a facility, you would have your limits. You will have hours and I don't want limitations. I don't want a schedule and I just want to be, I just want her to be with me through the end and knowing that I did that for both of us and having her in a facility, it wouldn't be as possible to get away to be with her as it will be as convenient to have her at home." Participant 4 (page 16, lines 37-43)

"Because I'd be running up there every day anyway. You know it. Just to be sure that he's clean, cared for, fed, what have you. So, my life would actually be more stressed. Yeah, I'd be getting up, getting dressed, driving to some facility, sitting there for hours. He'd be sedated. He wouldn't even be able to, well not that he talks now, but I would have no communication at all with him because he would be out of it. Um, and we'd go on day after day. So, I'm better right here with him right now." Participant 3 (page 3, lines 29, 33, 37-42, 46-47 to page 4, lines 1-2)

"Well, she was in the hospital and then in that rehab. She was only in that rehab for three days. My brothers were going nuts, but I knew that if she came home, everything was going to come down on me and those two took over and brought her home and this was Saratoga Rehab, which you know Saratoga is supposed to be the best, but then we read their reviews and they weren't really the best and that's why my brothers wanted to bring her home, and none of us could stand the fact that she was there in that place by herself through the night because no visitors at night and no in the rehab, family members are not allowed to spend the night. You get kicked out. So, we couldn't stand that." Participant 7 (page 24, lines 21-28, 32) 
The time providing care for her husband was for participant 3 a gift to work through any pains in their relationship. She acknowledged this was an experience of freedom that enabled her to be even more present to her husband.

"...so, I personally have been able to work through some of the difficult periods of our marriage. I can't talk to him about them (LAUGHS), but I never did when we were married. So, you learn to let it go. Just let it go, don't carry around any old resentments. I remember when you said that to me or when you did that and whatever and why did you say that and whatever. No, just let it go and the longer it goes the more time I will have to let it go. Just because in the end, it doesn't matter." (page 19, lines 18-24)

In a similar way, participant 1 has discovered through the process of caring for her mother at home that she has been able to work through past hurts. This reconciliation has provided an experience of freedom that allowed for a more positive relationship to be established between her and her mother.

"I feel that because I did have the opportunity to kind of work with all that stuff [hurt feelings from the past], right now I can have, it's kind of like I can start fresh. With that relationship now. . . [I] think it's a positive. Because I have more nurturing feelings toward her." (page 19, lines 2-9)

Strength. The participants in this study made reference to how caregiving was possible because of an inner strength they discovered through this process. Some were aware of this inner strength before they became a caregiver. Others discovered their inner strength during this time of caring for a family member. In many of the descriptions, the participants' responses supported the understanding of strength in building confidence in themselves while remaining hopeful in their ability to care appropriately for their loved one. The words that they shared during the interview such as "you really have to have that want in your heart," "caring for him has made me reach down for the best that is in me," "it [hospice services] makes me feel more secure and 
confident to care for mom," and "they [the hospice team] always tell me I am doing a great job," contributed to the identification of "Strength" as a theme.

The work of being a caregiver is something that participant 2 has discovered requires a strong determination. To persevere as a caregiver, he has had to find that strength in the mind to learn and in the heart to care for his parents.

"No, you just have to be, you know you really have to be strong minded. You really have to have that want in your heart, you know. It's not only oh you have to because you know it's your mom or your dad or one of your siblings. It has to come from your heart that you want to do it and you really have to be strong" (page 13, lines 10-15, 19, 23-26)

The caregiving role has many day-to-day challenges. Participant 3 realized she had to go deep within herself to find the inner strength to surmount these difficulties. It is that inner strength that maintains her hopefulness to care for her husband to the end.

"I say, caring for him has made me reach down for the best that is in me because there are days, let me tell you when you think I can't go on and then you say to yourself, but you go on. Yes, because that moment will pass and you will go on and, hey, there will be an end. I don't know if I'm strong enough to do that. I've never actually cared for a dying person but I'll have Stacey, my hospice nurse, and she's a great lady. I love that girl. She said, Judy, I'm here for you. You need me, you call and I'll be here. So, with Stacey and I, we can do it. Yeah, we should be able to, hopefully." (page 19, lines 34-42)

The availability of the hospice staff to come into the home of many of the participants has made caregiving possible. Many of the caregivers acknowledged the gratitude they have for the hospice team's support. They are hopeful, because of this strength, they will be able to keep their loved ones in the home during their final days. It was the advice on what to expect, assistance on how to care, and the brief respite offered during hospice visits that provided strength for these caregivers.

"We are very fortunate, and I am so grateful, and I tell them. Every time I see them, I tell them I am very grateful. Thank you very much because it's very important for the caregiver to see the nurses treating the loved one with, with a 
professionalism and also with compassion and respect." Participant 6 (page 6, lines 19-22)

"I'm very grateful for the hospice nurse who comes and my little Friday hospice volunteer David. He comes for two and a half hours Friday mornings. Priceless. I just get that little opportunity to get out and do a little shopping or what have you. So, absolutely, wonderful to have that assistance in my life at this time you know." Participant 3 (page 2, lines 3-10)

"So, it's been good experience with the hospice employees. With all, Martha and Stacey have given me a great deal of information on how to handle a situation with my mom and that makes you feel good and it makes you feel more you can go in and do a good job. So, it has been a good experience. With hospice, yes, in the six or seven months that we're in it doesn't seem long, but it does help." Participant 4 (page 19, lines 15-30)

Dedication. The caregivers recognized this time as an opportunity to reflect back on the relationship they had shared with their family member. This reminiscing has helped them discover meaning and peace as caregivers. It was remembering the bonds formed within their relationship through the years that now fortified their resolve to care for their family member in the home. The theme "Dedication" was identified through the examples provided in the responses of the participants such as "I have a sort of little routine like that that I go through every day," "give him all the care he needs, all the love that I can give him," "one cannot care for someone like this without compassion ... I think it was essential that we go this route," and "when it [caregiving tasks] is organized the day goes easier."

In providing care at home, participant 5 has been able to be a part of his wife's daily care. He is dedicated to performing, amongst other care tasks, different mental exercises with his wife in the hope of slowing the progression of her dementia.

"I can daily quiz her on how long we've been married and who our children are and who are grandchildren and where she went to college and where she went to school and her first pets and, I have a sort of a little routine like that I go through every day and even though it gets smaller and smaller her memories, it's still 
good. I think it keeps, it delays the process of her memory loss. That makes me feel real good because some days she won't remember anything and other days it's almost like it comes back." (page 8, lines 2-6, 10-11)

This time of caring for her mother at home has reminded participant 7 about the generosity of her parents. Because of this generosity, she is dedicated to maintain a loving relationship with her mother through death. By caring for her in the family home, participant 7 has found more opportunities to hold, touch, kiss, and be near her mother that would not have been possible had she been in a nursing home.

"Oh, it's [caring for her mom in the home] really, it's really enhanced it [their relationship], you know, especially physically. You know we're physical together, loving each other physically. It's very beautiful." (page 24, lines 10-11, 15)

It has been the many small moments of doing a task for her husband that has kept participant 6 dedicated to the role of caregiver. She understands these times to be enriching experiences for their relationship that she cherishes.

"It is a lot of little things, if we can put it like that. When he wakes up and I see a smile on his face and I see that there is life in his eyes, he sit down and eat a good breakfast, a good meal, ah, (PAUSES) he's here. He's with me and, ah, (PAUSES) I give him the best care that is possible and all my love. The hospice team accuse me that he's here because of me because all the care and all the love and everything I give him. That's my purpose to give him all the care he needs, all the love that I can give him and tell him so. I tell him many times over and over and I love you, you're my love, I love you. I talk to him a lot. I don't know, and I don't care, if he doesn't understand, but I think he recognize my voice and I tell him oh we have a whole life together. So, we have lots of things to talk about." (page 9, lines 1-10)

The caregiving role for participant 3 has required her to search deep within herself for inner strength. She has taken that core determination and combined it with compassion to help her remain dedicated to the care of her husband.

"Oh, one cannot care for someone like this without having compassion. You have to have compassion for them. Um, you know they can be very difficult because often times they don't know what you're doing for them and they don't appreciate 
it, but sometimes, occasionally a thank you comes through. Yes, so it goes without saying that he does understand that I am there for him, and (PAUSES) I think it was essential that we go this route." (page 19, lines 13-18)

Early in the caregiving experience, participant 2 recognized there were many tasks associated with caregiving. He was dedicated to keeping his mother at home and looked to place structure around his caregiving experience that would help him meet this goal. In scheduling each day, he discovered that he was able to enjoy each moment with his mother.

"It is emotionally draining too, you know, and, physical. You know you get drained and, you know I think about everything, but you just rest up and you just do it again (LAUGHS). Yeah, to me I hit it straight on. You know I don't sit there and go oh well, you know you just do it. Let's get this rolling. Let's get it on. And that's why like here when I have a caregiver, you know I do have a game plan, you know and that's why it works seven days a week. And that's the way I want it like that. I don't want it disorganized. And when it's organized the, the days go easier." (page 11, lines 22-24, 28-29, 33, 37-38, 42, 46)

The caregivers described the experience of having the opportunity to provide care at home as enriching the relationship they shared with their loved ones and, in some cases, with God. The experiences the participants shared were filled with descriptions of the importance of remaining close, physically and emotionally, during this journey. In being near their loved one as that person approached the end of life, the caregivers were able to focus on the significance of their relationship to their family member and with God. The participants' experiences of caring for their loved one at home conveyed a feeling of confident expectation for these relationships to remain vibrant and meaningful to the end.

The data contained within their responses supported the four themes that emerged: Duty, Freedom, Strength, and Dedication. While all four themes addressed the third line of inquiry of the study, a deeper reflection and analysis of each theme identified 
"duty" and "strength" as contributing substantially to the understanding of the overall study phenomenon. The participants described "duty" as a feeling of remaining connected to their loved one while providing a more secure place of love during the final days. The theme "strength" was the understanding that the participants had an interior quality that promoted self-confidence and hopefulness in being able to provide end of life care to their loved ones.

\section{Essence of the Lived Experience}

According to van Manen (1990), the purpose of a phenomenological study is to arrive at a "deeper understanding of the meaning of our everyday experiences" (p.9). This requires the researcher explore a particular phenomenon of interest with individuals who have already experienced that phenomenon. Their reflection of the lived experience contributes to the understanding of its essence, or that which makes a phenomenon what it is. The essence, then, of an experience is unveiled when the descriptions of individuals show the "significance of the experience in a deeper manner" (p.10).

The work of phenomenological writing in this study allowed for a deeper reflection and analysis of the participants experiences. According to van Manen (1990), an extended analysis of study themes will eventually "reawaken the lived quality and significance in a deeper manner" (p.10) of spiritual well-being in family caregivers of persons with dementia on palliative care living at home. Underpinning the essence of the lived experience was uncovering the structures of the phenomenon by examining more deeply the particular experiences of the participants. The analytic process of writing and rewriting, then, "adequately described in language the significance of the lived 
experience" (p.10) through the following: (a) being connected; (b) duty; (c) hardships; (d) strength; and (e) presence.

According to van Manen (1990), any object "real or imagined, empirically measurable or subjectively felt" that we are aware of in our human consciousness is a part of our lived experiences (p.9). Furthermore, the essence of a lived experience can only be "grasped through a study of the particulars encountered in lived experience" (p.10). The five themes from this study mentioned in the preceding paragraph have contributed to the most adequate grasping of this phenomenon discovered in the experiences of the participants.

The themes "being connected," "strength," and "presence" each express a feeling of hopefulness in the caregivers' understanding of their role. The participants shared how these themes enhanced their understanding of meaning and purpose as caregivers to their loved ones. All themes identified the importance of the relationship between the caregiver, the person with dementia, and God/spirituality. The themes "hardship" and "duty" acknowledged the challenges of the caregiving role, while at the same time recognizing the importance of being connected to their loved one in a way that ensured they could care for them in a safe place of love until the end. The themes "being connected" and "presence" identified the significance of the relationship between caregiver and loved one and included the importance of the relationship to God/spirituality. Finally, the theme "strength" uncovered the understanding of the caregivers' relationship with self and with other support systems, most notably with the hospice care team. As a result of this deeper reflection and analysis, the essence of this phenomenon was revealed. 
Spiritual well-being for caregivers in the context of this study, therefore, is the feeling of hopefulness that is the result of being connected through meaningful relationships with the caregiver's own self, the person with dementia, and God.

\section{Summary}

This chapter has presented the findings of the study that examined the lived experience of spiritual well-being amongst informal caregivers of persons with dementia on palliative care living at home. It presented both the description of the participants' characteristics and the thematic analysis of participant responses related to each line of inquiry. There were 10 family caregivers who agreed to participate in this study. Each encounter began with the participants completing a brief demographic survey. This was followed with their providing responses to interview questions. All interviews took place in the caregivers' homes. The thematic analysis identified four themes in each of the study's lines of inquiry. The participants' own words were included as direct quotes to provide a robust description of how these themes emerged. The themes identified in the first line of inquiry were isolation, hardships, awareness, and being connected. In the second line of inquiry the identified themes were presence, trust, sacrifice, and belonging. The themes identified in the third line of inquiry were duty, freedom, strength, and dedication. Finally, an essence of the experience was presented. The following chapter will discuss these findings and how they contribute to body of literature. 


\section{Chapter 5}

\section{Discussion}

This phenomenological study explored the lived experience of spiritual wellbeing amongst informal caregivers of persons with dementia on palliative care living at home. This chapter will begin with a summary of the study's findings followed by a discussion of those findings and their contributions to the body of literature. The study's limitations and strengths will then be reviewed. The chapter will conclude with a presentation of the significance of the study to further research.

\section{Summary of Findings}

In the review of literature in chapter two, it was noted there has been a growing interest on how spiritual well-being affects health outcomes. The focus has been, and continues to be, predominately on the relationship between spiritual well-being and the overall health in patients (Bai et al., 2015; Salmoirago-Blotcher et al., 2012). However, with the rapidly expanding need of patients to receive caregiving assistance at home, researchers have begun to examine the effect of spiritual well-being on the health of informal caregivers (McClain et al., 2003; Sun et al., 2016; Yeh \& Bull, 2009).

While there has been a developing body of literature on spiritual well-being and its relationship in populations of caregivers to persons with chronic illnesses, there is a paucity of research in the population of caregivers to persons with dementia who are on palliative care. This absence included no known attempt to interpret the meaning of spiritual well-being in informal caregivers of persons with dementia on palliative care living at home. In recognizing this gap in knowledge, a qualitative study using a 
phenomenological approach was most appropriate for this study's purpose of exploring the lived experience of spiritual well-being in this caregiving population.

To understand the meaning of the phenomenon of interest (spiritual well-being), this study was designed with three lines of inquiry. First, it examined the lived experience of individuals who provide care to a family member with dementia on palliative care and living at home. The unique experience to each participant was explored through specific questions on meaning, purpose, inner peace, and support. The description of their experiences included a general perception of not understanding the impact the caregiving role would have on them. In some instances, the caregivers revealed that trusted health care professionals had not prepared them for this role. The data from participants' responses supported the themes isolation from others, hardships, awareness, and being connected to the patient.

A second line of inquiry was to identify any spiritual feelings experienced by these family caregivers and explored what these meant within the context of spiritual well-being in this setting. The caregivers were asked to describe how they experienced spirituality before taking on this role and then how it has been experienced in the time since becoming a caregiver. Their description of spirituality conveyed a sense of hopefulness that the relationship they had with a higher power would sustain them through the caregiving experience. The themes that emerged from the data were presence, trust, sacrifice, and belonging.

The final line of inquiry explored any spiritual meaning that caregivers may have attributed to caring for a family member with dementia at home while on palliative care. This was discovered by asking the caregivers to describe both the decision-making 
process that led to caring for their loved at home and how that choice may have subsequently affected their relationship to the family member with dementia. For most of the caregivers, there was little understanding of what palliative care meant when they began receiving these services. However, over time they were able to recognize it as having a profound importance in the overall experience of caregiving. The responses of the caregivers supported the following themes: duty, freedom, strength, and dedication. In the case of each line of inquiry, if necessary, follow-up questions were posed to the participant to arrive at an even richer description of their experience of the phenomenon.

The purpose of phenomenological research is to provide a description, when possible, of the phenomenon of interest. According to van Manen (1990), "Writing gives appearance and body to thought" (p.127). The phenomenological method of reading, writing, listening, and rewriting was essential to arriving at a description of spiritual wellbeing in the context of this study's setting. This process supported the understanding of spiritual well-being as a multi-dimensional phenomenon described in the previous chapter (Chapter 4, p118):

"Spiritual well-being for caregivers in the context of this study, therefore, is the feeling of hopefulness that is the result of being connected through meaningful relationships with the caregiver's own self, the person with dementia, and God."

\section{Reflection on Findings}

As noted in chapter one, dementia is a disease that ultimately requires the person with dementia to receive caregiving assistance. In many cases, this assistance is provided in the home by a family member. Currently, there are approximately 16 million Americans who have taken on the role of caring for a loved one with dementia (Caregiver Action Network, 2014). This section of the chapter will examine the characteristics of 
the caregivers in this study and compare those findings with findings found in the literature. A reflection will follow that places the participants' lived experience of spiritual well-being in the context of the caregiving literature.

\section{Caregiver Characteristics}

The characteristics of the participants in this study were consistent with what is reported in the literature. Peacock, Duggleby, \& Koop (2014) enrolled a sample of family caregivers to persons with dementia at the end of life who ranged in age from 49 to 89. Of the sample, $64 \%$ were female. These characteristics are also supported by the Alzheimer's Association annual report "Facts and Figures." In its 2018 report, the Alzheimer's Association noted that $83 \%$ of dementia caregiving is provided by informal caregivers (a family member or friend), 34\% are 65 years or older, and $67 \%$ are females.

The National Center on Caregiving (2018) reports that $85 \%$ of caregivers are a family member and of those, $42 \%$ are adult children. While the report shows no distinction in patient diagnosis, this percentage is notably lower than the $60 \%$ of adult children providing care in this current study. However, in one 2012 study, $71 \%$ of the family caregivers of persons with dementia who participated were adult children (Navab, Negarandeh, \& Peyrovi, 2012). The absence of a spouse to the person with dementia in their study, though, may have contributed to the higher than average number of adult children taking on the role of caregiver. Additionally, the length of time on palliative care was higher in the current study than what was reported by the National Hospice and Palliative Care Organization. The extant study utilized participants whose loved one with dementia received early referral to palliative care. This may be one reason the current study's data in "length of time on palliative care" exceeds what was reported by the 
National Hospice and Palliative Care Organization to be the mean length of stay on hospice services: 104 days (National Hospice and Palliative Care Organization, 2017).

The Pew Research Center conducts an annual "Religious Landscape Study" that assesses the size and demographics of the different religions practiced in the United States. The results can be viewed nationally, regionally, and locally. For the purposes of this reflection, the San Diego Metro Area demographics from the 2018 Religious Landscape Study were viewed. According to that study, the three most identified religious affiliation for adults in San Diego are Catholic (32\%), Mainline Protestant (16\%), Evangelical Protestants (14\%), and "none" (27\%) (Pew Forum, 2018). These are consistent with the findings from the current research other than the $30 \%$ of participants identifying as Protestant (Mainline and Evangelical). The same study identifies daily prayer $(56 \%)$ as a frequent activity for these adults, while weekly attendance at church is much lower $(31 \%)$. This is slightly higher than the findings of the current study that reported $50 \%$ of the participants engaging in some form of daily prayer, and $20 \%$ attending church weekly.

\section{Caregivers' Lived Experience of Spiritual Well-Being}

The caregivers in this current study were unwavering in their identification of the importance of relationships to their overall caregiving experience. They described this relatedness as belonging to church and community groups, being connected to their loved one, and having the opportunity, through the assistance of palliative care services, to spend unlimited time with the person with dementia. The significance of relationships for these caregivers is consistent with what is found in the literature related to spirituality. The relationships with self, others, and the Sacred are all attributed to the meaning of 
spirituality (Acton \& Miller, 2003; Burkardt, 1989; Penman et a.,, 2009; Tanyi, 2002). In a study by Day, Anderson, and Davis (2014), a major theme that emerged was "attachment" to the person with dementia. This theme conveyed the caregivers' understanding of the role as providing the opportunity to share positive experiences with their loved one. This is consistent with the description of "being connected to the patient" "belonging," and "freedom" in the current study.

As mentioned previously, there has been, for over 30 years, a strong interest in the effects of spirituality on a person's health. The research on spirituality has reported that caregivers who have strong social support systems or high levels of spiritual well-being are less likely to experience depression (Kaye \& Robinson, 1994; Yeh \& Bull, 2009). Conversely, a study by Papastavrou et al. (2007) has shown that when caring for a person with dementia in the home, the caregiver experiences increased relational deprivation. The results in this current study suggest those findings are accurate. Several of the participants described how caring for a person with dementia has left them often feeling isolated from others and unable to participate in many of the social activities that were meaningful to them. However, the participants did not describe this feeling of isolation as contributing to experiences of depression.

In some studies, caregiving has been documented as a cultural expectation of family members to care for another (Benedetti, Cohen, \& Taylor, 2013; Lee Casado, Lee, Hong \& Hong, 2015). This was not found to be the case with the participants in this current study. However, as noted in a study by Mars et al. (2017), the emergence of the theme "obligation" was consistent with caregivers in this research who understood their role to be a necessary response to a family need. Some referred to this as an obligation or 
duty, while others conveyed that it was the right and only thing to do in the moment. In all but one case, the caregivers believed their dedication to this role enabled them to grow closer to their loved one. Similar to previous research, these caregivers described their commitment to the caregiving role to include maintaining a closeness to their loved one and having the opportunity to share important moments (Acton \& Miller, 2003; Kristanti et al., 2018; Penman et al., 2009).

The family member caring for a person with a progressively debilitating illness like dementia is often confronted by different challenges. In a study by Mars et al. (2017), a theme that emerged from participants' experiences of caring for a loved one with Alzheimer's disease was "an arduous journey." The researchers described this as the amount of hard work that was required of them. This responsibility was overwhelming at times and often very stressful. In Day et al. (2014), the theme "strain" was identified by their participants. This theme expressed the tremendous amount of stress that caregivers experienced resulting from the caregiving duties placed upon them. The findings of this current study are consistent with these previous studies, particularly the identification of the themes "hardships" and "sacrifices."

Many of the participants in this current research commented that initially there was little change in the relationship with their loved one. However, in time everything abruptly was put on hold. The person with dementia could no longer engage with the caregiver as they once did, leaving the caregiver to make several sacrifices in their daily routine. In most cases, the caregivers in this study were not prepared for the struggles they were to face in their role. These struggles were either physical or emotional and have been referred to as "burdens" in the literature (Gallagher et al., 2011; Spurlock, 
2005). The data from this current study, though, supports a deeper understanding of these struggles as "hardships."

While not explored specifically here, there is literature that suggests that spirituality includes an inner energy that allows a person to address life's hardships and eventually arrive at an inner peace (Hodge \& Sun, 2012; Lepherd, 2015; Reed, 1992). Some participants in this current study made reference to a conscious awareness of something inside that sustained them in the caregiving role. While not directly referring to that conscious awareness as an inner energy, a few of the caregivers were quite demonstrative when speaking of this awareness. They used their hands to point towards their chest indicating there is something inside of themselves that gives significance to the caregiving role. Yet for some of the caregivers, this conscious awareness did not appear in their descriptions of the experience attributable to an inner energy that is a part of spirituality. Likewise, most participants in this study found the focused attention on their loved one that was required as a caregiver to be stressful. Because of that experience it was challenging at times for the caregivers to be aware of inner peace.

For many participants in this study, each day brought something new about caregiving they had to learn how to handle. In some situations, the caregivers were unsure of their ability to perform one particular caregiving task or another. They were dependent upon the guidance of their hospice care teams to learn what to anticipate as the disease progressed. This is consistent with the findings of Day et al. (2014) that identified the themes of "uncertainty" and "doubt." The participants in their study were fearful of an adverse outcome as a result of something they did or did not do for their loved one. In another qualitative study by Kristanti et al. (2018), the theme "problems 
with caregiving" emerged. One category of that theme was "challenges," which they described as concerns by the caregivers of their ability to provide quality care. The challenges these caregivers faced reflected their worry about changes in their loved one and whether they would be able to cope as those changes appeared.

The caregivers who participated in this study revealed a belief in an ever-present higher power. This belief is what provided a sense of hope that sustained them in the caregiving role. They most often experienced this hopefulness through the act of being present with their loved one. For those who expressed a specific faith, it was through that belief that God was revealed to them in their caregiving role. In the case of those who did not follow a particular faith tradition it was the caregiving role that revealed an inner belief in themselves. In Mars et al. (2017), the theme "faith in God" emerged from their participants' descriptions. This theme conveyed the belief that a higher power would enable them to cope with their caregiving duties. The category "faith" under the theme "beliefs related to caregiving" in Kristanti et al. (2018) described the caregivers' values as they related to religion. It was these values that strengthened their motivation to continue as a caregiver and in some instances, even helped them grow closer to God.

In summary, this reflection has situated the findings of this study in the context of the body of literature on caregivers related to spiritual well-being. The 10 caregivers who participated in this study provided descriptions of their own experience that, while they are not generalizable, were largely consistent with what has been noted in literature previously. The most notable missing characteristic in this current study was the absence of African American caregivers. This is an interesting finding given reports by the Alzheimer's Association that the incidence of Alzheimer's Dementia is twice as high in 
African Americans compared to White Americans in California (Alzheimer's

Association, 2018). However, only slightly more than $8 \%$ of all palliative care recipients are African American (National Hospice and Palliative Care Organization, 2017). The access to informal caregivers in this study was predominately from one health care organization. The ethnic composition of the population in that palliative care program is not known.

The lived experience of the caregivers in this study were congruent with the known literature on caregiving and spirituality. The importance of relationship and being connected noted in the participants' descriptions is similar to what has been written in the literature previously. These relationships promoted the feeling of hopefulness expressed by the caregivers in this study in their ability to continue in the caregiving journey. The belief in a higher power is what sustained their hopefulness. An important contribution of this study to the body of literature was identifying the theme "hardships" and differentiating it from "burdens." In making this distinction, this study is consistent with recent qualitative studies on the lived experience of Alzheimer's Dementia caregivers that identified similar themes. In reflecting on the findings of this study, it is clear that the lived experiences of these caregivers have made a valuable contribution to the literature.

\section{Limitations and Strengths of Study}

This study's pursuit of understanding the meaning of the phenomenon, spiritual well-being in the context of informal caregiving of persons with dementia on palliative care living at home, had certain limitations. The extensive experience of the researcher with both spirituality and palliative care was a potential bias during the interview process. 
This was addressed through journaling pre- and post-interview notes to recognize what may have influenced the researcher during a particular encounter with a participant. By doing this, the researcher was able to be more fully present to the experience of the phenomenon being described by the participants.

Another limitation was the group of participants that were invited to participate in this study. The qualitative design of the study employed a purposeful recruitment of participants. The intent was to ask informal caregivers from a variety of hospice organizations in Southern California to participate in the study. However, in the end all but one participant was from the same hospice organization. The inability to gain access to multiple hospice organizations may have limited the number of experiences that could have been expressed by other caregivers and descriptions of the phenomenon to this specific cohort of participants.

A strength of this study was that it was the first known study to explore the lived experience of spiritual well-being of family caregivers of persons with dementia on palliative care living at home. As discussed in chapter two, spiritual well-being is one component of a person's health-related quality of life. Prior to this study, it was unknown what meaning caregivers of persons with dementia on palliative care living at home would attribute to spiritual well-being. The only publication of the meaning of spiritual well-being has been a conceptual analysis published in Chinese. Therefore, this study's incorporation of concepts of spiritual well-being into the interview questions has supported the first robust description in English of the phenomenon.

Another strength of this study was the qualitative design. A value of qualitative research is the data is always being analyzed throughout the period of data gathering. 
This allows for the researcher to reflect on the participants' responses to interview questions throughout the research process. When necessary, additional probing questions were asked to help participants provide richer explanations of their experience of the phenomenon. For example, in this study, asking a participant to describe their personal spirituality was initially met with reservation. However, when the participants were asked to describe their general understanding of the concept of spirituality, they were subsequently found to be more willing to discuss their own spirituality.

Finally, the researcher's passion for spiritual well-being and palliative care was an additional strength of the study. The passion the researcher has for this lived experience was also obvious to the participants of this study. It created a connected space between researcher and participant that was safe and open to a dialogue about the lived experience of the phenomenon.

\section{Implications for Research}

The participants in this study were generous in sharing the story of their caregiving experience for a loved one with dementia. They described this experience as having enriched their relationships with themselves, the person with dementia, and in some cases, God. There were seven caregivers who had previously embraced that role for other family members. However, for all 10 caregivers, this was the first experience of having palliative care support.

The value of palliative care services in the caregiving experience was evident in the participants' stories. There was a perception, though, by all caregivers as not initially understanding the meaning of palliative care. Despite this, all caregivers explained how the support provided by their palliative care teams was instrumental in their ability to care 
for their loved one in their home. They shared that it was everything from educating them on managing the physical care of their loved one to the simple act of giving them time to step away for brief periods of respite that proved to be so significant.

The stories shared by this specific group of caregivers conveyed an anticipation of what is to come for them after the caregiving experience concludes. This anticipation gave meaning and purpose to their role. As well, it filled them with a hope to be strong in the moment and to remain connected to their loved one through the end of life. In arriving at a description of the essence of spiritual well-being through the exercise of phenomenological writing on the stories of their experiences, this study has provided a foundation for future research in palliative care.

\section{Nursing Research and Palliative Care}

Palliative care is a growing area of research interest. Much of that research to date, though, has been conducted by physicians. Nurse scientists can, and should, contribute important research findings related to the field of palliative care. This qualitative study has provided a phenomenological description of spiritual well-being amongst informal caregivers of persons with dementia on palliative care living at home. However, as noted earlier, this study was limited by the majority of its participants being from one palliative care organization. Future studies, therefore, should look to gain access to other palliative care organizations to further explore the caregivers' lived experiences of this phenomenon amongst different cultural backgrounds and at different points along the trajectory of the progression of dementia.

The results of this study demonstrated the distinction between palliative care and hospice care services was not well understood among these participants. This reality 
provides multiple opportunities for additional research. First, a study that explores potential barriers to how people understand these terms is warranted. Second, research is needed to examine the effect of early palliative care consults on health outcomes of both the patient and the caregiver. Finally, as noted in this study, the awareness of spirituality was more palpable as the person with dementia declined. Therefore, future research that compares the understanding of spirituality in the periods of palliative and hospice care is warranted.

\section{Nursing Research and Spiritual Well-Being}

The participants in this study predominately self-identified as being White. This is not surprising when more than $86 \%$ of palliative care recipients are White (National Hospice and Palliative Care Organization, 2017). However, a study that explores the lived experience of caregivers of other races and ethnicities is warranted. For example, the spiritual perspectives of African American and Hispanic caregivers would contribute to a more robust description of spiritual well-being.

It has already been mentioned that family caregivers identified belonging to a group as important to their understanding of spiritual well-being. They also revealed that the caregiving experience prevented them from leaving the person with dementia to attend those group gatherings. The use of mantram and other alternative medicine modalities in the home to reduce caregiver stress and improve spiritual well-being has been noted in other caregiving populations (Bormann et al., 2009). Future study in the caregiving population of palliative care patients with dementia using such interventions is warranted. 
The participants in this study described how being able to touch their loved one helped address the importance of being connected to them. There are a variety of alternative and complementary medicine modalities that have been used with success in reducing stress in some populations (Wardell \& Engebretson, 2001; Wilkinson et al., 2002). An interventional study using such modalities, for example healing touch, in caregivers of palliative care patients with dementia is recommended.

\section{Summary}

This study examined the lived experience of spiritual well-being in family caregivers of persons with dementia on palliative care living at home. Despite dementia being the third most common primary diagnosis of palliative care recipients, there has been limited research on the experience of family caregivers to persons with dementia. Furthermore, while spiritual well-being has been explored in other caregiving populations, little is known about the experience of this phenomenon by informal caregivers of persons with dementia in the palliative care field. This gap in knowledge made the qualitative design of this study ideal for arriving at a description of the phenomenon.

The family caregivers who participated in this study provided rich data to analyze as it related to the study's lines of inquiry and ultimate goal of arriving at a description of spiritual well-being in the context of this study. The analytic approach of van Manen (1990) helped identify themes for each of the study's lines of inquiry. Then, through process of phenomenological writing, a robust description representing the lived experiences of the participants emerged. This is a significant contribution to literature as it is the first known description of spiritual well-being amongst informal caregivers of 
persons with dementia on palliative care living at home. It acknowledges the value of their experiences in a deeper manner, enhancing their understanding of life's meaning and purpose, and bringing them a hopefulness through remaining connected to those they love, thereby, allowing their loved one to live fully until they die. 


\section{References}

Acton, G.J. \& Miller, E.W. (2003). Spirituality in caregivers of family members with dementia. Journal of Holistic Nursing, 21(2), 117-130.

Adams, R.N., Mosher, C.E., Cannady, R.S., Lucette, A., \& Kim, Y. (2014). Caregiving experiences predict changes in spiritual well-being among family caregivers of cancer patients. Psycho-Oncology, 23(10), 1178-1184.

Afzal, N., Buhagiar, K., Flood, J., \& Cosgrave, M. (2010). Quality of end-of-life care for dementia patients during acute hospital admission: A retrospective study in Ireland. General Hospital Psychiatry, 32(2), 141-146.

Alzheimer's Association. (2018). 2018 Alzheimer's disease facts and figures. Retrieved from http://www.alz.org

Bai, M., Lazenby, M., Jeon, S., Dixon, J., \& McCorkle, R. (2015). Exploring the relationship between spiritual well-being and quality of life among patients newly diagnosed with advanced cancer. Palliative \& Supportive Care, 13(4), 927-935.

Benedetti, R., Cohen, L., \& Taylor, M. (2013). “There's really no other option”: Italian Australian's experiences of caring for a family member with dementia. Journal of Women \& Aging, 25(2), 138-164.

Bormann, J., Warren, K.A., Regalbuto, L., Glaser, D., Kelly, A., Schnack, J., \& Hinton, L. (2009). A spiritually based caregiver intervention with telephone delivery for family caregivers of veterans with dementia. Family \& Community Health, 32(4), 345-353.

Burkhardt, M.A. (1989). Spirituality: An analysis of the concept. Holistic Nursing Practice, 3(3), 69-77. 
Burton, A.M., Sautter, J.M., Tulsky, J.A., Lindquist, J.H., Hays, J.C., Olsen, M.K., ... Steinhauser, K.E. (2012). Burden and well-being among a diverse sample of cancer, congestive heart failure, and chronic obstructive pulmonary disease caregivers. Journal of Pain and Symptom Management, 44(3), 410-420.

Canada, A.L., Fitchett, G., Murphy, P.E., Stein, K., Portier, K., Crammer, C., \& Peterman, A.H. (2013). Racial/ethnic differences in spiritual well-being among cancer survivors. Journal of Behavioral Medicine, 36(5), 441-453.

Caregiver Action Network. (2014). 2014 Caregiver Statistics. Retrieved from http://www.caregiveraction.org

Day, J.R., Anderson, R.A., \& Davis, L.L. (2014). Compassion fatigue in adult daughter caregivers of a parent with dementia. Issues in Mental Health Nursing, 35(10), 796-804.

del-Pino-Casado, R., Frias-Osuna, A., \& Palomino-Moral, P.A. (2011). Subjective burden and cultural motives for caregiving in informal caregivers of older people. Journal of Nursing Scholarship, 43(3), 282-291.

Dowling, M. (2007). From Husserl to van Manen. A review of different phenomenological approaches. International Journal of Nursing Studies, 44(1), 131-142.

Dukes, S. (1984). Phenomenological methodology in the human sciences. Journal of Religion and Health, 23(3), 197-203.

Edmondson, D., Park, C.L., Blank, T.O., Fenster, J.R., \& Mills, M.A. (2008). Deconstructing spiritual well-being: Existential well-being and HRQOL in cancer survivors. Psycho-Oncology, 17(2), 161-169. 
Family Caregiver Alliance. (2018). Caregiver statistics: Demographics. Retrieved from http://www.caregiver.org

Ferrell, B., Coyle, N., \& Paice, J.A. (2015). Textbook of palliative nursing (4th ed.). New York, NY: Oxford University Press.

Gallagher, D., Ni Mhaolain, A., Crosby, L., Ryan, D., Lacey, L., Coen, R.F., ... Lawlor, B.A. (2011). Dependence and caregiver burden in Alzheimer's disease and mild cognitive impairment. American Journal of Alzheimer's Disease \& Other Dementias, 26(2), 110-114.

Gallart, A., Cruz, F., \& Zabalegui, A. (2013). Factors influencing burden among nonprofessional immigrant caregivers: A case-control study. Journal of Advanced Nursing, 69(3), 642-654.

Harrison-Dening, K. (2013). Dementia: Diagnosis and early interventions. British Journal of Neuroscience Nursing, 9(3), 131-137.

Hodge, D.R., \& Sun, F. (2012). Positive feelings of caregiving among Latino Alzheimer's family caregivers: Understanding the role of spirituality. Aging \& Mental Health, 16(6), 689-698.

Holloway, I., \& Wheeler, S. (2010). Qualitative research in nursing and healthcare (3rd ed.). West Sussex, United Kingdom: John Wiley \& Sons Ltd.

Kaye, J. \& Robinson, K.M. (1994). Spirituality among caregivers. Image: Journal of Nursing Scholarship, 26(3), 218-221.

Kristanti, M.S., Engels, Y., Effendy, C., Astuti Utarini, A., Vernooij-Dassen, M., ... Jeon, Y.H. (2018). Comparison of the lived experiences of family caregivers of 
patients with dementia and of patients with cancer in Indonesia. International Psychogeriatrics, 30(6), 903-914.

Lee, V. (2008). The existential plight of cancer: Meaning making as a concrete approach to the intangible search for meaning. Supportive Care in Cancer, 16(7), 779-785.

Lee Casado, B., Lee, S.E., Hong, M., \& Hong, S. (2015). The experience of family caregivers of older Korean Americans with dementia symptoms. Clinical Gerontologist, 38(1), 32-48.

Lepherd, L. (2015). Spirituality: Everyone has it, but what is it? International Journal of Nursing Practice, 21(5), 566-574.

Mars, D., Davis, B.L., Montgomery, A.J., Burns, D.P., Baker, S.R., \& Coffey, D. (2017). The lived experience of African-American informal caregivers of family members with Alzheimer's disease and related dementias. Journal of National Black Nurses Association, 28(2), 19-25.

McClain, C.S., Rosenfeld, B., \& Breitbart, W. (2003). Effect of spiritual well-being on end-of-life despair in terminally-ill cancer patients. Lancet, 361(9369), 16031607.

Meghani, S.H. (2004). A concept analysis of palliative care in the United States. Journal of Advanced Nursing, 46(2), 152-161.

Munhall, P. (1994). Revisioning phenomenology: Nursing and health science research. New York, NY: National League for Nursing Press.

National Hospice and Palliative Care Organization. (2017). NHPCO's facts and figures: Hospice care in America. Retrieved from http://www.nhpco.org 
Navab, E., Negarandeh, R., \& Peyrovi, H. (2012). Lived experiences of Iranian family member caregivers of persons with Alzheimer's disease: Caring as 'captured in the whirlpool of time'. Journal of Clinical Nursing, 21(7/8), 1078-1086.

Papastavrou, E., Kalokerinou, A., Papacostas, S.S., Tsangari, H., \& Sourtzi, P. (2007). Caring for a relative with dementia: Family caregiver burden. Journal of Advanced Nursing, 58(5), 446-457.

Peacock, S., Dubbleby, W., \& Koop, P. (2014). The lived experience of family caregivers who provided end-of-life care to persons with advanced dementia. Palliative \& Supportive Care, 12(2), 117-126.

Penman, J., Oliver, M., \& Harrington, A. (2009). Spirituality and spiritual engagement as perceived by palliative care clients and caregivers. Australian Journal of Advanced Nursing, 26(4), 29-35.

Perren, S., Schmid, R., \& Wettstein, A. (2006). Caregivers' adaptation to change: The impact of increasing impairment of persons suffering from dementia on their caregivers' subjective well-being. Aging \& Mental Health, 10(5), 539-548.

Peterman, A.H., Fitchett, G., Brady, M.J., Hernandez, L., \& Cella, D. (2002). Measuring spiritual well-being in people with cancer: The Functional Assessment of Chronic Illness Therapy-Spiritual Well-Being Scale (FACIT-Sp). Annals of Behavioral Medicine, 24(1), 49-58.

Peterman, A.H., Reeve, C.L., Winford, E.C., Cotton, S., Salsman, J.M., McQuellon, R.,... Campbell, C. (2014). Measuring meaning and peace with the FACITSpiritual Well-Being Scale: Distinction without a difference? Psychological Assessment, 26(1), 127-137. 
Pew Forum. (2018). Religion in America: U.S. religious data, demographics and statistics. Retrieved from http://www.pewforum.org

Rabow, M.W., Hauser, J.M., \& Adams, J. (2004). Supporting family caregivers at the end of life: “They Don’t Know What They Don’t Know”. JAMA, 291(4), 483-491.

Razani, J., Corona, R., Quilici, J., Matevosyan, A., Funes, C., Larco, A., . .Lu, P. (2014). The effects of declining functional abilities in dementia patients and increases in psychological distress on caregiver burden over a one-year period. Clinical Gerontologist, 37(3), 235-252.

Reed, P.G. (1992). An emerging paradigm for the investigation of spirituality in nursing. Research in Nursing \& Health, 15(5), 349-357.

Reinart, K.G., \& Koenig, H.G. (2013). Re-examining definitions of spirituality in nursing research. Journal of Advanced Nursing, 69(12), 2622-2634.

Salmoirago-Blotcher, E., Crawford, S., Tran, C., Goldberg, R., Rosenthal, L., \& Ockene, I. (2012). Spiritual well-being may buffer psychological distress in patients with implantable cardioverter defibrillators. Journal of Evidenced-Based Complementary \& Alternative Medicine, 17(3), 148-154.

Shah, A.A., Snow, A.L., \& Kunik, M.E. (2002). Spiritual and religious coping in caregivers of patients with Alzheimer's disease. Clinical Gerontologist, 24(3/4), 127-136.

Smith, A.L. \& Harkness, J. (2002). Spirituality and meaning: A qualitative inquiry with caregivers of Alzheimer's disease. Journal of Family Psychotherapy, 13(1-2), 87108. 
Spurlock, W.R. (2005). Spiritual well-being and caregiver burden in Alzheimer's Caregivers. Geriatric Nursing, 26(3), 154-161.

Sun, F., \& Hodge, D.R. (2014). Latino Alzheimer's disease caregivers and depression: Using the stress coping model to examine the effects of spirituality and religion. Journal of Applied Gerontology, 33(3), 291-315.

Sun, V., Kim, J.Y., Irish, T.L., Borneman, T., Sidhu, R.K., Klein, L., \& Ferrell, B. (2016). Palliative care and spiritual well-being in lung cancer patients and family caregivers. Psycho-Oncology, 25(12), 1448-1455.

Tanyi, R.A. (2002). Towards clarification of the meaning of spirituality. Journal of Advanced Nursing, 39(5), 500-509.

Taylor, E.J. (2003). Spiritual needs of patients with cancer and family caregivers. Cancer Nursing, 26(4), 260-266.

Tuohy, D., Cooney, A., Dowling, M., Murphy, K., \& Sixsmith, J. (2013). An overview of interpretive phenomenology as a research methodology. Nurse Researcher, 20(6), $17-20$.

van Manen, M. (1990). Researching lived experience: Human science for an action sensitive pedagogy. London, Ontario, Canada: The University of Western Ontario.

Walker, L.O., \& Avant, K.C. (2011). Strategies for theory construction in nursing (5th ed.). Upper Saddle River, NJ: Prentice Hall.

Wardell, D.W., \& Engebretson, J. (2001). Biological correlates of Reiki touch healing. Journal of Advanced Nursing, 33(4), 439-445. 
Wilkinson, A.M., \& Lynn, J. (2005). Caregiving for advanced chronic illness patients. Techniques in Regional Anesthesia and Pain Management, 9(3), 122-132.

Wilkinson, D.S., Knox, P.L., Chatman, J.E., Johnson, T.L., Barbour, N., Myles, Y., \& Reel, A. (2002). The clinical effectiveness of healing touch. Journal of Alternative \& Complementary Medicine, 8(1), 33-47.

Winterling, J., Wasteson, E., Glimelius, B., Sjoden, P., \& Nordin, K. (2004). Substantial changes in life: Perceptions in patients with newly diagnosed advanced cancer and their spouses. Cancer Nursing, 27(5), 381-388.

Yeh, P., \& Bull, M. (2009). Influences of spiritual well-being and coping on mental health of family caregivers for elders. Research in Gerontological Nursing, 2(3), 173-181. 
Appendix A

University of San Diego Committee on Protection of Human Subjects

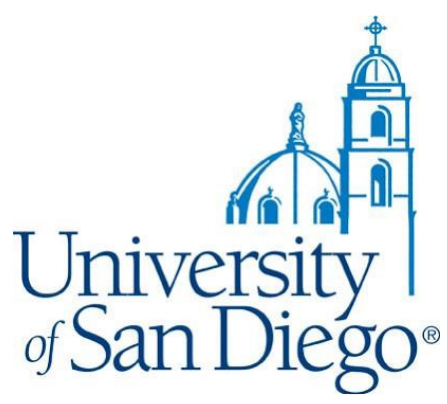

Jun 8, 2017 1:17 PM PDT

Michael Baumgardner

Hahn School of Nursing \& Health Science

Re: Expedited - Initial - IRB-2017-155, The Lived Experience of Spiritual WellBeing Amongst Informal Caregivers of Individuals with Dementia in Palliative Care

Dear Michael Baumgardner:

The Institutional Review Board has rendered the decision below for IRB-2017155, The Lived Experience of Spiritual Well-Being Amongst Informal Caregivers of Individuals with Dementia in Palliative Care.

Decision: Approved

Selected Category: 7. Research on individual or group characteristics or behavior (including, but not limited to, research on perception, cognition, motivation, identity, language, communication, cultural beliefs or practices, and social behavior) or research employing survey, interview, oral history, focus group, program evaluation, human factors evaluation, or quality assurance methodologies.

Findings:

Note: We send IRB correspondence regarding student research to the faculty advisor, who bears the ultimate responsibility for the conduct of the research. We request that the faculty advisor share this correspondence with the student researcher.

The next deadline for submitting project proposals to the Provost's Office for full review is N/A. You may submit a project proposal for expedited or exempt 
review at any time.

Sincerely,

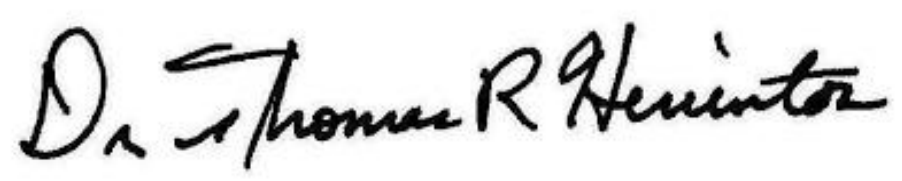

Dr. Thomas R. Herrinton

Administrator, Institutional Review Board

Office of the Vice President and Provost

Hughes Administration Center, Room 214

5998 Alcalá Park, San Diego, CA 92110-2492

Phone (619) 260-4553 • Fax (619) 260-2210 • www.sandiego.edu 
Appendix B

Recruitment Flyer

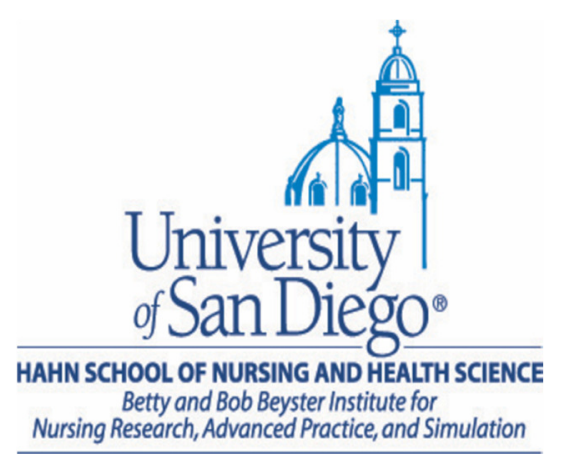

\section{Participants are needed in a Research Study:}

The Lived Experience of Spiritual Well-Being amongst Informal Caregivers of an Individual with Dementia in Palliative Care

I am seeking people who are providing care to an individual with dementia in palliative care. I am a doctoral nursing student at the University of San Diego conducting a study to learn more about caregiving and if caregivers may experience spiritual well-being. Participation involves a 90-minute interview. Participants will receive a $\$ 25$ Visa Gift Card. Please contact Michael Baumgardner for more information at (619)200-0609 or email $\underline{\text { michaelb-11@sandiego.edu }}$

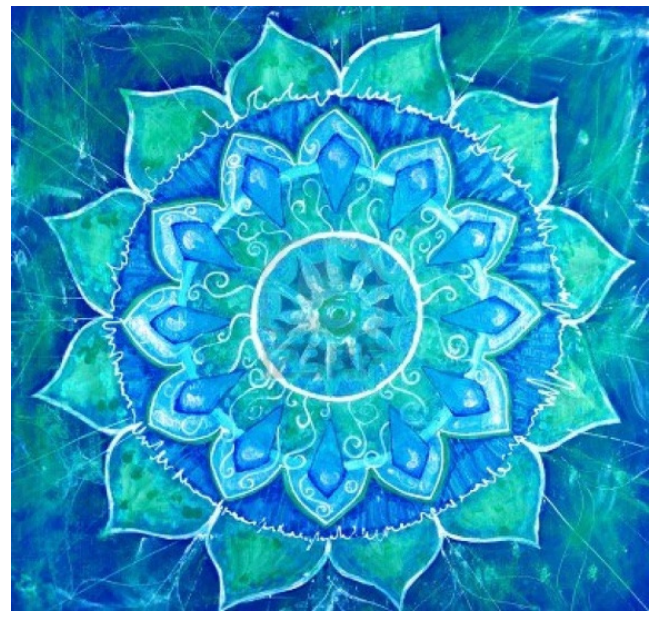




\section{Appendix C \\ Informed Consent \\ University of San Diego \\ Institutional Review Board \\ Research Participant Consent Form}

For the research study entitled:

The Lived Experience of Spiritual Well-Being Amongst Informal Caregivers of

Persons with Alzheimer's and Dementia enrolled in Palliative Care.

\section{Purpose of the research study}

Michael Baumgardner is a doctoral student in the Hahn School of Nursing at the University of San Diego. You are invited to participate in a research study he is conducting. The purpose of this research study is to explore the experience of family caregivers of a person with Alzheimer's receiving palliative care and the meaning of spiritual well-being for the caregivers.

\section{What you will be asked to do}

If you decide to be in this study, you will be asked to:

Complete a brief questionnaire about yourself, your relationship to the individual with dementia, and any spiritual/religious traditions that are important to you.

Participate in a private interview about your experience as a caregiver to someone with dementia.

You will be audiotaped during the interview.

Your participation in this study will take a total of 90 minutes.

\section{Foreseeable risks or discomforts}


Sometimes when people are asked to think about their feelings, they feel sad or anxious. If you would like to talk to someone about your feelings at any time, you can call toll-free, 24 hours a day: San Diego Mental Health Hotline at 1-800-4793339

\section{$\underline{\text { IV. Benefits }}$}

While there may be no direct benefit to you from participating in this study, the indirect benefit of participating will be knowing that you helped researchers better understand the experience of caring for a loved one with dementia and the meaning of spiritual well-being as a caregiver.

\section{$\underline{\text { V. Confidentiality }}$}

Any information provided and/or identifying records will remain confidential and kept in a locked file and/or password-protected computer file in the researcher's office for a minimum of five years. All data collected from you will be coded with a number or pseudonym (fake name). Your real name will not be used. The results of this research project may be made public and information quoted in professional journals and meetings, but information from this study will only be reported as a group, and not individually.

\section{$\underline{\text { VI. Compensation }}$}

If you participate in the study, the researcher will give you a $\$ 25$ Visa Gift Card in the following way: personally at the time of the interview. You will receive this compensation even if you decide not to complete the entire interview session. 


\section{Voluntary Nature of this Research}

Participation in this study is entirely voluntary. You do not have to do this, and you can refuse to answer any question or quit at any time. Deciding not to participate or not answering any of the questions will have no effect on any benefits you're entitled to, like your health care, or your employment or grades.

You can withdraw from this study at any time without penalty.

\section{Contact Information}

If you have any questions about this research, you may contact either:

1) Michael Baumgardner, $\mathrm{PhD}(\mathrm{c})$, Principal Investigator

Email: michaelb-11@sandiego.edu

Phone: (619) 200-0609

2) Dr. Ann Mayo, DNSc

Email: Amayo@sandiego.edu

Phone: (619) 260-7481

I have read and understand this form, and consent to the research it describes to me. I have received a copy of this consent form for my records.

Signature of Participant

Date

Name of Participant (Printed)

Signature of Investigator

Date 
Code Number:

\section{Appendix D \\ Demographic Survey}

\section{Demographic Profile Questionnaire}

1. What is your age?

2. What is your gender? $\mathrm{M} \quad \mathrm{F}$

3. What is your race or ethnicity? White African American/Black Asian Hispanic/Latino Native American Other

4. What is your occupational status?

a. Full time outside the home

b. Full time inside the home

c. Part time outside the home

d. Retired

5. How long have you been an informal caregiver (to everyone you have ever care for)?

6. What is your relationship to the individual with dementia?

a. Spouse

b. Child: Son Daughter

c. Relative

d. Friend

e. Other

7. How long have you known this individual?

8. How long have you been this individual's caregiver?

9. How long has this individual been on palliative care services?

10. Do you consider yourself to be a spiritual/religious person? If so, what is the name?

11. Do you belong to a particular spiritual/religious tradition?

12. What types of spiritual/religious practices do you practice?

13. How frequently do you engage in these practices? 